\title{
HDL Biogenesis, Remodeling, and Catabolism
}

\author{
Vassilis I. Zannis, Panagiotis Fotakis, Georgios Koukos, Dimitris \\ Kardassis, Christian Ehnholm, Matti Jauhiainen, and Angeliki Chroni
}

\section{Contents}

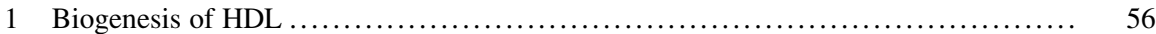

1.1 ATP-Binding Cassette Transporter A1 (ABCA1) ...................... 57

1.1.1 Structure of apoA-I and Its Interactions with ABCA1 In Vitro ......... 57

1.1.2 Interaction of apoA-I with ABCA1 In Vivo Initiates the Biogenesis of HDL ............................................... 58

1.1.3 Unique Mutations in apoA-I May Affect apoA-I/ABCA1 Interactions and Inhibit the First Step in the Pathway of HDL Biogenesis ......... 60

1.2 Lecithin/Cholesterol Acyltransferase (LCAT) ............................ 63

1.2.1 Interactions of Lipid-Bound ApoA-I with LCAT ..................... 63

1.2.2 ApoA-I Mutations that Affect apoA-I/LCAT Interactions .............. 64

\section{V.I. Zannis $(\bowtie) \cdot$ P. Fotakis}

Molecular Genetics, Whitaker Cardiovascular Institute, Boston University School of Medicine, Boston, MA 02118, USA

Department of Biochemistry, University of Crete Medical School and Institute of Molecular Biology and Biotechnology, Foundation of Research and Technology of Hellas, Heraklion, Crete 71110, Greece

e-mail:vzannis@bu.edu

G. Koukos

Molecular Genetics, Whitaker Cardiovascular Institute, Boston University School of Medicine, Boston, MA 02118, USA

D. Kardassis

Department of Biochemistry, University of Crete Medical School and Institute of Molecular Biology and Biotechnology, Foundation of Research and Technology of Hellas, Heraklion, Crete 71110, Greece

C. Ehnholm • M. Jauhiainen

National Institute for Health and Welfare, Public Health Genomics Unit, Biomedicum, Helsinki FI-00251, Finland

A. Chroni

Institute of Biosciences and Applications, National Center for Scientific Research "Demokritos", Athens 15310 , Greece 
1.3 ApoA-I Mutations May Induce Hypertriglyceridemia and/or Hypercholesterolemia

1.3.1 Potential Mechanism of Dyslipidemia Resulting from apoA-I

Mutations ....

1.4 ApoE and apoA-IV Participate in the Biogenesis of HDL Particles Containing the Corresponding Proteins ............................................ 72

1.5 Clinical Relevance of the Aberrant HDL Phenotypes ....................... 74

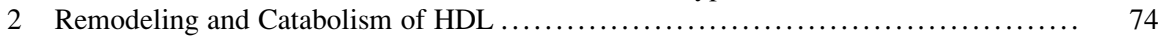

2.1 ATP-Binding Cassette Transporter G1 ............................. 76

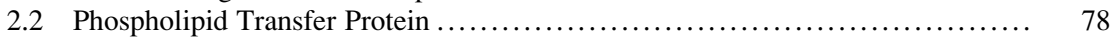

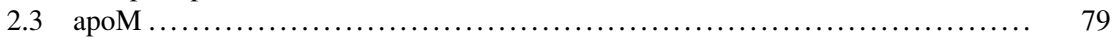

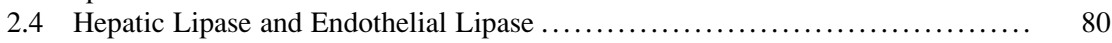

2.5 Cholesteryl Ester Transfer Protein $\ldots \ldots \ldots \ldots \ldots \ldots \ldots \ldots \ldots \ldots \ldots \ldots \ldots \ldots, 82$

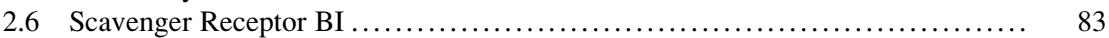

2.6.1 Role of SR-BI in HDL Remodeling Based on Its In Vitro Interactions

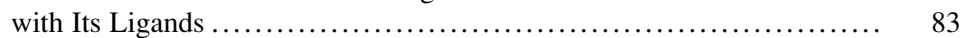

2.6.2 In Vivo Functions of SR-BI ................................... 84

2.7 Role of Ecto-F ${ }_{1}$-ATPase/P2Y $\mathrm{Y}_{13}$ Pathway in Hepatic HDL Clearance ............ 86

2.8 Transcytosis of apoA-I and HDL by Endothelial Cells ...................... 86

2.9 The Role of Cubilin in apoA-I and HDL Catabolism by the Kidney ........... 87

3 HDL Subclasses ..................................................... 88

3.1 The Origin and Metabolism of Pre $\beta$-HDL Subpopulations ................... 88

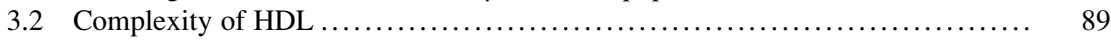

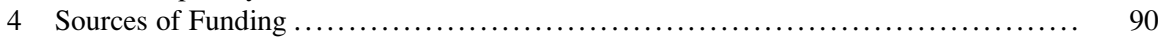

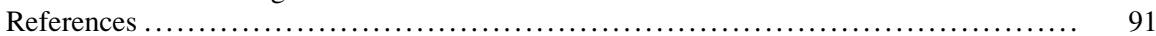

\section{Abstract}

In this chapter, we review how HDL is generated, remodeled, and catabolized in plasma. We describe key features of the proteins that participate in these processes, emphasizing how mutations in apolipoprotein A-I (apoA-I) and the other proteins affect HDL metabolism.

The biogenesis of HDL initially requires functional interaction of apoA-I with the ATP-binding cassette transporter A1 (ABCA1) and subsequently interactions of the lipidated apoA-I forms with lecithin/cholesterol acyltransferase (LCAT). Mutations in these proteins either prevent or impair the formation and possibly the functionality of HDL.

Remodeling and catabolism of HDL is the result of interactions of HDL with cell receptors and other membrane and plasma proteins including hepatic lipase (HL), endothelial lipase (EL), phospholipid transfer protein (PLTP), cholesteryl ester transfer protein (CETP), apolipoprotein $\mathrm{M}$ (apoM), scavenger receptor class B type I (SR-BI), ATP-binding cassette transporter G1 (ABCG1), the F1 subunit of ATPase (Ecto F1-ATPase), and the cubulin/megalin receptor.

Similarly to apoA-I, apolipoprotein E and apolipoprotein A-IV were shown to form discrete HDL particles containing these apolipoproteins which may have important but still unexplored functions. Furthermore, several plasma proteins were found associated with HDL and may modulate its biological functions. The effect of these proteins on the functionality of HDL is the topic of ongoing research. 


\section{Keywords \\ HDL biogenesis • HDL remodeling • HDL catabolism • HDL phenotypes • Apolipoprotein A-I mutations • Apolipoprotein E • Apolipoprotein A-IV • ATP- binding cassette transporter A1 (ABCA1) • Lecithin/cholesterol acyltransferase (LCAT) - HDL subclasses - Pre $\beta$ - and $\alpha$-HDL particles • Dyslipidemia • Hypertriglyceridemia $\bullet$ Lipoprotein lipase (LPL) • Hepatic lipase (HL) • Endo- thelial lipase (EL) • Phospholipid transfer protein (PLTP) - Apolipoprotein M • Cholesteryl ester transfer protein (CETP) - Scavenger receptor class B type I (SR-BI) • ATP-binding cassette transporter G1 (ABCG1) • Ecto-F 1 -ATPase • Cubilin • Transcytosis $\bullet$ Clinical phenotypes}

\section{Abbreviations}

$\begin{array}{ll}\text { ABCA1 } & \text { ATP-binding cassette transporter A1 } \\ \text { ABCG1 } & \text { ATP-binding cassette transporter G1 } \\ \text { apoA-I } & \text { Apolipoprotein A-I } \\ \text { apoA-IV } & \text { Apolipoprotein A-IV } \\ \text { apoB } & \text { Apolipoprotein B } \\ \text { apoE } & \text { Apolipoprotein E } \\ \text { apoJ } & \text { Apolipoprotein J } \\ \text { apoM } & \text { Apolipoprotein M } \\ \text { BHK cells } & \text { Baby hamster kidney cells } \\ \text { Caco-2 cells } & \text { Human epithelial colorectal adenocarcinoma cells } \\ \text { CAD } & \text { Coronary artery disease } \\ \text { CD36 } & \text { Cluster of differentiation 36 } \\ \text { CE } & \text { Cholesterol ester } \\ \text { CETP } & \text { Cholesteryl ester transfer protein } \\ \text { CHO cells } & \text { Chinese hamster ovary cells } \\ \text { eNOS } & \text { Endothelial nitric oxide synthase } \\ \text { EL } & \text { Endothelial lipase } \\ \text { EM } & \text { Electron microscopy } \\ \text { FED } & \text { Fish eye disease } \\ \text { FLD } & \text { Familial LCAT deficiency } \\ \text { FPLC } & \text { Fast protein liquid chromatography } \\ \text { HA-PLTP } & \text { High-activity PLTP } \\ \text { HDL } & \text { High-density lipoprotein } \\ \text { HDL-A-IV } & \text { apoA-IV-containing HDL } \\ \text { HDL-C } & \text { HDL cholesterol } \\ \text { HDL-E } & \text { apoE-containing HDL } \\ \text { HEK293 cells } & \text { Human embryonic kidney 293 cells } \\ & \end{array}$




$\begin{array}{ll}\text { HepG2 cells } & \text { Liver hepatocellular carcinoma cells } \\ \text { HL } & \text { Hepatic lipase } \\ \text { IDL } & \text { Intermediate density lipoprotein } \\ \text { LA-PLTP } & \text { Low-activity PLTP } \\ \text { LCAT } & \text { Lecithin/cholesterol acyltransferase } \\ \text { LDL } & \text { Low-density lipoprotein } \\ \text { LDLr } & \text { Low-density lipoprotein receptor } \\ \text { MPO } & \text { Myeloperoxidase } \\ \text { PLA1 } & \text { Phospholipase A1 } \\ \text { PLTP } & \text { Phospholipid transfer protein } \\ \text { RCT } & \text { Reverse cholesterol transport } \\ \text { rHDL } & \text { Recombinant HDL } \\ \text { SNP } & \text { Single-nucleotide polymorphism } \\ \text { SR-BI } & \text { Scavenger receptor class B type I } \\ \text { SREBPs } & \text { Sterol regulatory element-binding proteins } \\ \text { TC } & \text { Total cholesterol } \\ \text { VEGF-A } & \text { Vascular endothelial growth factor A } \\ \text { VLDL } & \text { Very low-density Lipoprotein } \\ \text { WT } & \text { Wild type }\end{array}$

\section{Biogenesis of HDL}

The biogenesis of HDL is a complex process and involves several membrane bound and plasma proteins (Zannis et al. 2004a). The first step in HDL biogenesis involves secretion of apoA-I mainly by the liver and the intestine (Zannis et al. 1985). Secreted apoA-I interacts functionally with ABCA1, and this interaction leads to the transfer of cellular phospholipids and cholesterol to lipid-poor apoA-I. The lipidated apoA-I is gradually converted to discoidal particles enriched in unesterified cholesterol. The esterification of free cholesterol by the enzyme lecithin/cholesterol acyltransferase (LCAT) (Zannis et al. 2006a) converts the discoidal to spherical HDL particles (Fig. 1).

The absence or inactivating mutations in apoA-I, ABCA1, and LCAT prevent the formation of apoA-I-containing HDL (Daniil et al. 2011). For this reason, we classify the apoA-I, ABCA1, and LCAT interactions that will be discussed in this chapter as early steps in the biogenesis of HDL. Following a similar pathway, apoE and apoA-IV can also synthesize HDL particles that contain these proteins (Duka et al. 2013; Kypreos and Zannis 2007). The first part of this review provides important information on the unique properties of apoA-I that permits it to acquire lipids via interactions with ABCA1 and LCAT. It also provides examples of how specific mutations in apoA-I disrupt specific steps in the pathway of HDL biogenesis and generate distinct aberrant HDL phenotypes. The HDL phenotypes described here can serve as molecular markers that could be used for the diagnosis, prognosis, 


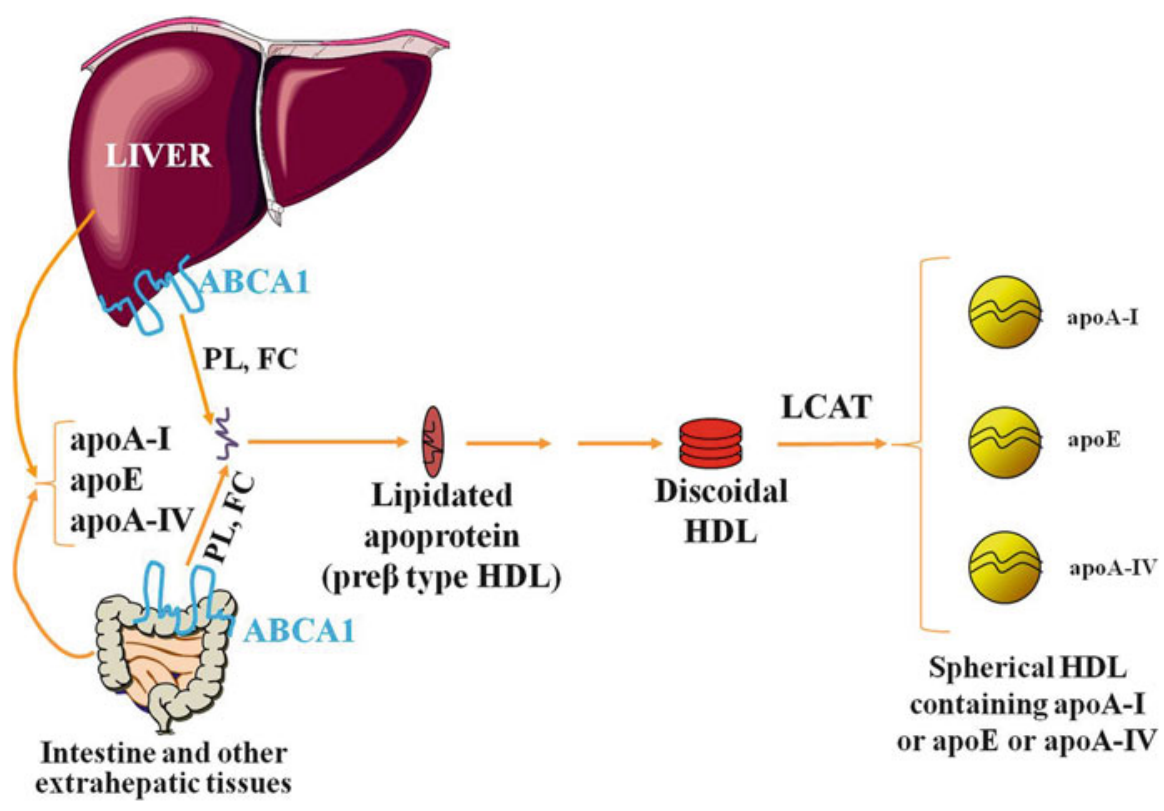

Fig. 1 Schematic representation of the pathway of the biogenesis of HDL containing apoA-I or apoE or apoA-IV

and potential treatment of HDL abnormalities or dyslipidemias associated with HDL.

\subsection{ATP-Binding Cassette Transporter A1 (ABCA1)}

\subsubsection{Structure of apoA-I and Its Interactions with ABCA1 In Vitro}

apoA-I contains 22 or 11 amino acid repeats which, according to the models of Nolte and Atkinson (1992), are organized in amphipathic a-helices (Segrest et al. 1974). Based on the crystal structure of apoA-I in solution (Borhani et al. 1997, 1999), a belt model was proposed to explain the structure of apoA-I on discoidal HDL particles (Segrest et al. 1999). Various models have been proposed to explain the arrangement of apoA-I on spherical HDL particles based on structural work and cross-linking(Wu et al. 2011; Silva et al. 2008; Huang et al. 2011). Details on the structure of apoA-I and HDL are provided in chapter "Structure of HDL: Particle Subclasses and Molecular Components."

$\mathrm{ABCA} 1$ is a ubiquitous protein that belongs to the $\mathrm{ABC}$ family of transporters and is expressed abundantly in the liver, macrophages, brain, and various other tissues (Langmann et al. 1999; Kielar et al. 2001). ABCA1 is localized only on the basolateral surface of the hepatocytes (Neufeld et al. 2002); it is also found on endocytic vesicles and was shown to travel between late endocytic vesicles and the cell surface (Neufeld et al. 2001). ABCA1 promotes efflux of cellular phospholipids 
and cholesterol to lipid-free or minimally lipidated apoA-I and other apolipoproteins, but not to spherical HDL particles (Wang et al. 2000; Remaley et al. 2001).

Studies in HeLa cells that expressed an ABCA1 green fluorescence fusion protein showed the intracellular trafficking of ABCA1 complexed to apoA-I (Neufeld et al. 2001, 2002). Other studies showed that in macrophages ABCA1 associates with apoA-I in the coated pits, is internalized, interacts with intracellular lipid pools, and is re-secreted as a lipidated particle (Takahashi and Smith 1999; Smith et al. 2002; Lorenzi et al. 2008). A similar pathway that leads to transcytosis has been described in endothelial cells (Cavelier et al. 2006; Ohnsorg et al. 2011).

A series of cell culture and in vitro experiments investigated the ability of apoAI mutants to promote $\mathrm{ABCA} 1$-mediated efflux of cholesterol and phospholipids and to cross-link to ABCA1. These mutants had amino-terminal deletions, carboxyterminal deletions that removed the 220-231 region, carboxy-terminal deletions that maintained the 220-231 region, and double deletions of the amino- and carboxyterminal regions (Chroni et al. 2003).

These studies presented in Chroni et al. (2003) showed that wild-type (WT) ABCA1-mediated cholesterol and phospholipid efflux was not affected by aminoterminal apoA-I deletions, but it was diminished by carboxy-terminal deletions in which residues 220-231 were removed. Efflux was not affected by deletion of the carboxy-terminal 232-243 region, and it was restored to $80 \%$ of WT control by double deletions of both the amino- and carboxy-termini (Zannis et al. 2004a, 2006a; Chroni et al. 2003; Reardon et al. 2001). Lipid efflux was either unaffected or moderately reduced by a variety of point mutations or deletions of internal helices 2-7. The findings indicated that different combinations of central helices can promote lipid efflux (Chroni et al. 2004a, b). Chemical cross-linking/ immunoprecipitation studies showed that the ability of apoA-I mutants to promote ABCA1-depended lipid efflux is correlated with the ability of these mutants to be cross-linked efficiently to ABCA1 (Chroni et al. 2004b). Cross-linking between apoA-I and ABCA1 and cholesterol efflux was also affected by mutations in ABCA1 that are found in patients with Tangier disease. The majority of the ABCA1 mutants cross-link poorly to WT apoA-I and have diminished capacity to promote cholesterol efflux (Bodzioch et al. 1999; Fitzgerald et al. 2002). A notable exemption is the ABCA1[W590S] mutant which cross-linked stronger to apoA-I than to WT ABCA1 but had diminished capacity to promote cholesterol efflux and to promote formation of HDL (Bodzioch et al. 1999; Fitzgerald et al. 2001, 2002). We suggested that this ABCA1 mutation may have altered the environment of the binding site of ABCA1 in such a way that the binding of apoA-I is strong but not productive and thus prevented efficient lipid efflux (Chroni et al. 2004b).

\subsubsection{Interaction of apoA-I with ABCA1 In Vivo Initiates the Biogenesis of HDL}

Inactivating mutations in ABCA1 found in patients with Tangier disease are associated with very low levels of total plasma and HDL cholesterol, diminished capacity to promote cholesterol efflux, formation of pre $\beta$-migrating particles, and 
a

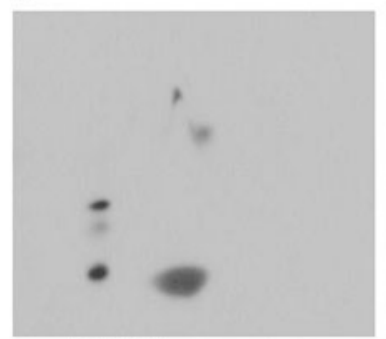

ABCA1 comp het (p.C1477R/IVS25:1G->C) b

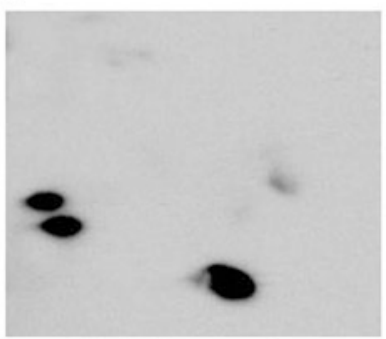

ABCA1 comp het (p.Q1038X / p.N1800H)
C

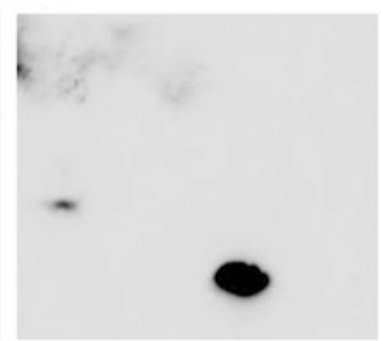

ABCA1 hom

(p.L1056P)

Fig. 2 Two-dimensional gel electrophoresis of plasma obtained from homozygotes or compound heterozygotes ABCA1-deficient human subjects with Tangier disease as indicated [Adapted from Daniil et al. (2011)]

abnormal lipid deposition in various tissues (Daniil et al. 2011; Brunham et al. 2006b; Orso et al. 2000; Assmann et al. 2001; Timmins et al. 2005).

Analysis of the serum of carriers with ABCA1 mutations by two-dimensional gel electrophoresis and western blotting using a rabbit polyclonal anti-human apoA-I antibody showed that subjects homozygous or compound mutant heterozygous for ABCA1 fail to form $\alpha$-HDL particles, but instead they form pre $\beta$ - and other small-size particles (Fig. 2).

As explained later, such particles are found in the plasma of mice expressing C-terminal mutants and may be created by mechanisms that involve nonproductive interactions between ABCA1 and apoA-I (Chroni et al. 2007; Fotakis et al. 2013a).

Several ABCA1 mutations in humans that alter the functions of ABCA1 are associated with increased susceptibility to atherosclerosis (Singaraja et al. 2003). Specific amino-acid substitutions found in the Danish general population were associated with increased risk for ischemic heart disease and reduced life expectancy through unknown mechanisms (Frikke-Schmidt et al. 2008). Inactivation of the ABCA1 gene in mice leads to low total serum cholesterol levels, lipid deposition in various tissues, impaired growth, and neuronal development and mimics the phenotype described for patients with Tangier disease (Orso et al. 2000). In addition ABCA1-deficient mice exhibit moderate increase in cholesterol absorption in response to high cholesterol diet (McNeish et al. 2000; Aiello et al. 2002). The role of ABCA1 on the lipid content of bile salts and cholesterol secretion is not clear (Vaisman et al. 2001; Groen et al. 2001).

Bone marrow transplantation experiments indicated that ABCA1 plays an important role in the control of macrophage recruitment to the tissues (Van Eck et al. 2002, 2006).

The contribution of ABCA1 in the pathogenesis of atherosclerosis in mice is presented in chapter "Mouse Models of Disturbed HDL Metabolism" (Hoesha and Van Eck). In men and mice, the majority of HDL is produced by the liver (Brunham et al. 2006a). When the liver and intestinal ABCA1 genes were inactivated in mice, 
HDL was not found in plasma, indicating that the liver and the intestine are the only sites that contribute to the production of HDL (Timmins et al. 2005). Following intestinal-specific inactivation of the ABCA1 gene in mice, the HDL that was generated by the liver accounted for $70 \%$ of the HDL found in WT mice (Brunham et al. 2006a). In mice that do not express hepatic ABCA1, the HDL concentration in the lymph was greatly diminished despite the fact that the intestine contributes $30 \%$ to the synthesis of HDL. This implies that the HDL that is produced in the intestine is secreted directly into the plasma (Brunham et al. 2006a). This is further supported by the finding that in mice that do not express intestinal ABCA1, the apoA-I and cholesterol concentration of lymph was not affected (Brunham et al. 2006a).

In liver-specific or whole-body ABCA1 knockout mice, the plasma HDL catabolism and the fractional catabolic rate of HDL by the liver and to a lesser extent by the kidney and the adrenal is increased (Timmins et al. 2005; Singaraja et al. 2006). In ABCA1-deficient mice, lipidated apoA-I particles or pre $\beta$-HDL failed to mature and are rapidly catabolized by the kidney (Timmins et al. 2005).

\subsubsection{Unique Mutations in apoA-I May Affect apoA-I/ABCA1 Interactions and Inhibit the First Step in the Pathway of HDL Biogenesis}

The in vivo interactions of apoA-I with ABCA1 were studied systematically by adenovirus-mediated gene transfer of WT and mutant apoA-I forms. Similar studies were performed to probe the interactions of lipid-bound apoA-I with LCAT. Four to five days postinfection plasma was collected and analyzed for lipids and lipoproteins and by two-dimensional gel electrophoresis to identify the HDL subpopulations. The plasma was fractionated by density gradient ultracentrifugation and fast protein liquid chromatography (FPLC), and the HDL fraction was analyzed by electron microscopy (EM) to assess the size and shape of HDL (Chroni et al. 2003; Reardon et al. 2001). Also the hepatic mRNA levels of apoA-I were determined to ensure that there was comparable expression of the WT and the mutant apoA-I forms (Zannis et al. 2004a; Chroni et al. 2003, 2007; Reardon et al. 2001).

We have studied most recently the effect of two sets of point mutations in the 218-222 and 225-230 region of apoA-I that affects apoA-I/ABCA1 interactions on the biogenesis of HDL. Adenovirus-mediated gene transfer of these mutants in apoA-I ${ }^{-l-} \mathrm{x} \mathrm{apoE}^{-/-}$mice (Fotakis et al. 2013a, b) showed that compared to the WT apoA-I, the expression of an apoA-I[L218A/L219A/V221A/L222A] mutant decreased plasma cholesterol, apoA-I, and HDL cholesterol levels and generated pre $\beta$ - and $\alpha 4$ HDL subpopulations (Fotakis et al. 2013a) (Table 1 and Fig. 3a-g).

To eliminate the involvement of apoE in the generation of apoE-containing HDL particles (Kypreos and Zannis 2007), the apoA-I[L218A/L219A/V221A/L222A] mutant was expressed in apoA $-\mathrm{I}^{-1-} \mathrm{x}$ apoE ${ }^{-/-}$mice via adenovirus-mediated gene transfer (Fotakis et al. 2013a). In this mouse background, the FPLC fractionation of the plasma showed the near absence of an HDL cholesterol peak. Density gradient ultracentrifugation of the plasma showed small amount of the apoA-I in HDL3 and in $d<1.21 \mathrm{~g} / \mathrm{ml}$ fractions (Fig. 3a). EM analysis showed the presence of discoidal particles along with larger particles corresponding in size to IDL/LDL (Fig. 3b). 
Table 1 Plasma lipids and hepatic mRNA levels of apoA- $-\mathrm{I}^{-/-}$or apoA-I $\mathrm{I}^{-/-} \mathrm{x}$ apoE ${ }^{-/-}$mice expressing WT and mutant forms of apoA-I in the presence and absence of LCAT as indicated

\begin{tabular}{|c|c|c|c|c|}
\hline Protein expressed & $\begin{array}{l}\text { Total } \\
\text { cholesterol } \\
(\mathrm{mg} / \mathrm{dL})\end{array}$ & $\begin{array}{l}\text { Triglycerides } \\
(\mathrm{mg} / \mathrm{dL})\end{array}$ & $\begin{array}{l}\text { Relative } \\
\text { apoA-I } \\
\text { mRNA } \\
(\%)\end{array}$ & $\begin{array}{l}\text { apoA-I } \\
\text { plasma } \\
\text { levels } \\
(\mathrm{mg} / \mathrm{dL}) \\
\end{array}$ \\
\hline WT apoA-I in apoA-I ${ }^{-l-}$ mice & $278 \pm 74$ & $78 \pm 24$ & $100 \pm 26$ & $260 \pm 40$ \\
\hline $\begin{array}{l}\text { apoA-I[L218A/L219A/V221A/ } \\
\text { L222A] in apoA-I }{ }^{-/-} \text {mice }\end{array}$ & $45 \pm 14$ & $50 \pm 20$ & $95 \pm 24$ & $41 \pm 5$ \\
\hline $\begin{array}{l}\text { WT apoA-I in apoA- } I^{-/-} \mathrm{x} \\
\text { apoE }^{-l-} \text { mice }\end{array}$ & $1,343 \pm 104$ & $294 \pm 129$ & $100 \pm 13$ & - \\
\hline $\begin{array}{l}\text { apoA-I[L218A/L219A/V221A/ } \\
\text { L222A] in apoA-I }{ }^{-1-} \mathrm{x} \mathrm{apoE}^{-1-} \\
\text { mice }\end{array}$ & $778 \pm 52$ & $18 \pm 2$ & $92 \pm 23$ & - \\
\hline $\begin{array}{l}\text { apoA-I[L218A/L219A/V221A/ } \\
\text { L222A] plus LCAT in apoA-I }{ }^{-/-} \\
\mathrm{x} \mathrm{apoE}^{-1-} \text { mice }\end{array}$ & $754 \pm 122$ & $37 \pm 10$ & $90 \pm 3$ & - \\
\hline
\end{tabular}
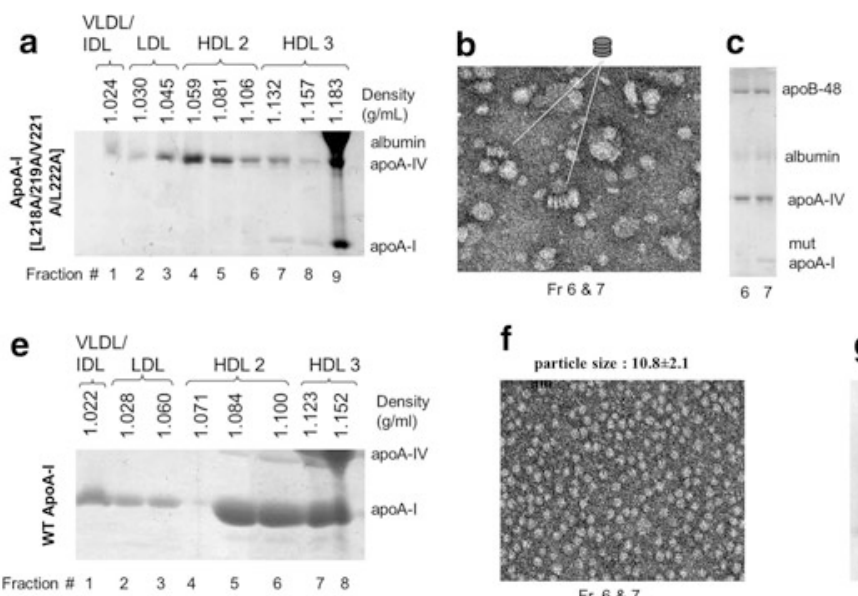

f

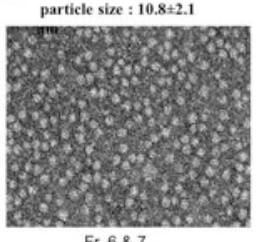

d

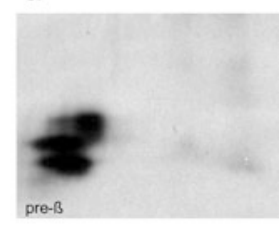

g

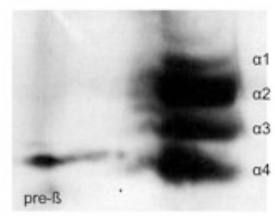

Fig. 3 (a-g) ApoA-I mutations and their effect on the HDL phenotypes. Analysis of plasma of apoA-I ${ }^{-1-} \mathrm{x}$ apoE ${ }^{-1-}$ mice infected with adenoviruses expressing the WT apoA-I or the apoA-I [L218A/L219A/V221A/L222A] mutant, as indicated, by density gradient ultracentrifugation and SDS-PAGE (a, e). EM analysis of HDL fractions 6-7 obtained from apoA-I ${ }^{-1-} \mathrm{x}^{-1 p o E^{-1-}}$ mice expressing the WT apoA-I or the apoA-I[L218A/L219A/V221A/L222A] mutant, as indicated, following density gradient ultracentrifugation of plasma (b, f). SDS gel electrophoresis showing apoprotein composition of fractions 6 and 7 (c) used for the EM analysis in panel b. Two-dimensional gel electrophoresis of plasma of apoA-I ${ }^{-1-} \mathrm{x}$ apoE ${ }^{-/-}$mice infected with adenoviruses expressing WT apoA-I or the apoA-I[L218A/L219A/V221A/L222A] mutant, as indicated $(\mathbf{d}, \mathbf{g})$ 
These particles may originate from apoB-48 containing lipoproteins that are found in the HDL fractions (Fig. 3c). Two-dimensional gel electrophoresis showed the presence of only pre $\beta$-HDL particles (Fig. 3d). Control experiments showed that WT apoA-I when expressed in apoA- $\mathrm{I}^{-/-} \mathrm{x} \mathrm{apoE}^{-/-}$mice floated predominantly in the HDL2/HDL3 region and generated spherical particles and normal pre $\beta$ - and $\alpha$-HDL subpopulation (Fig. $3 \mathrm{e}-\mathrm{g}$ ).

Co-expression of the apoA-I[L218A/L219A/V221A/L222A] mutant and human LCAT in apoA-I $\mathrm{I}^{-/-} \mathrm{x}$ apoE ${ }^{-/-}$mice did not correct the plasma apoA-I levels and did not correct the aberrant HDL phenotype.

The findings shed light to previous studies which showed that carboxy-terminal deletion mutants that lacked the 220-231 region of apoA-I prevented the biogenesis of normal $\alpha$-HDL particles but allowed the formation of pre $\beta$-HDL particles (Chroni et al. 2003, 2007).

Studies discussed in a later section showed that naturally occurring point mutations in apoA-I when expressed in mouse models activate LCAT insufficiently and in some instances lead to the accumulation of discoidal HDL particles in plasma (Koukos et al. 2007a, b; Chroni et al. 2005a). A characteristic feature of these mutations is that they could be corrected in vivo by the co-expression of the mutant apoA-I and LCAT.

The phenotype produced by the apoA-I[L218A/L219A/V221A/L222A] mutations is distinct from all previously described phenotypes and cannot be corrected by overexpression of LCAT. In addition, the mutant protein had reduced capability to promote the ABCA1-mediated cholesterol efflux. Although other interpretations are possible, the in vivo and in vitro data suggest that the interaction of the apoA-I [L218A/L219A/V221A/L222A] mutant with ABCA1 results in defective lipidation of apoA-I that leads to the generation of pre $\beta$-HDL particles that are not a good substrate for LCAT. If this interpretation is correct, the normal lipidation of apoA-I may require a precise initial orientation of the apoA-I ligand within the binding site of ABCA1 that is similar to that described for enzymesubstrate interactions. Such a configuration would allow correct lipidation of apoAI that could subsequently undergo cholesterol esterification and formation of mature HDL, whereas incorrectly lipidated apoA-I becomes a poor substrate for LCAT.

In addition to the unique role of the L218/L219/V221/L222 residues in the biogenesis of HDL, the same residues are also required to confer trans-endothelial transport capacity (Ohnsorg et al. 2011) and bactericidal activity (Biedzka-Sarek et al. 2011) to apoA-I. These overall properties suggest that the L218/L219/V221/ L222 residues represent an effector domain for several activities of apoA-I.

The phenotype generated by the expression of the apoA-I[F225A/V227A/ F229A/L230A] mutant was similar to that obtained with the apoA-I[L218A/ L219A/V221A/L222A] mutant. However co-expression of the apoA-I[F225A/ V227A/F229A/L230A] mutant and human LCAT corrected the abnormal HDL levels, created normal pre $\beta$ - and $\alpha$-HDL subpopulations, and generated spherical HDL particles (Fotakis et al. 2013b). 


\subsection{Lecithin/Cholesterol Acyltransferase (LCAT)}

\subsubsection{Interactions of Lipid-Bound ApoA-I with LCAT}

Plasma LCAT is a 416 amino acid long plasma protein that is synthesized and secreted primarily by the liver and to a much lesser extent by the brain and the testis (Warden et al. 1989; Simon and Boyer 1970). LCAT interacts with discoidal and spherical HDL and catalyzes the transfer of the 2-acyl group of lecithin or phosphatidylethanolamine to the free hydroxyl residue of cholesterol to form cholesteryl ester, using apoA-I as an activator (Fielding et al. 1972; Zannis et al. 2004b). It also catalyzes the reverse reaction of esterification of lysolecithin to lecithin (Subbaiah et al. 1980). The esterification of free cholesterol of HDL in vivo converts the discoidal to mature spherical HDL particles (Jonas 2000; Chroni et al. 2005a). Regarding the mechanism of activation of LCAT by apoA-I, it has been proposed that residues R130 and K133 play an important role in the formation of an amphipathic presentation tunnel located between helices 5-5 in the double belt model. Such a tunnel could allow migration of the hydrophobic acyl chains of phospholipids and the amphipathic unesterified cholesterol from the bilayer to the active site of LCAT that contains sites for phospholipase activity and esterification activity (Jones et al. 2009). The esterification of the cholesterol converts the 3.67 residues per turn helices to an idealized 3.6 residues per turn helix (Borhani et al. 1997).

Mutations in LCAT are associated with two phenotypes. The familial LCAT deficiency (FLD) is characterized by the inability of the mutant LCAT to esterify cholesterol on HDL and LDL and the accumulation of discoidal HDL in the plasma. The fish eye disease (FED) is characterized by the inability of mutant LCAT to esterify cholesterol on HDL only. Both diseases are characterized by low HDL levels (Santamarina-Fojo et al. 2001) and formation of pre $\beta$ - and $\alpha 4$ subpopulations.

Analysis of plasma of patients with complete LCAT deficiency (homozygous or compound heterozygous carriers of functional LCAT mutations) by two-dimensional electrophoresis shows mostly the presence of small $\alpha$-HDL subpopulation (Daniil et al. 2011) (Fig. 4a, b). Analysis of plasma of LCAT-deficient mice by two-dimensional electrophoresis shows the presence of pre $\beta$ - and smallsize $\alpha 4$ HDL particles (Fig. 4c). Expression of human LCAT by adenovirusmediated gene transfer generated large-size $\alpha$-HDL subpopulations (Fig. 4d). In contrast, expression of a LCAT mutant generated pre $\beta$-HDL along with small-size $\alpha 4, \alpha 3$, and $\alpha 2$ HDL subpopulations (Fig. 4e).

Sera obtained from LCAT heterozygotes had increased capacity to promote ABCA1-mediated cholesterol efflux and decreased capacity to promote ABCG1and SR-BI-mediated cholesterol efflux from macrophages as compared with sera obtained from normal subjects. These properties were attributed to the increased pre $\beta$ - and decreased $\alpha$-HDL subpopulations in the sera of the LCAT heterozygotes (Calabresi et al. 2009b). Heterozygosity for LCAT mutations in the Italian population was not associated with increased preclinical atherosclerosis (Calabresi et al. 2009a). 
a

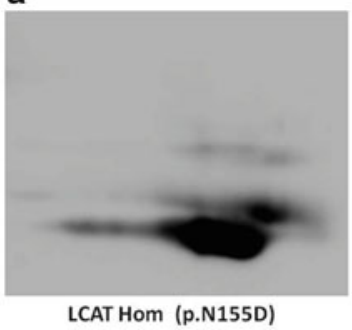

b

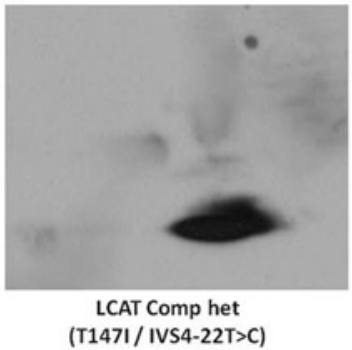

c

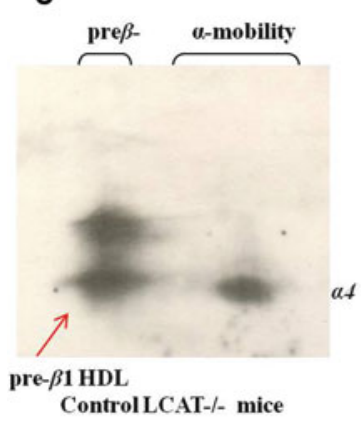

d

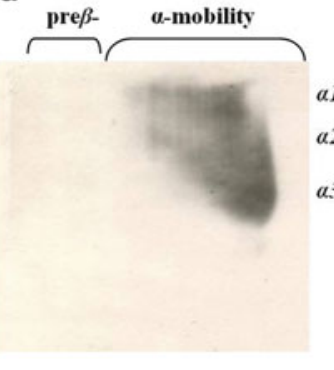

LCAT-/- mice received WT LCAT e

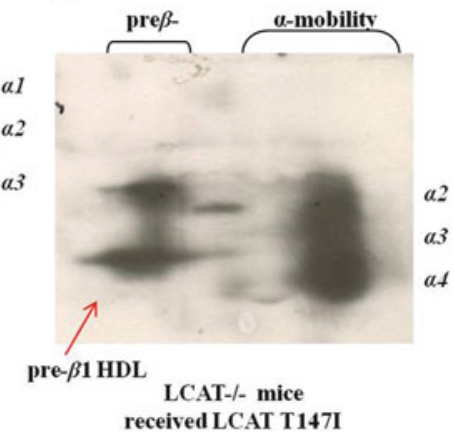

Fig. 4 (a-e) Two-dimensional gel electrophoresis from plasma obtained from one homozygote and one compound heterozygote for LCAT deficiency as indicated (a, b) (Daniil et al. 2011). Two-dimensional gel electrophoresis of plasma obtained from plasma of control $\mathrm{LCAT}^{-1-}$ mice (a) and $\mathrm{LCAT}^{-1-}$ mice infected with an adenovirus expressing either the WT human LCAT (d) or human LCAT[T147I] found in a patient with fish eye disease (e). LCAT cDNA probes of WT and LCAT mutants were provided by Dr. J.A. Kuivenhoven (Medical Center of Groningen)

The LCAT activation ability of apoA-I is inhibited following treatment with MPO (Shao et al. 2008). In addition myeloperoxidase modification alters several functions of HDL and generates pro-inflammatory HDL particles (Undurti et al. 2009).

\subsubsection{ApoA-I Mutations that Affect apoA-I/LCAT Interactions}

Several naturally occurring apoA-I mutations that produce pathological phenotypes have been described (Zannis et al. 2006b; Sorci-Thomas and Thomas 2002; Miettinen et al. 1997b). It has been estimated that structural mutations of apoA-I occur in $0.3 \%$ of the Japanese population and may affect the plasma HDL levels (Yamakawa-Kobayashi et al. 1999). From a total of 46 natural mutations of apoA-I, 25 are associated with low HDL levels, and 17 of these mutants reduce the capacity of apoA-I to activate LCAT (Sorci-Thomas and Thomas 2002; Zannis et al. 2006b). These mutations are clustered predominantly in or at the vicinity of helix 6 of apoA-I and some of them predispose to atherosclerosis (Huang et al. 1998; Miller et al. 1998; Miettinen et al. 1997b; Miccoli et al. 1996). Here we describe how some representative mutations of this category affect the biogenesis and maturation of HDL. 
Previous studies showed that hemizygotes (compound heterozygotes for an apoA-I null allele and an apoA-I(L141R) Pisa allele) had greatly decreased plasma apoA-I levels and near absence of HDL cholesterol. Plasma from hemizygotes contained pre $\beta 1-H D L$ and low concentration of small particles with alpha electrophoretic mobility (Miccoli et al. 1997). Heterozygotes for apoA-I(L141R) $)_{\text {Pisa }}$ had approximately half-normal values for HDL cholesterol and plasma apoA-I (Miccoli et al. 1996; Pisciotta et al. 2003). Three male hemizygote patients and one heterozygote patient developed coronary stenosis (Miccoli et al. 1996).

Other studies also showed that heterozygotes for apoA-I(L159R $)_{\text {FIN }}$ mutation had greatly reduced plasma levels of HDL cholesterol and apoA-I (Miettinen et al. 1997a) that was mainly distributed in the HDL3 region and had abnormal electrophoretic mobility (Miettinen et al. 1997b; McManus et al. 2001). They also had small-size (8-9 $\mathrm{nm}$ ) HDL particles and decreased plasma and HDL cholesteryl ester levels (Miettinen et al. 1997b; McManus et al. 2001). Human HDL containing apoA-I(L159R $)_{\text {FIN }}$ had increased fractional catabolic rate compared to normal HDL, indicating increased catabolism of the mutant apoA-I protein (Miettinen et al. 1997a, b). Only one affected patient with this mutation had clinically manifested atherosclerosis (Miettinen et al. 1997b).

To explain the etiology and potential therapy of genetically determined low levels of HDL resulting from natural apoA-I mutations, we have studied the in vitro and in vivo properties of the naturally occurring mutants, apoA-I [L141A $]_{\text {Pisa }}$ and apoA-I[L159R]FIN (Koukos et al. 2007a). In vitro studies showed that both mutants were secreted efficiently from cells, had normal ability to promote ABCA1-mediated cholesterol efflux, but greatly diminished capacity to activate LCAT (0.4-2 \% of WT apoA-I). Adenovirus-mediated gene transfer showed that compared to WT apoA-I, expression of either of the two mutants in apoA-Ideficient (apoA-I ${ }^{-/-}$) mice greatly decreased total plasma cholesterol and apoA-I levels as well as the CE/TC ratio compared to WT apoA-I (Table 2). Another change that was associated with differences between the WT apoA-I and either of

Table 2 Plasma lipids and hepatic mRNA levels of apoA-I ${ }^{-/-}$mice expressing WT and the mutant forms of apoA-I in the presence and absence of LCAT as indicated

\begin{tabular}{|c|c|c|c|c|c|}
\hline Protein expressed & $\begin{array}{l}\text { Cholesterol } \\
(\mathrm{mg} / \mathrm{dl})\end{array}$ & $\mathrm{CE} / \mathrm{TC}$ & $\begin{array}{l}\text { Triglycerides } \\
(\mathrm{mg} / \mathrm{dl})\end{array}$ & $\begin{array}{l}\text { Relative } \\
\text { ApoA-I } \\
\text { mRNA } \\
(\%)\end{array}$ & $\begin{array}{l}\text { Apo A-I } \\
\text { Protein } \\
(\mathrm{mg} / \mathrm{dl})\end{array}$ \\
\hline apo A-I WT & $148 \pm 11$ & $0.78 \pm 0.01$ & $63 \pm 1$ & $100 \pm 32$ & $186 \pm 34$ \\
\hline apoA-I (L141R) $)_{\text {Pisa }}$ & $23 \pm 0.4$ & $0.44 \pm 0.03$ & $11 \pm 2.8$ & $88 \pm 9$ & $17 \pm 4$ \\
\hline $\begin{array}{l}\text { apoA-I } \\
(\text { L141R) })_{\text {Pisa }}+\text { LCAT }\end{array}$ & $184 \pm 53$ & $0.68 \pm 0.01$ & $41 \pm 0.3$ & $91 \pm 2$ & $224 \pm 7$ \\
\hline apoA-I (L159R) $)_{\text {FIN }}$ & $16 \pm 5$ & $0.13 \pm 0.04$ & $25 \pm 4$ & $216 \pm 32$ & $25 \pm 9$ \\
\hline $\begin{array}{l}\text { apoA-I } \\
(\mathrm{L} 159 \mathrm{R})_{\mathrm{FIN}}+\mathrm{LCAT}\end{array}$ & $224 \pm 22$ & $0.73 \pm 0.01$ & $53 \pm 15$ & $63 \pm 9$ & $190 \pm 20$ \\
\hline apo A-I (R159L) Oslo & $43 \pm 13$ & $0.23 \pm 0.01$ & $36 \pm 4$ & $117 \pm 30$ & $66 \pm 31$ \\
\hline apo A-I (R160L) Oslo & $250 \pm 47$ & $0.082 \pm 0.01$ & $62 \pm 11$ & $60 \pm 1$ & $127 \pm 26$ \\
\hline
\end{tabular}




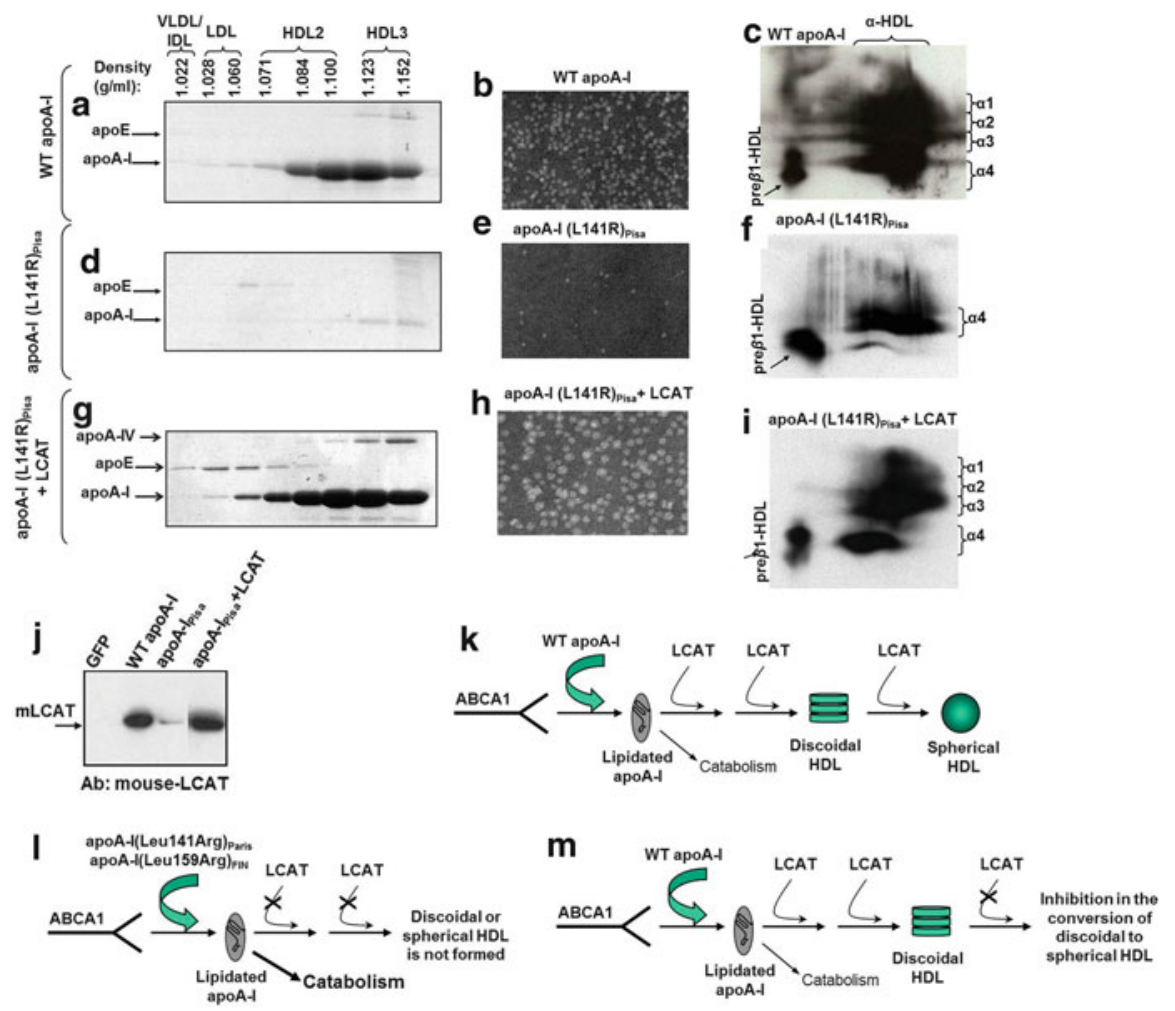

Fig. 5 (a-m) ApoA-I mutation that influence activity of LCAT. Analysis of plasma of apoA-I ${ }^{-/-}$ mice infected with adenoviruses expressing the WT apoA-I or the apoA-I[L141 $]_{\text {Pisa }}$ mutant alone or in combination with human LCAT by density gradient ultracentrifugation and SDS-PAGE (a, d, g) as indicated. EM analysis of HDL fractions 6-7 obtained from apoA- $\mathrm{I}^{-1-}$ mice expressing the WT apoA-I or the apoA-I[L141R $]_{\text {Pisa }}$ or mutant alone or in combination with human LCAT, following density gradient ultracentrifugation of plasma, as indicated $(\mathbf{b}, \mathbf{e}, \mathbf{h})$. Two-dimensional gel electrophoresis of plasma of apoA- $\mathrm{I}^{-/-}$mice infected with adenoviruses expressing WT apoAI or the apoA-I[L141q $]_{\text {Pisa }}$ or mutant alone or in combination with human LCAT, as indicated (c, $\mathbf{f}$, i). Western blot analysis of plasma from apoA- $\mathrm{I}^{-1-}$ mice infected with adenoviruses expressing either the control protein, GFP, or the WT apoA-I or the apoA-I(L141R) Pisa alone or in combination with human LCAT, as indicated at the top of the figure (j). Schematic representation showing the pathway of biogenesis of HDL (k) and how the apoA-I(L141R $)_{\text {Pisa }}$ and apoA-I(L159R) FIN mutants affect the esterification of cholesterol of the pre-HDL particles and prevent their conversion to discoidal and spherical HDL, thus promoting their catabolism (I). Schematic representation showing the inability of the apoA-I(R160L) Oslo mutant to convert the discoidal to spherical HDL particles (m)

the two mutants was the greatly decreased HDL cholesterol peak as determined by FPLC fractionation of the plasma. Density gradient ultracentrifugation of plasma showed great reduction of the amount of apoA-I that floated in the HDL region of the apoA-I[L141R $]_{\text {Pisa }}$ mutant as compared to WT apoA-I (Fig. 5a, d). EM analysis 
of the HDL fractions obtained by density gradient ultracentrifugation showed the presence of a large number of spherical HDL for WT apoA-I but only a few spherical HDL particles for the apoA-I[L141R $]_{\text {Pisa }}$ mutant (Fig. 5b, e). Two-dimensional gel electrophoresis of the plasma showed the formation of small amount of pre $\beta$-HDL and large amount of $\alpha 1, \alpha 2, \alpha 3, \alpha 4$ HDL subpopulations for the WT apoA-I and only pre $\beta$ - and small-size $\alpha 4$ HDL subpopulations for the apoA-I[L141R $]_{\text {Pisa }}$ mutant (Fig. 5c, f). Similar results were observed for apoA-I $[\mathrm{L} 159 \mathrm{R}]_{\text {FIN }}$ (Koukos et al. 2007a).

Coinfection of apoA-I ${ }^{-/-}$mice with adenoviruses expressing either of the two mutants and human LCAT normalized the plasma apoA-I, the total plasma cholesterol levels, and the CE/TC ratio (Table 2) and increased the HDL cholesterol peak and the amount of apoA-I that floated in the HDL region (Fig. 5g). It also generated large amount of spherical HDL (Fig. 5h) and restored the normal pre $\beta$ - and $\alpha$-HDL subpopulations (Fig. 5i). Similar results were observed for apoA-I[L159R $]_{\text {FIN }}$ (Koukos et al. 2007a).

Another interesting naturally occurring apoA-I mutation is the apoA-I

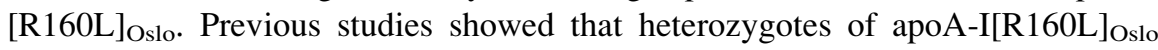
have approximately 60 and $70 \%$ of normal HDL and apoA-I levels, respectively, from pre $\beta 1$-and small-size $\alpha$-HDL particles and have a $30 \%$ reduction in their plasma LCAT activity (Leren et al. 1997). Gene transfer of the apoA-I[R160L] Oslo mutant in apoA-I $\mathrm{I}^{-/-}$mice resulted in low plasma cholesterol and apoA-I levels (Table 2) and generated discoidal particles with $\alpha 4$ electrophoretic mobility. The aberrant phenotype could be corrected by co-expression of this mutant with human LCAT (Koukos et al. 2007b).

Similar but not identical phenotypes were produced by expressing the bioengineered apoA-I[R160V/H162A] and apoA-I[R149A] mutants and the naturally occurring mutants apoA-I[R151C $]_{\text {Paris }}$ and apoA-I[L144R $]_{\text {Zaragosa }}$ (Haase et al. 2011; Chroni et al. 2005a; Koukos et al. 2007b). This phenotype could be corrected by co-expression of the mutant with human LCAT.

The last two mutations have not been associated with incidence of atherosclerosis in humans.

The apoA-I mutations discussed here offer a valuable tool to dissect the molecular events which lead to the biogenesis of HDL and possibly to understand the types of molecular interactions between apoA-I and LCAT which lead to the activation of the enzyme.

In our case, residues R149, R153, and R160 were reported to create a positive electrostatic potential around apoA-I. Mutations in these residues reduced drastically the ability of rHDL particles containing these apoA-I mutants to activate LCAT in vitro (Roosbeek et al. 2001). Based on the "belt" model for discoidal rHDL, these residues are located on the hydrophilic face of the apoA-I helices and do not form intramolecular salt bridges in the antiparallel apoA-I dimer that covers the fatty acyl chain of the discoidal particle. This arrangement allows in principle these apoA-I residues to form salt bridges or hydrogen bonds with appropriate residues of LCAT and thus contribute to LCAT activation. 
To explain the low HDL levels and the abnormal HDL phenotype of the apoA$\mathrm{I}^{-/-}$mice expressing the apoA-I(L141R) $)_{\text {Pisa, }}$, we analyzed the relative abundance of the endogenous mouse LCAT following gene transfer of the apoA-I(L141R) mutant alone or in the presence of LCAT. This analysis showed a dramatic increase of the mouse LCAT in mice expressing the apoA-I(L141R $)_{\text {Pisa }}$ mutant as compared to mice expressing the WT apoA-I. Coinfection of apoA-I ${ }^{-1-}$ mice with the apoA-I $(\text { L141R) })_{\text {Pisa }}$ mutant and human LCAT restored the mouse LCAT to normal levels (those observed in the presence of WT apoA-I) (Fig. 5j). The depletion of the endogenous LCAT in mice expressing the mutant forms of apoA-I could be the result of rapid degradation of endogenous mouse LCAT bound to minimally lipidated apoA-I mutants possibly by the kidney.

The ability of the apoA-I[L141R $]_{\text {Pisa }}$ and apoA-I(L159R) $)_{\text {FIN }}$ mutants to be secreted efficiently from cells and to promote ABCA1-mediated cholesterol efflux suggests that the functional interactions between apoA-I and ABCA1 that lead to the lipidation of apoA-I are normal and the low apoA-I and HDL levels caused by these two mutants are the result of fast removal of the lipidated nascent HDL particles from the plasma compartment. This interpretation is supported by the increased catabolic rate of HDL containing apoA-I(L159R) FIN $_{\text {(Miettinen }}$ et al. 1997b) and the accumulation of proapoA-I in the plasma of hemizygotes for apoA-I(L141R) Pisa $($ Miccoli et al. 1996). Accumulation of proapoA-I has been previously observed in patients with Tangier disease (Zannis et al. 1982) that are characterized by increased catabolic rate of HDL (Assmann et al. 2001). It has been also shown previously that cubilin, a $600 \mathrm{KDa}$ membrane protein, binds both apoAI and HDL and promotes their catabolism by the kidney (Kozyraki et al. 1999; Hammad et al. 1999).

Previous studies showed that pre $\beta$-HDL is an efficient substrate of LCAT (Nakamura et al. 2004b). In the presence of excess LCAT, the esterification of the cholesterol of the newly formed pre $\beta$-particles appears to prevent their fast catabolism and allows them to proceed in the formation of discoidal and spherical

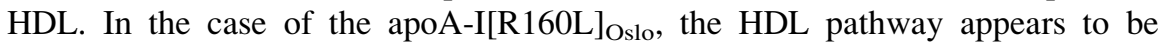
inhibited in the step of the conversion of the discoidal to spherical HDL particles. Figure 5k-m depicts the normal pathway of the biogenesis of HDL (Fig. 5k) and the disruption of this pathway by the apoA-I(L141R $)_{\text {Pisa }}$ and apoA-I(L159R $)_{\text {FIN }}$ (Fig. 5l) and apoA-I[R160L $]_{\text {Oslo }}$ mutants (Fig. 5m).

\subsection{ApoA-I Mutations May Induce Hypertriglyceridemia and/or Hypercholesterolemia}

A series of apoA-I mutations had resulted in severe hypertriglyceridemia (Chroni et al. 2004a; 2005b) (Table 3). The most recently studied case was apoA-I[D89A/ E91A/E92A] mutant where the charged residues were substituted by alanines. The capacity of the apoA-I[D89A/E91A/E92A] mutant to promote ABCA1-mediated cholesterol efflux and activate LCAT in vitro was approximately $2 / 3$ of that of WT apoA-I (Kateifides et al. 2011). 
Table 3 Plasma lipids and hepatic mRNA levels of apoA-I ${ }^{-/-}$mice expressing WT and the mutant forms of apoA-I as indicated

\begin{tabular}{|c|c|c|c|c|c|}
\hline $\begin{array}{l}\text { Protein } \\
\text { expressed }\end{array}$ & $\begin{array}{l}\text { Cholesterol } \\
(\mathrm{mg} / \mathrm{dL})\end{array}$ & $\mathrm{CE} / \mathrm{TC}$ & $\begin{array}{l}\text { Triglycerides } \\
\text { (mg/dL) }\end{array}$ & \begin{tabular}{|l} 
Relative \\
apo A-I \\
mRNA $(\%)$
\end{tabular} & $\begin{array}{l}\text { Plasma } \\
\text { apo A-I } \\
(\mathrm{mg} / \mathrm{dL})\end{array}$ \\
\hline apo $\mathrm{A}-\mathrm{I}^{-/-}$ & $33 \pm 6$ & - & $42 \pm 7$ & - & - \\
\hline WT apoA-I & $268 \pm 55$ & $0.72 \pm 0.06$ & $70 \pm 11$ & $100 \pm 32$ & $283 \pm 84$ \\
\hline $\begin{array}{l}\text { apo A-I [D89A/ } \\
\text { E91A/E92A] }\end{array}$ & $497 \pm 139$ & $0.36 \pm 0.31$ & $2,106 \pm 1,629$ & $101 \pm 24$ & $235 \pm 106$ \\
\hline $\begin{array}{l}\text { apo A-I [D89A/ } \\
\text { E91A/E92A] } \\
+ \text { hLPL }\end{array}$ & $122 \pm 56$ & $0.44 \pm 0.14$ & $49 \pm 16$ & $41 \pm 6$ & $99 \pm 18$ \\
\hline $\begin{array}{l}\text { apo A-I [ } \Delta(62- \\
78)]\end{array}$ & $220 \pm 16$ & - & $986 \pm 289$ & $130 \pm 5$ & $265 \pm 36$ \\
\hline $\begin{array}{l}\text { apo A-I [E110A/ } \\
\text { E111A] }\end{array}$ & $520 \pm 45$ & - & $1,510 \pm 590$ & $69 \pm 23$ & $204 \pm 27$ \\
\hline
\end{tabular}

In vivo studies using adenovirus-mediated gene transfer in apoA-I-deficient mice showed that compared to WT apoA-I, the apoA-I[D89A/E91A/E92A] mutant increased plasma and HDL cholesterol, reduced the CE/TC ratio, and caused severe hypertriglyceridemia (Table 3) (Kateifides et al. 2011). Following density gradient ultracentrifugation of plasma, approximately $40 \%$ of the apoA-I mutant was distributed in the VLDL/IDL region. In contrast, the WT apoA-I was distributed in the HDL2/HDL3 region (Fig. 6a). Whereas the WT apoA-I formed spherical HDL (Fig. 5b), the apoA-I[D89A/E91A/E92A] mutant formed mostly spherical and few discoidal HDL particles as determined by EM (Fig. 6b). Two-dimensional gel electrophoresis showed that WT apoA-I formed normal pre $\beta$ - and $\alpha$-HDL subpopulations, whereas the apoA-I[D89A/E91A/E92A] mutants formed pre $\beta$ and $\alpha 4$ HDL subpopulations (Fig. 6c) (Kateifides et al. 2011).

Co-expression of apoA-I[D89A/E91A/E92A] mutants and human lipoprotein lipase in apoA-I-deficient mice abolished hypertriglyceridemia (Table 3), redistributed apoA-I in the HDL2/HDL3 regions (Fig. 6d), restored in part the $\alpha 1,2,3,4$ HDL subpopulations (Fig. 6f), but did not change significantly the cholesterol ester to total cholesterol ratio (Table 3 ) or the formation of discoidal HDL particles (Fig. 6e) (Kateifides et al. 2011).

The findings indicate that residues D89, E91, and E92 of apoA-I are important for plasma cholesterol and triglyceride homeostasis as well as for the maturation of HDL.

The lipid, lipoprotein, and HDL profiles generated by another mutant, apoA-I [K94A/K96A], where the charged residues were changed to Alanines, were similar to those of WT apoA-I, indicating that the observed changes on the HDL phenotype were unique for the charged residues D89, E91, and E92 (Kateifides et al. 2011). Expression of a deletion mutant, apoA-I[ $\Delta 89-99]$, in apoA-I ${ }^{-/-}$mice, increased plasma cholesterol levels, increased the plasma pre $\beta$-HDL subpopulation, generated discoidal HDL particles, but did not induce hypertriglyceridemia (Chroni et al. 2005b). 

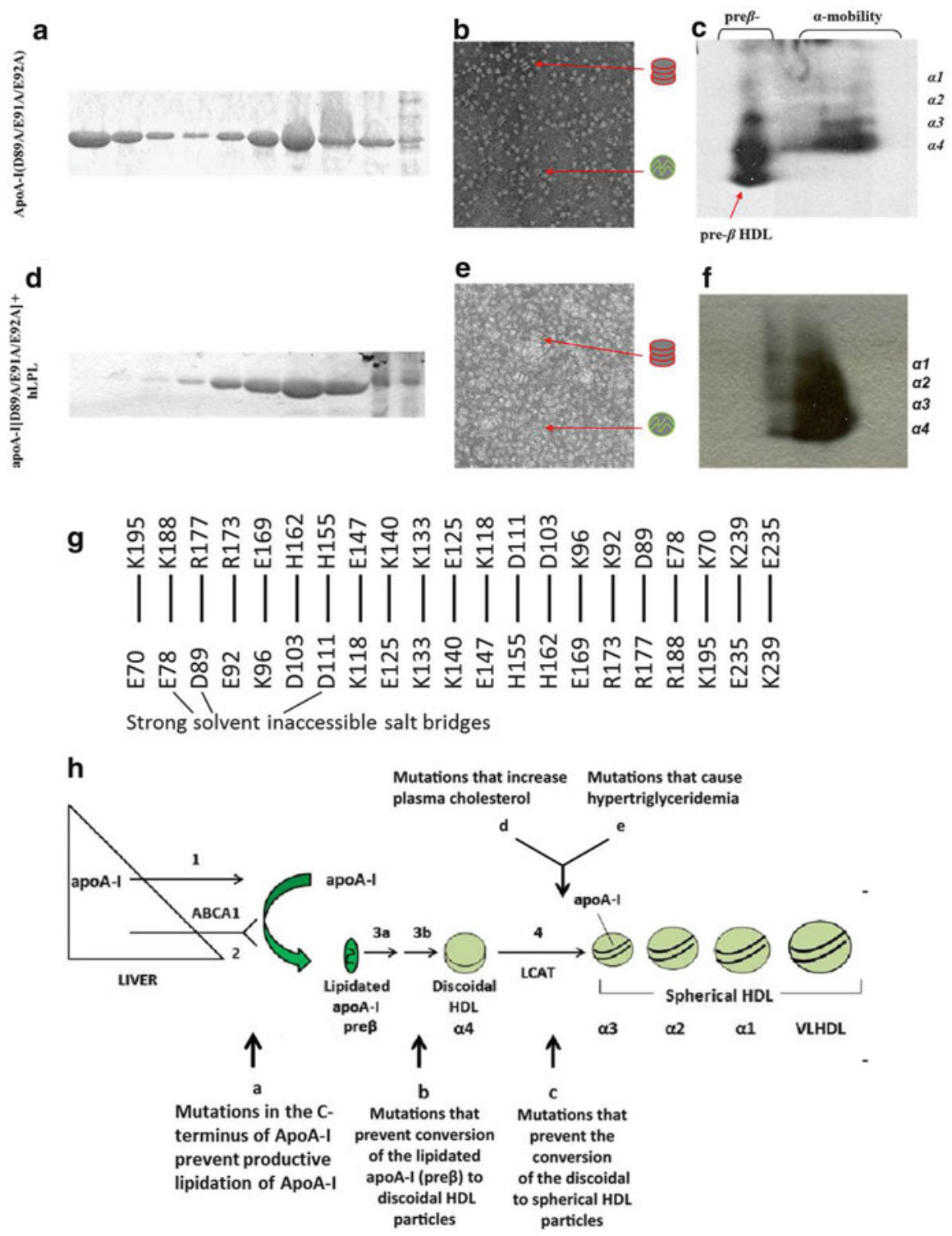

Fig. 6 (a-h) Effects of apoA-I mutations on the induction of dyslipidemia. Location of the apoA-I mutations that cause hypertriglyceridemia as indicated. Analysis of plasma of apoA- $\mathrm{I}^{-1-}$ mice infected with adenoviruses expressing the apoA-I[D89A/E91A/E92A] mutant alone or in combination with human LPL, as indicated, by density gradient ultracentrifugation and SDS-PAGE (a, d). EM analysis of HDL fractions 6-7 obtained from apoA-I ${ }^{-1-}$ mice expressing the apoA-I [D89A/E91A/E92A] mutant alone or in combination with LPL, as indicated, following density gradient ultracentrifugation of plasma $(\mathbf{b}, \mathbf{e})$. Two-dimensional gel electrophoresis of plasma of apoA- $\mathrm{I}^{-1-}$ mice infected with adenoviruses expressing the apoA-I[D89A/E91A/E92A] mutant alone or in combination with LPL, as indicated (c, f). Schematic representation of the solvent inaccessible interhelical charged interactions of apoA-I dimers arranged in an antiparallel 


\subsubsection{Potential Mechanism of Dyslipidemia Resulting from apoA-I Mutations}

The apoA-I[D89A/E91A/E92A] mutant has two similar characteristics with two other mutants in different regions of apoA-I, the apoA-I $[\Delta(61-78)]$ and the apoA-I [E110A/ E111A] (Chroni et al. 2004a; 2005b), that cause hypertriglyceridemia (Table 3). The first characteristic is that all three mutants caused accumulation of apoA-I in the VLDL/ IDL region. As shown previously, the accumulation of apoA-I in the lower densities affects the in vitro lipolysis of the VLDL/IDL fraction by exogenous lipoprotein lipase (Chroni et al. 2004a; 2005b). The second characteristic is that the three apoA-I mutants have lost negative-charged residues that are present in the WT sequence. The E78, D89, and E111 residues have the ability to form solvent inaccessible salt bridges with positively charged residues present in the antiparallel apoA-I molecule of a discoidal HDL particle (Segrest et al. 1999) (Fig. 6g).

In these arrangements of the apoA-I molecules on the HDL particle, residues E78 in helix 2, D89 in helix 3, and E111 in helix 4 can form solvent inaccessible salt bridges with residues R188 in helix 8, R177 in helix 7, and H155 in helix 6, respectively, of the antiparallel strand. The affinity of all three mutants for triglyceriderich lipoprotein particles is further supported by binding studies to triglyceride-rich emulsion particles (Gorshkova and Atkinson 2011).

It is interesting that in the $11 / 3 \alpha$-helical wheel residues E78, D89, and E111 are all located in wheel position 2 . With the exception of R188, all other five residues involved in salt bridges are conserved in mammals.

The lipid and lipoprotein abnormalities observed in this mutant suggest that the increased abundance of apoA-I in the VLDL/IDL region may create lipoprotein lipase insufficiency that is responsible for the induction of hypertriglyceridemia.

The persistence of discoidal particle following the lipoprotein lipase treatment indicates a direct effect of the [D89A/E91A/E92A] mutation in the activation of LCAT in vivo. Previous studies showed that discoidal and small-size HDL particles and LCAT associated with them may be catabolized fast by the kidney and thus lead to LCAT insufficiency and reduced plasma HDL levels (Koukos et al. 2007a; Timmins et al. 2005; Miettinen et al. 1997a).

It is conceivable that loosening of the structure of apoA-I around the D89 or E92 area due to the substitution of the original residues by alanines may provide new surfaces for interaction of HDL with other proteins or lipoprotein particles such as VLDL in ways that inhibit triglyceride hydrolysis. Furthermore, the accumulation of discoidal HDL as well as the formation of pre $\beta$ - and small $\alpha 4$ HDL particles as shown by the in vivo experiments indicate that replacement of D89, E91, and E92 by A has a direct impact on the activation of LCAT.

The preceding analyses described in Figs. 3, 4, 5, and 6 demonstrate that expression of mutant apoA-I forms in different mouse models disrupted specific steps along the pathway of the biogenesis of HDL and generated discrete lipid and HDL

Fig. 6 (continued) orientation in the belt model of rHDL (g). The pathway of HDL biogenesis. Superimposed on the pathway are defects that inhibit different steps of this pathway (h) 

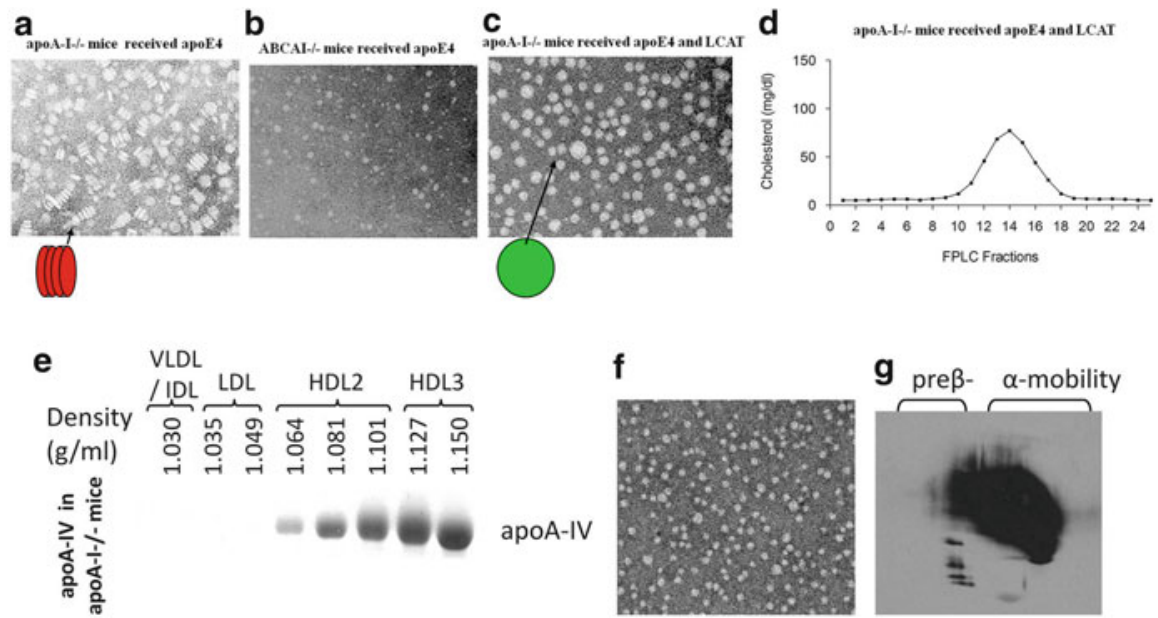

apoA-I-/- mice received apoA-IV

Fig. $7 \mathrm{EM}$ analysis of apoA- $\mathrm{I}^{-/-}$and $\mathrm{ABCA} 1^{-/-}$mice following infection with adenovirus expressing human apoE4 as indicated (a, b). EM analysis of apoA- $\mathrm{I}^{-1-}$ mice following infection with adenovirus expressing human apoE4 and LCAT (c). FPLC profile of apoA-I ${ }^{-1-}$ mice expressing apoE4 and LCAT (d). Analyses of the plasma of apoA- $\mathrm{I}^{-1-}$ mice following infection with adenovirus expressing human apoA-IV by density gradient ultracentrifugation and SDS-PAGE (e), EM (f), and two-dimensional gel electrophoresis (g)

phenotypes (Zannis et al. 2006b). The phenotypes generated included inhibition of the formation of HDL (Chroni et al. 2003, 2007; Fotakis et al. 2013a, b), generation of unstable intermediates (Koukos et al. 2007a), inhibition of the activation of LCAT (Chroni et al. 2005a; Koukos et al. 2007b), and increase in plasma cholesterol or increase in both plasma cholesterol and triglycerides (Chroni et al. 2004a, 2005b; Kateifides et al. 2011) (Fig. 6h).

\subsection{ApoE and apoA-IV Participate in the Biogenesis of HDL Particles Containing the Corresponding Proteins}

Using adenovirus-mediated gene transfer in apoA-I- or ABCA1-deficient mice, we obtained unequivocal evidence that apoE of any phenotype participates in the biogenesis of apoE-containing HDL particles (HDL-E) using a similar pathway that is used for the biogenesis of apoA-I-containing HDL particles (Kypreos and Zannis 2007). In the initial experiments, gene transfer of an apoE4-expressing adenovirus increased both HDL and the triglyceride-rich VLDL/IDL/LDL fraction and generated discoidal HDL particles (Fig. 7a). Control experiments showed the absence of discoidal or spherical HDL-size particles in the plasma of apoA-Ideficient mice. The involvement of ABCA1 which was established by gene transfer of apoE in $\mathrm{ABCA} 1^{-/-}$mice prior to and after treatment with apoE4, and indicated that apoE4 could not promote formation of $\mathrm{HDL}$ particles in $\mathrm{ABCA} 1^{-/-}$mice 
(Fig. 7b). Other experiments in apoA-I $\mathrm{I}^{-/-} \mathrm{x} \mathrm{apoE}^{-/-}$mice established that residues 1-202 of apoE are sufficient to promote biogenesis of apoE-containing HDL (Vezeridis et al. 2011). Coinfection of apoA-I $\mathrm{I}^{-/}$mice with a mixture of adenoviruses expressing both apoE4 and human LCAT converted the discoidal to spherical HDL (Fig. 7c), suggesting that LCAT is essential for the maturation of the discoidal apoE-containing HDL to spherical particles (Kypreos and Zannis 2007). The LCAT treatment also cleared the triglyceride-rich lipoproteins and increased the HDL cholesterol peak as determined by FPLC (Fig. 7d).

These findings suggest that in contrast to apoA-I where the C-terminal domain is required for the biogenesis of HDL (Chroni et al. 2007), the carboxy-terminal domain of apoE is not required for HDL formation. Overall, the findings indicate that apoE has a dual functionality. In addition to its documented role in the clearance of triglyceride-rich lipoproteins, it participates in the biogenesis of HDL-E in a process that is similar to that of apoA-I.

HDL-E thus formed may have antioxidant and anti-inflammatory functions similar to those described for apoA-I-containing HDL, which may contribute to the atheroprotective properties of apoE (Mineo et al. 2003; Plump et al. 1992; Schaefer et al. 1986; Navab et al. 2000). ApoE-containing HDL may also have important biological functions in the brain ( $\mathrm{Li}$ et al. 2003).

A similar set of gene transfer experiments in apoA-I $\mathrm{I}^{-1-}$ and apoA-I ${ }^{-1-} \mathrm{x}^{-1 p o E^{-1-}}$ mice also established that similar to apoE, apoA-IV also participates in the biogenesis of apoA-IV containing HDL (HDL-A-IV) and requires for this purpose the activity of ABCA1 and LCAT (Duka et al. 2013).

Gene transfer of apoA-IV in apoA-I ${ }^{-/-}$mice did not change plasma lipid levels. Density gradient ultracentrifugation showed that apoA-IV floated in the HDL2/ HDL3 region (Fig. 7e), promoted the formation of spherical HDL particles as determined by electron microscopy (Fig. 7f), and generated mostly $\alpha$ - and a few pre $\beta$-HDL subpopulations as determined by two-dimensional gel electrophoresis (Fig. 7g). When expressed in apoA-I $\mathrm{I}^{-/-} \times \mathrm{apoE}^{-/-}$mice, apoA-IV increased plasma cholesterol and triglyceride levels and shifted the distribution of the apoA-IV protein in the lower density fractions. This treatment likewise generated spherical particles and $\alpha$ - and pre $\beta$-like HDL subpopulations. Co-expression of apoA-IV and LCAT in apoA-I ${ }^{-1-}$ mice restored the formation of HDL-A-IV. Spherical and $\alpha$-migrating HDL particles were not detectable following gene transfer of apoA-IV in ABCA $1^{-l-}$ or $\mathrm{LCAT}^{-/-}$mice (Duka et al. 2013). The ability of apoA-IV to promote biogenesis of HDL may explain previously reported anti-inflammatory and atheroprotective properties of apoA-IV.

In vitro studies showed that lipid-free apoA-IV and reconstituted HDL-A-IV promoted ABCA1- and scavenger receptor BI (SR-BI)-mediated cholesterol efflux, with the same efficiency as apoA-I and apoE (Chroni et al. 2005c; Duka et al. 2013). 


\subsection{Clinical Relevance of the Aberrant HDL Phenotypes}

Genome-wide association studies indicated that specific gene loci were associated with low or high HDL cholesterol and triglyceride levels and could in principle affect the risk for coronary artery disease (CAD) (Teslovich et al. 2010). Prospective population studies have also shown that HDL has a protective role against CAD (Gordon et al. 1989). The beneficial functions of HDL are also supported by the atheroprotective effect of apoA-I overexpression in transgenic mice (Rubin et al. 1991; Paszty et al. 1994) or rabbits (Emmanuel et al. 1996) or following adenovirus-mediated gene transfer in mice (Belalcazar et al. 2003; Benoit et al. 1999; Tangirala et al. 1999). The studies described above provide molecular markers that could be used for the diagnosis, prognosis, and potential treatment of HDL abnormalities or dyslipidemias associated with the biogenesis and remodeling of HDL. Diagnostic phenotypes such as those depicted in Figs. 2a-c, 3a-d, 4a, b, $5 \mathrm{~d}-\mathrm{f}$, and $6 \mathrm{a}-\mathrm{c}$ can be used to assess defects in apoA-I, ABCA1, and LCAT respectively.

The HDL phenotypes observed in human patients carrying the apoA-I $[\mathrm{L} 141 \mathrm{R}]_{\text {Pisa }}$ and apoA-I[L159R $]_{\text {Fin }}$ mutations resemble closely the phenotypes observed in apoA-I-deficient mice expressing these mutants and indicate the validity of the gene transfer studies in mice to establish defects in HDL biogenesis. It is possible that phenotypes generated by mutagenesis of apoA-I may exist in the human population and can be detected by one or more of the analyses described previously. The correction of the aberrant HDL phenotypes by treatment with LCAT suggests a potential therapeutic intervention for HDL abnormalities that result from specific mutations in apoA-I or conditions that result in low HDL levels. Additional supporting evidence has been obtained by adenovirus-mediated gene transfer of human LCAT in squirrel monkeys. This treatment increased two-fold the HDL levels without affecting apoA-I levels, increased the size of HDL, and decreased apoB levels (Amar et al. 2009).

The potential contribution of apoA-I mutations to hypertriglyceridemia in humans is interesting. Hypertriglyceridemia resulting from apoA-I mutations may be further aggravated by other genetic and environment factors such as diabetes and thyroid status. The contribution of apoA-I mutations to hypertriglyceridemia could be addressed in future studies in selected populations of patients with hypertriglyceridemia of unknown etiology.

\section{Remodeling and Catabolism of HDL}

Following synthesis by the liver and the intestine, HDL is remodeled by various plasma proteins and is subsequently catabolized in the plasma by cell receptors and other plasma proteins (Fig. 8a-d).

Turnover studies showed that the mean plasma residence time of radiolabeled

${ }^{125}$ I-HDL2 and HDL3 was 6 days for normal subjects (Schaefer et al. 1979) and 0.22 days for patients with Tangier disease (Schaefer et al. 1981). Using stable 

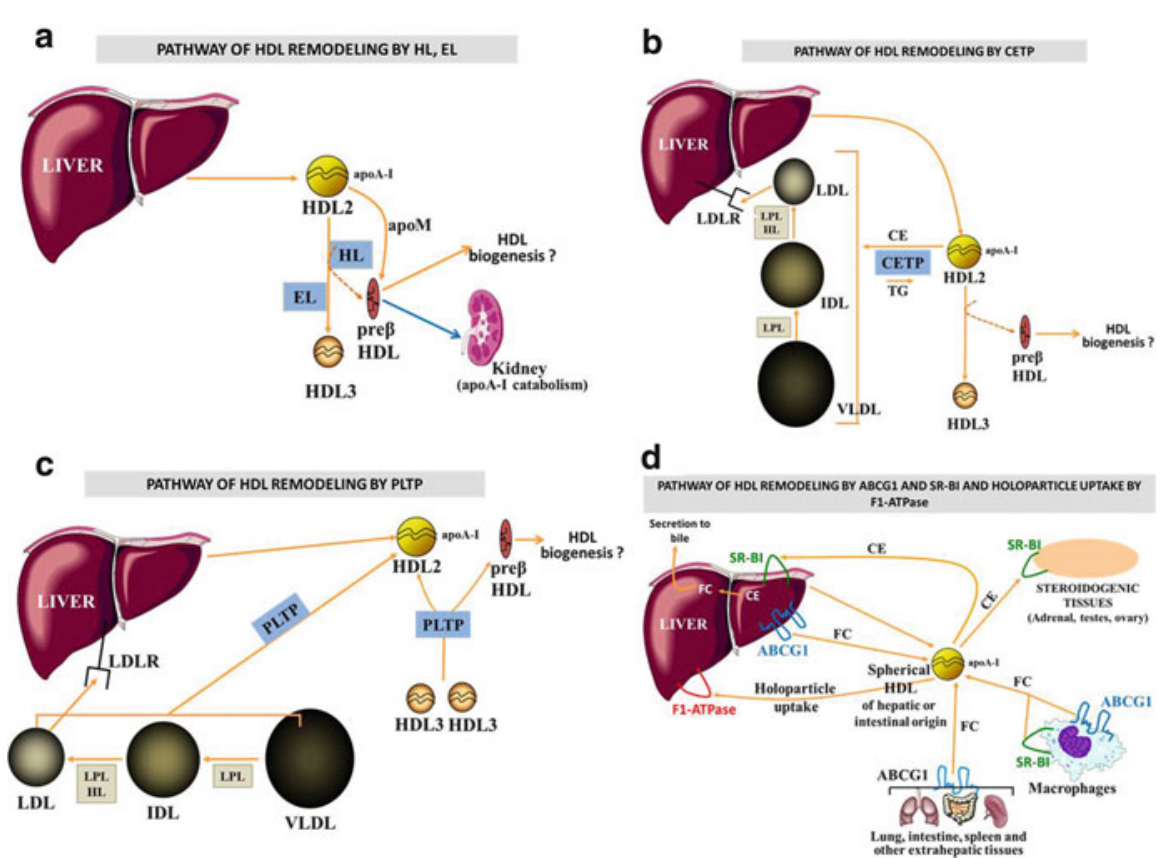

Fig. 8 (a-d) Schematic representation of the pathway of HDL remodeling by the action of hepatic and endothelial lipase (a), CETP (b), PLTP (c), and SR-BI, ABCG1, and HDL holoparticle uptake by F1-ATPase (d)

isotope turnover kinetic measurements, the resident time was estimated to be 4-5 days. The fractional catabolic rates (FCR) were expressed as pools per day, and the secretion rates that were determined by this method for men and women were similar. The FCR were not affected significantly by diet, diabetes, or LDL receptor defects, but it was increased in subjects with increased glucose tolerance (Marsh et al. 2000). HDL remodeling affects the structure and metabolic turnover of HDL and generates a dynamic mixture of discrete HDL subfractions that vary in size, shape, apolipoprotein, and lipid composition and functions (Siggins et al. 2007; Fielding and Fielding 2007; Xu and Nilsson-Ehle 2007; Harder and McPherson 2007).

Remodeling of HDL by the action of hepatic lipase (HL) and endothelial lipase (EL) involves hydrolysis of residual triglycerides and some phospholipids of HDL (Maugeais et al. 2003a; Santamarina-Fojo et al. 2004), leads to the conversion of HDL2 to HDL3 and pre $\beta$-HDL (Ishida et al. 2003; Krauss et al. 1974; Breckenridge et al. 1982; Brunzell and Deeb 2001), and accelerates the catabolism of HDL. Pre $\beta$-HDL formation also requires the functions of apolipoprotein M (apoM) (Wolfrum et al. 2005).

Portion of the cholesteryl esters formed by the actions of LCAT can be transferred to VLDL/IDL/LDL by the cholesteryl ester transfer protein (CETP) 
(Hopkins and Barter 1980; Barter et al. 2003) The phospholipid transfer protein (PLTP) can transfer the phospholipids from VLDL/IDL to the HDL particle during lipolysis to generate HDL2 and can also convert HDL3 particles to HDL2 and pre $\beta$-HDL (Tall et al. 1983; Lusa et al. 1996). HDL-binding proteins/receptors or transporters have been documented at all steps of HDL metabolism and involve the SR-BI, which is mostly expressed in hepatocytes, macrophages, and steroidogenic tissues and mediates selective CE uptake by the cells and tissues and cholesterol efflux (Gu et al. 1998; Krieger 1999; Rohrl and Stangl 2013; Pagler et al. 2006a); the ABCG1, which mediates cholesterol efflux (Nakamura et al. 2004a); the ecto$\mathrm{F}_{1}$-ATPase subunit, which mediates HDL holoparticle uptake by the liver (Martinez et al. 2003, 2007); and the cubilin/megalin receptors for removal of apoA-I and pre $\beta$-HDL by the kidney (Martinez et al. 2007).

\subsection{ATP-Binding Cassette Transporter G1}

HDL can be remodeled following interactions with ABCG1, a $67 \mathrm{kDa}$ protein, which is a member of the $\mathrm{ABC}$ family of half transporters. ABCG1 is expressed in the spleen, thymus, lung, and brain (Savary et al. 1996; Croop et al. 1997; Nakamura et al. 2004a) and was reported to be localized on plasma membrane, the Golgi, and recycling endosomes (Wang et al. 2006; Vaughan and Oram 2005; Sturek et al. 2010a; Xie et al. 2006a). The expression of ABCG1 is induced by LXR agonists in macrophages and the liver or by cholesterol loading in macrophages (Klucken et al. 2000; Venkateswaran et al. 2000; Wang et al. 2006). Overexpression of ABCG1 promotes cholesterol efflux from different cells to HDL but not to lipid-free apoA-I (Wang et al. 2004, 2006; Nakamura et al. 2004a; Vaughan and Oram 2005) (Fig. 8d). HDL obtained from CETPdeficient subjects or patients treated with the CETP inhibitors torcetrapib or anacetrapib was shown to have enhanced ability to promote ABCG1-dependent cholesterol efflux from macrophages (Matsuura et al. 2006; Yvan-Charvet et al. 2007, 2010). ABCG1-mediated cholesterol efflux to HDL is abolished by mutations in the ATP-binding Walker A motif indicating that the ATP-binding domain in ABCG1 is essential for both lipid transport activity and protein trafficking (Vaughan and Oram 2005). In addition, ABCG1 was shown to promote efflux of 7-ketocholesterol and related oxysterols from macrophages and endothelial cells to HDL, thus protecting cells from apoptosis (Terasaka et al. 2007; Li et al. 2010). In macrophages, ABCG1, and not SR-BI or ABCA1, has been shown recently to be primarily responsible for free cholesterol mobilization to rHDL (Cuchel et al. 2010a).

Studies in ABCG1-deficient mice also suggested that ABCG1 plays a critical role in the efflux of cellular cholesterol to HDL (Kennedy et al. 2005). Studies using intraperitoneal injection of mice with $\left[{ }^{3} \mathrm{H}\right]$ cholesterol-labeled $\mathrm{J} 774$ macrophages with either increased or reduced ABCG1 expression, as well as primary macrophages lacking ABCG1 expression, and measurement of the macrophagederived $\left[{ }^{3} \mathrm{H}\right]$ cholesterol levels in plasma and feces, showed that ABCG1 plays a 
critical role in promoting macrophage reverse cholesterol transport in vivo (Wang et al. 2007). Nevertheless, the studies in ABCG1-deficient and ABCG1 transgenic mice showed that plasma lipids, HDL, and other lipoprotein levels were not affected (Kennedy et al. 2005; Out et al. 2007; Burgess et al. 2008). Other studies showed that loss of ABCG1 gene in mice results in massive lipid accumulation in hepatocytes and in macrophages within multiple tissues, with the more marked accumulation in pulmonary macrophages (Kennedy et al. 2005; Out et al. 2006, 2007; Burgess et al. 2008; Baldan et al. 2006; Ranalletta et al. 2006; Wojcik et al. 2008). In addition, ABCG1 has been suggested to mediate cholesterol efflux to HDL particles from other cell types than macrophages, including adipocytes (Zhang et al. 2010) and human placental endothelial cells, where it may facilitate the transfer of maternal cholesterol to the fetus (Stefulj et al. 2009).

Previous studies indicated that there is little or no specificity of ABCG1 for the acceptor of cholesterol since LDL, $\mathrm{HDL}_{2}, \mathrm{HDL}_{3}$, phospholipid/apoA-I particles of various sizes and small unilamellar particles can function as acceptors for cholesterol from cells in an ABCG1-mediated manner (Sankaranarayanan et al. 2009; Favari et al. 2009). However, a recent study by us showed that the ABCG1mediated efflux of cholesterol to rHDL containing different apoA-I mutants is diminished by deletion of the carboxyl-terminal domain 185-243 from full-length apoA-I (Daniil et al. 2013). Analysis of rHDL used in these studies suggested that the impairment of ABCG1-mediated cholesterol efflux is not due to major differences in particle composition or size between rHDL particles containing WT apoA-I or apoA-I $[\Delta(185-243)]$.

The mechanism by which ABCG1 promotes sterol efflux to extracellular acceptors has not been resolved. The earlier studies failed to detect specific HDL association in BHK or HEK293 cells overexpressing the human ABCG1 (Wang et al. 2004; Sankaranarayanan et al. 2009). Also the initial studies had suggested that ABCG1 is localized to both the plasma membrane and internal membrane structures (Vaughan and Oram 2005; Wang et al. 2006; Xie et al. 2006b), while more recent studies suggested that ABCG1 is localized to endosomes and recycling endosomes (Sturek et al. 2010b; Tarling and Edwards 2011). It has been proposed that ABCG1 could transport sterols across the bilayer of endosomes before their fusion with the plasma membrane and thus redistribute these sterols to the outer leaflet of the plasma membrane and facilitate their subsequent efflux of sterols to HDL or other acceptors (Tarling and Edwards 2011; Vaughan and Oram 2005). However, the similar pattern of lipid-free and rHDL-bound apoA-I mutants to promote ABCA1- and ABCG1-mediated cholesterol efflux is compatible with a transient localization of ABCG1 in the plasma membrane that will allow its interaction with lipoprotein acceptors (Chroni et al. 2003, 2004b; Daniil et al. 2013). The similar cholesterol efflux capacity of lipid-free and lipidated apoA-I mutants could favor a model where lipid-free apoA-I is lipidated in an ABCA1mediated process, changes its conformation, and subsequently accepts more cholesterol from membrane pools generated by ABCA1 or ABCG1.

The different capacity of rHDL-associated apoA-I $[\Delta(185-243)]$ mutant to promote ABCG1-mediated cholesterol and 7-ketocholesterol efflux (Daniil et al. 2013) 
may be related to the looser association of 7-ketocholesterol with the plasma membrane compared to cholesterol (Kan et al. 1992).

The finding that lipid-free and lipid-bound apoA-I $[\Delta(185-243)]$ has reduced capacity to promote ABCA1- and ABCG1-mediated cholesterol efflux, respectively, may have physiological significance since proteolysis of HDL-associated apoA-I in vivo may affect its ability to promote cholesterol efflux from macrophages. In this regard, proteolysis of apoA-I by metalloproteinases present in the arterial wall or alveolar macrophages (Russell et al. 2002; Galis et al. 1995) produces various fragments that correspond to apoA-I cleaved after residues 191 or 188 and are compatible in size with apoA-I[ $\Delta(185-243)]$ (Lindstedt et al. 1999; Eberini et al. 2002). This may explain the accumulation of foam cells containing high cholesterol levels in alveolar macrophages of ABCG1-deficient mice (Kennedy et al. 2005; Out et al. 2006).

A recent study using high-density genotyping arrays containing singlenucleotide polymorphisms suggested an association between HDL cholesterol levels in humans and ABCG1 (Edmondson et al. 2011). Recent genetic association studies in humans identified functional variants in ABCG1 associated with increased risk of coronary artery disease (Xu et al. 2011; Schou et al. 2012), suggesting an important role of ABCG1 in the protection from atherosclerosis and cardiovascular disease.

\subsection{Phospholipid Transfer Protein}

Phospholipid transfer protein (PLTP) transfers phospholipids, diacylglycerol (Rao et al. 1997), free cholesterol (Nishida and Nishida 1997), R-tocopherol (vitamin E) (Kostner et al. 1995), and lipopolysaccharide among lipoproteins and between lipoproteins and cells (Hailman et al. 1996; Levels et al. 2005) (Fig. 8c). In vitro studies have identified a number of functions for PLTP in HDL metabolism (Albers and Cheung 2004; Siggins et al. 2007). PLTP displays two major functions in circulation: (1) it transforms HDL particles in a conversion or fusion process whereby small HDL3 particles are fused leading to the generation of large fused HDL particles and pre $\beta$-HDL that can participate in cholesterol removal from cells (Vikstedt et al. 2007a), and (2) it transfers post-lipolytic VLDL surface phospholipids to HDL (Albers and Cheung 2004; Siggins et al. 2007). Functions of PLTP which may influence the formation of atherosclerotic lesions include the generation of acceptors for lipid efflux from cells, regulation of plasma HDL levels, protection of lipoproteins from oxidation, and regulation of production of atherogenic lipoproteins (Jiang et al. 2001).

In human plasma, two distinct forms of PLTP are present, one with high activity (HA-PLTP) and the other with low activity (LA-PLTP) (Oka et al. 2000; Karkkainen et al. 2002). It was reported that phospholipid transfer activity is a prerequisite for efficient PLTP-mediated HDL enlargement (Huuskonen et al. 2000) and that enrichment of triglyceride in the HDL core could promote such fusion (Rye et al. 1998). Of these two forms, only the high specific activity 
PLTP promotes macrophage cholesterol efflux via fusion of HDL particles that leads to the release of lipid-poor pre $\beta$-mobile apoA-I particles which act as efficient cholesterol acceptors (Vikstedt et al. 2007a). The mechanisms by which LA-PLTP is generated and its physiological functions are currently unknown. However, since apoE is able to interact with PLTP, and apoE-containing proteoliposomes can activate inactive or low active PLTP, the presence of apoE in PLTP complexes is expected to enhance PLTP activity. This is consistent with the suggestion that apoE may play a role in regulating the PLTP activity level in plasma (Janis et al. 2005). HA- and LA-PLTP forms are surface-active proteins, and the low active form was demonstrated to dock more strongly onto a phospholipid monolayer surface as compared to HA-PLTP form (Setala et al. 2007). It is therefore possible that LA-PLTP form could play other important lipid transfer-independent functions such as signaling on cell surface as suggested (Albers et al. 2012).

Although the role of PLTP in lipoprotein metabolism and atherogenesis has been intensively studied in gene-targeted mouse models and using in vitro experiments, the physiological role of PLTP in human metabolism is far from being resolved. Genetic approach has provided some evidence that genetic variation at the PLTP locus affects its phospholipid transfer activity and HDL particle size and might highlight its relevance in cholesterol efflux process (Vergeer et al. 2010a). PLTPdeficient mice have a marked decrease in HDL and apoA-I (Jiang et al. 1999) but reduced atherosclerosis in the background of $\mathrm{apoE}^{-/-}$or apoB-transgenic mice (Jiang et al. 2001). It has also been reported that macrophage-derived PLTP contributes significantly to total plasma PLTP activity and deficiency of PLTP in macrophages leads to reduced atherosclerosis in $\mathrm{LDLr}^{-1-}$ mice (Vikstedt et al. 2007b). There is also an interesting interaction between PLTP and CETP since it was demonstrated that purified PLTP enhances cholesteryl ester transfer from $\mathrm{HDL}_{3}$ to VLDL (Tollefson et al. 1988), although PLTP has no cholesterol ester transfer activity of its own. Moreover, CETP transgenic/PLTP KO mice have significantly lower plasma CETP activity as compared to that of CETP transgenic mice (Kawano et al. 2000). Currently, the physiological relevance of this PLTPCETP interaction in HDL metabolism is poorly understood.

\section{3 apoM}

Apolipoprotein M (apoM), which is also involved in HDL remodeling (Fig. 8a), is a $26 \mathrm{kDa}$ glycoprotein that belongs to the lipocalin protein superfamily and has been shown to bind lipophilic ligands in its hydrophobic binding pocket (Xu and Dahlback 1999; Nielsen et al. 2009; Dahlback and Nielsen 2009; Hu et al. 2010). It is secreted by the liver and to a lesser extent by the kidney and associates with HDL through its retained N-terminal signal peptide (Christoffersen et al. 2008a; Axler et al. 2008) and to a lesser extent with other lipoproteins. ApoM is involved in the recycling of small lipophilic ligands via the multi-ligand receptor megalin (Nielsen et al. 2009) and has been shown to participate in the remodeling and maturation of HDL in plasma. 
Studies in humans and in mice overexpressing or lacking apoM have shown a positive association between plasma apoM levels and total as well as HDL and LDL cholesterol concentrations (Axler et al. 2007; Plomgaard et al. 2009; Christoffersen et al. 2008b). Lack of hepatocyte nuclear factor-1 $\alpha$ (HNF-1 $\alpha$ ) (Shih et al. 2001) or inhibition of apoM expression in C57BL/6 mice injected with small interfering RNA for apoM (Wolfrum et al. 2005) is characterized by diminished concentration of pre $\beta$-HDL particles and presence of large-size HDL particles. In vitro experiments using plasma obtained from WT mice, apoM knockout, and apoM transgenic mice showed that apoM increases the formation of pre $\beta$-HDL particles following incubation of the plasma at $37^{\circ} \mathrm{C}$ (Christoffersen et al. 2008b).

These studies also indicate that apoM-containing HDL particles isolated from human plasma and the plasma of apoM transgenic mice have increased capacity to stimulate cholesterol efflux from macrophage foam cells and are more efficient in protecting against LDL oxidation (Wolfrum et al. 2005; Christoffersen et al. 2008b). Cell culture studies indicated that expression of apoM in cells transfected with ABCA1 increases the size of pre $\beta$-HDL (Mulya et al. 2010).

Reduced plasma apoM levels have been reported in animal models of diabetes and some patients with diabetes and metabolic syndrome (Plomgaard et al. 2009; Dullaart et al. 2009; Xu et al. 2006), indicating potential involvement of apoM in the development of diabetes. Genetic linkage studies in Chinese populations have also associated two single-nucleotide polymorphisms (SNPs) located in the apoM proximal promoter region (SNP T-778C and SNP T-855C) with the development of coronary artery disease (Xu et al. 2008; Jiao et al. 2007) and one of them (the $\mathrm{T}-778 \mathrm{C}$ ) associated with susceptibility to coronary artery disease.

Adenovirus-mediated gene transfer of apoM in LDL-receptor-deficient mice or hepatic overexpression of apoM in apoM transgenic mice partially protected the mice from atherosclerosis development (Christoffersen et al. 2008b; Wolfrum et al. 2005). Data accumulating until now strongly suggest a protective role for apoM, and the protection might be mediated via HDL.

\subsection{Hepatic Lipase and Endothelial Lipase}

HDL is first remodeled in the circulation and subsequently catabolized by cells and tissues. Hepatic lipase (HL) and endothelial lipase (EL) are two plasma lipases playing an important role in HDL remodeling (Fig. 8a). HL and EL have specificity primarily for phospholipids and to a lesser extend for triglycerides of apoBcontaining lipoprotein remnants and large HDL (Maugeais et al. 2003a; Santamarina-Fojo et al. 2004). HL-deficient mice exhibit elevated levels of large HDL particles enriched in phospholipids and apoE (Homanics et al. 1995) and reduced atherosclerosis in the background of apoE ${ }^{-1-}$ mice (Karackattu et al. 2006; Mezdour et al. 1997). In contrast, overexpression of HL in mice reduced plasma HDL levels (Braschi et al. 1998). A rat liver perfusion of human native HDL2 or triglyceride-enriched HDL promoted the formation of the pre $\beta 1$-HDL subspecies and a reduction of the $\alpha$-HDL2 (Barrans et al. 1994). These changes were attributed 
to the triglyceride lipase activity of HL (Barrans et al. 1994). Characterization of pre $\beta 1-H D L$ showed that these particles contain one to two molecules of apoA-I, associated with phospholipids, and some free and esterified cholesterol (Guendouzi et al. 1999). When compared to triglyceride-rich HDL2, remnant-HDL2 had lost on the average one molecule of apoA-I, $60 \%$ of triglycerides, and $15 \%$ of phospholipids. The estimated composition supported the hypothesis that HL had splitted the initial particle into one pre $\beta 1$-HDL and one remnant-HDL2. RemnantHDL2 had different composition and properties from HDL3, suggesting that HL did not promote the direct conversion of HDL2 to HDL3 (Guendouzi et al. 1999). Analysis of HL transgenic rabbits suggested that HL reduces the size of $\alpha$-migrating HDL and increases the rate of catabolism of apoA-I (Kee et al. 2002). Cell studies showed that HL promotes selective HDL3 cholesterol ester uptake independent from SR-BI and that proteoglycans are needed for the HL action on selective CE uptake (Brundert et al. 2003). Earlier studies in mice deficient in both HL and EL suggested an additive effect of HL and EL on plasma HDL levels but not on macrophage-mediated reverse cholesterol transport in mice (Brown et al. 2010). However, a recent study demonstrated that targeted inactivation of both HL and EL in mice promoted macrophage-to-feces RCT and enhanced HDL antioxidant properties (Escola-Gil et al. 2013).

HL-deficient patients have elevated plasma concentrations of cholesterol in the HDL and $\beta$-VLDL and increased concentration of triglycerides and phospholipids in the LDL and HDL (Breckenridge et al. 1982). Analyses carried out in complete and partial HL-deficient subjects as well as in normotriglyceridemic and hypertriglyceridemic controls suggested that HL activity is important for physiologically balanced HDL metabolism (Ruel et al. 2004). However, the presence of HL may not be necessary for normal HDL-mediated reverse cholesterol transport process and is not associated with pro-atherogenic changes in HDL composition and metabolism (Ruel et al. 2004). In addition, another Mendelian randomization study showed that subjects with loss-of-function genetic variants of HL have elevated levels of HDL cholesterol, but are not associated with risk of ischemic cardiovascular disease and therefore may not be protected against ischemic cardiovascular disease (Johannsen et al. 2009).

Endothelial lipase (EL) has phospholipase activity (mostly PLA1 activity) and low levels of triglyceride lipase activity (Jaye et al. 1999). Overexpression of EL in mice markedly decreased plasma HDL cholesterol and apoA-I levels, had a modest effect on apoB-containing lipoproteins, and increased 2.5-3-fold the uptake of the HDL by the kidney and the liver (Ishida et al. 2003; Maugeais et al. 2003a). In contrast, the EL deficiency in mice increased HDL cholesterol levels (Ishida et al. 2003; Ma et al. 2003) and reduced atherosclerosis in the background of apoE ${ }^{-/-}$mice (Ishida et al. 2004). Analysis of atherosclerosis prone $\mathrm{LDLR}^{-/-} \mathrm{x}$ ApoB(100/100) mice suggested that EL and the HDL cholesterol levels were regulated by SREBPs and VEGF-A (Kivela et al. 2012). Overexpression of EL in mice markedly decreased plasma HDL cholesterol and apoA-I levels and had a modest effect on apoB-containing lipoproteins (Maugeais et al. 2003b; Ishida et al. 2003). Furthermore, the HDL phospholipid and cholesteryl ester content 
decreased, while HDL triglyceride content increased (Nijstad et al. 2009) and the free cholesterol content remained unaltered. Fast protein liquid chromatography analysis and agarose gel electrophoresis showed that the expression of EL resulted in the generation of small pre $\beta$-HDL particles (Nijstad et al. 2009). In addition, overexpression of EL increased the selective uptake of hepatic HDL cholesteryl ester by SR-BI as well as hepatic holoparticle uptake. This resulted in a dramatic increase in the uptake of the HDL protein, but not the cholesteryl ester moieties, into the kidneys (Nijstad et al. 2009). These data support a model in which EL-mediated phospholipid hydrolysis of HDL destabilizes the particle, resulting in the shedding of poorly lipidated apoA-I from the particle surface, which are preferentially cleared by the kidneys and via increased selective uptake by SR-BI.

Several genetic EL variants have been reported to be associated with plasma HDL-C levels (deLemos et al. 2002; Edmondson et al. 2009), and genome-wide association studies have shown that single-nucleotide polymorphisms (SNPs) near LIPG (EL) are associated with plasma HDL-C levels (Kathiresan et al. 2008a, 2009; Teslovich et al. 2010). However, the relationship of genetic variation in the EL locus with the risk for coronary artery disease remains uncertain (Vergeer et al. 2010b). A newer study showed that carriers of an EL mutant characterized by complete loss of function had significantly higher plasma HDL cholesterol levels compared to carriers having partial loss-of-function mutations (Singaraja et al. 2013). Apolipoprotein B-depleted serum from carriers of HL with complete loss of function had significantly enhanced capacity to promote cholesterol efflux as compared to apoB-depleted serum obtained from HL carriers with partial loss of function (Singaraja et al. 2013). In the same study, it was reported that carriers of certain EL mutations exhibited trends toward reduced coronary artery disease in four independent cohorts (Singaraja et al. 2013).

\subsection{Cholesteryl Ester Transfer Protein}

Cholesteryl ester transfer protein (CETP) promotes the transfer of cholesteryl esters from HDL to VLDL, IDL, and LDL in exchange for triglycerides (Fig. 8b). It was estimated that $66 \%$ of the cholesteryl esters of HDL return to the liver by the action of CETP, indicating an important role of CETP in reverse cholesterol transport (Barter et al. 2003), and $33 \%$ by the action of SR-BI (Fielding and Fielding 2007). Deficiency in CETP in humans is associated with increased plasma levels of HDL (hyperalphalipoproteinemia) (Inazu et al. 1990; Maruyama et al. 2003) and decreased levels of small pre $\beta 1-H D L$ particles (Arai et al. 2000; Asztalos 2004). An early study showed that the hyperalphalipoproteinemia and high plasma HDL cholesterol levels in a Japanese family without incidence of atherosclerosis was the result of deficiency in CETP (Koizumi et al. 1985). Inhibition of CETP activity by CETP inhibitors increased HDL cholesterol levels and the size of HDL particle and decreased LDL cholesterol levels in human subjects, but did not increase atheroprotection (Landmesser et al. 2012; Brousseau et al. 2004; de Grooth et al. 2002). However, subsequent studies indicated that heterozygous mutations 
in CETP increase the risk for CAD (Hirano et al. 1995, 1997; Zhong et al. 1996). The effect of CETP on the HDL pathway was also studied in mice expressing the human CETP gene. CETP transgenic mice have a significant decrease in apoA-I and HDL levels (Melchior et al. 1994) and increased pre $\beta$-HDL levels (Francone et al. 1996) and are susceptible to atherosclerosis in the background of $\mathrm{apoE}^{-1-}$ or $\mathrm{LDLr}^{-1-}$ mice (Plump et al. 1999).

\subsection{Scavenger Receptor BI}

\subsubsection{Role of SR-BI in HDL Remodeling Based on Its In Vitro Interactions with Its Ligands}

SR-BI is an $82 \mathrm{kDa}$ membrane glycoprotein consisting of a large extracellular domain, two transmembrane domains, and two cytoplasmic amino and carboxyterminal domains (Krieger 1999). SR-BI is primarily expressed in the liver, steroidogenic tissues, and endothelial cells but is also found in other tissues (Acton et al. 1996), and it binds a variety of ligands including HDL, LDL, VLDL, and modified lipoproteins. SR-BI has also been shown to affect chylomicron metabolism in vivo and bind non-HDL lipoproteins in vitro (Out et al. 2004b, 2005; Krieger 1999, 2001; Acton et al. 1994, 1996; Murao et al. 1997). The most important property of SR-BI is considered its ability to act as the HDL receptor (Fig. 8d).

It has been shown that SR-BI binds to native HDL and discoidal reconstituted HDL containing apoA-I or apoE, through their apolipoprotein moieties (Krieger 2001; Chroni et al. 2005c; Liadaki et al. 2000; Xu et al. 1997). When it is bound to HDL, SR-BI mediates selective uptake of cholesteryl ester, triglycerides, phospholipids, and vitamin E from HDL to cells (Acton et al. 1996; Greene et al. 2001; Thuahnai et al. 2001; Stangl et al. 1999; Gu et al. 1998, 2000b; Urban et al. 2000). It also promotes bidirectional movement of unesterified cholesterol (Ji et al. 1997; Gu et al. 2000a). Interactions of HDL with SR-BI are responsible for mobilization of free cholesterol from the whole body (Ji et al. 1997; Gu et al. 2000a; Cuchel et al. 2010b). SR-BI-mediated HDL holoparticle endocytosis may also be involved in SR-BI-mediated selective CE uptake under certain conditions in some types of cells (Pagler et al. 2006b; Ahras et al. 2008). To understand the molecular interaction of SR-BI with HDL, SR-BI mutants which display altered biological functions were generated by in vitro mutagenesis. A SR-BI[M158R] mutant does not bind HDL (Gu et al. 2000a). A SR-BI[Q402R/Q418R] mutant also does not bind HDL, but in contrast with the first mutant, it binds LDL (Gu et al. 2000a; b). A SR-BI[G420H] mutant has normal selective cholesteryl ester uptake but reduced cholesterol efflux to HDL and reduced hydrolysis of internalized cholesteryl esters (Parathath et al. 2004). Cell culture cholesterol efflux studies using rHDL containing mutated apoA-I and these SR-BI mutants showed that the greater reduction of cholesterol efflux in cells expressing WT SR-BI was with the mutants apoA-I[D102A/D103A] and apoA-I [R160V/H162A] (21\% and $49 \%$, respectively) (Liu et al. 2002). 
Follow-up in vivo studies showed apoA-I-deficient mice infected with an adenovirus expressing the apoA-I[D102A/D103A] had an HDL phenotype that resembled that of WT apoA-I (Chroni et al. 2005a). In contrast, mice expressing the apoA-I[R160V/H162A] had a phenotype similar to that described for apoA-I $[\mathrm{R} 160 \mathrm{~L}]_{\text {Oslo }}$ that could be corrected by co-expression of the apoA-I[R160L $]_{\text {Oslo }}$ mutant and human LCAT (Chroni et al. 2005a). Following density gradient ultracentrifugation, the apoA-I[R160V/H162A] mutant that floated in the HDL region was decreased relatively to WT apoA-I, and it was shifted toward the HDL3 region (Chroni et al. 2005a).

When the mutant SR-BI[M158R] was examined, several apoA-I mutants tested had reduced efflux and bound less tightly compared to WT apoA-I with the exception of rHDL that contained the mutant apoA-I[A160V/H162A]. The binding of this mutant was almost as tight to the cells that expressed SR-BI[M158R] mutant as it was for the cells that expressed WT SR-BI (Liu et al. 2002). Based on these findings, it was suggested that efficient SR-BI-mediated cholesterol efflux requires not only direct binding ( $\mathrm{Gu}$ et al. 2000a) but also the formation of a productive complex between SR-BI and the rHDL particle (Liu et al. 2002).

\subsubsection{In Vivo Functions of SR-BI}

Expression of SR-BI in the liver was shown to be critical for the control of plasma levels of HDL cholesterol (HDL-C) (Leiva et al. 2011; Zhang et al. 2007), and its expression in the steroidogenic tissues is important for synthesis of steroid hormones (Landschulz et al. 1996; Krieger 1999). Transgenic mice expressing SR-BI in the liver had decreased apoA-I and HDL cholesterol levels and increased clearance of VLDL and LDL (Wang et al. 1998; Ueda et al. 1999). SR-BI-deficient mice had decreased HDL cholesterol clearance (Out et al. 2004a), twofold increased plasma cholesterol, and presence of large-size abnormal apoE-enriched particles that were distributed in the HDL/IDL/LDL region (Rigotti et al. 1997). The in vivo phenotypes generated by overexpression or deficiency of SR-BI are consistent with its in vitro functions to promote selectively lipid transport from HDL to cells and efflux of free cholesterol from cells. SR-BI has also been shown to affect chylomicron metabolism in vivo (Out et al. 2004b; 2005).

Deficiency of SR-BI in mice reduced greatly the cholesteryl ester stores of steroidogenic tissues and decreased the secretion of biliary cholesterol by approximately $50 \%$. However, the SR-BI deficiency did not affect the secretion of the pool size of bile acids or the fecal secretion of bile acids and the intestinal cholesterol absorption (Rigotti et al. 1997; Mardones et al. 2001). These findings established that two important functions of SR-BI are the transfer of the CE of HDL to the liver and subsequent incorporation into the bile for excretion (Rigotti et al. 1997; Mardones et al. 2001) and the delivery of cholesteryl esters to the steroidogenic tissues where it is utilized for synthesis of steroid hormones (Ji et al. 1999). Furthermore SR-BI controls the concentrations and composition of plasma HDL (Krieger 2001; Wang et al. 1998; Ueda et al. 1999; Rigotti et al. 1997; Webb et al. 2002) and protects different mouse models from atherosclerosis (Hildebrand et al. 2010; Arai et al. 1999; Ueda et al. 2000; Kozarsky et al. 2000; Huszar et al. 2000; 
Trigatti et al. 1999; Braun et al. 2002, 2003; Karackattu et al. 2005; Zhang et al. 2005).

SR-BI deficiency also caused defective maturation of oocytes and red blood cells due to accumulation of cholesterol in the plasma membrane of progenitor cells (Trigatti et al. 1999; Holm et al. 2002) and caused infertility in the female but not the male mice (Trigatti et al. 1999; Yesilaltay et al. 2006a). The infertility could be corrected by restoration of SR-BI gene by adenovirus-mediated gene transfer (Yesilaltay et al. 2006b). Subsequent experiments showed a negative correlation of follicular HDL cholesterol levels in women and embryo fragmentation during in vitro fertilization (Browne et al. 2009). Taken together these data suggest a role of HDL in oocyte development and embryogenesis. The SR-BI-mediated selective uptake of the CE of HDL by the liver is a complex process and requires the functions of a liver-specific protein, PDZK1, that contains four PDZ domains that can recognize the C-terminal region of SR-BI. Interaction of PDZK1 with the C-terminal region of SR-BI, posttranscriptionally, regulates localization and stability of SR-BI (Fenske et al. 2009). Inactivation of hepatic PDZK1 significantly affected plasma HDL metabolism and structure and caused occlusive atherosclerosis in double-deficient mice for apoE and PDKZ (Kocher et al. 2008; Yesilaltay et al. 2009). The detailed mechanism of SR-BI-facilitated selective uptake of the $\mathrm{CE}$ of HDL is not yet clear. It has been suggested that HDL binding to hepatic SR-BI allows the entry of cholesteryl esters into a channel that is generated by SR-BI and along which cholesteryl esters move down their concentration gradient into the cell membrane. During this movement, HDL particles donate their CE to hepatocytes without the simultaneous uptake and degradation of the whole HDL particle.

Recent findings reviewed in Meyer et al. (2013) indicated that SR-BI-independent cholesterol ester uptake processes may also operate in macrophages. Liverspecific or whole-body ABCA1 deficiency in mice accelerated HDL catabolism in plasma without changing the hepatic expression of SR-BI, suggesting that other membrane proteins, such as those involved in the hepatic $\mathrm{F}_{1}-\mathrm{ATPase} / \mathrm{P} 2 \mathrm{Y}_{13}$ pathway (Martinez et al. 2003) (see below for more detail) and CD36 (Brundert et al. 2011), may be involved in the selective cholesteryl ester uptake. In a largescale human study, several CD36 SNPs were strongly associated with HDL cholesterol levels, thus pointing to a potential role of CD36 in the regulation of human HDL metabolism (Love-Gregory et al. 2008).

Interactions of HDL with SR-BI in endothelial cells trigger signaling mechanisms that involve activation of eNOS and release of nitric oxide that causes vasodilation (Mineo et al. 2003; Yuhanna et al. 2001; Li et al. 2002; Gong et al. 2003).

Human subjects have been identified with a P297S substitution in SR-BI. Heterozygote carriers for this mutation had increased HDL levels and decreased adrenal steroidogenesis and dysfunctional platelets, but did not develop atherosclerosis. HDL derived from these subjects had decreased ability to promote cholesterol efflux from macrophages (Vergeer et al. 2011). A recent study has shown the impact of SR-BI SNPs on female fertility (Yates et al. 2011). 


\subsection{Role of Ecto-F - -ATPase/P2Y 13 Pathway in Hepatic HDL Clearance}

Based on Biacore's surface plasmon resonance studies of hepatic membranes, Martinez and his colleagues (Martinez et al. 2003) demonstrated the presence of a $50 \mathrm{kDa}$ apoA-I binding protein that was identical to the subunit of the $\beta$-chain of ATP synthase (Boyer 1997). The HDL-binding protein was identified as ecto-F 1- $^{-}$ ATPase that recognizes apoA-I (Fig. 8d). The multi-subunit ATPase complex consists of two major domains called $F_{0}$ and $F_{1}$ (Boyer 1997). The ecto- $F_{1}-A T P a s e$ protein, which resides on cell membranes, hydrolyzes ATP to ADP and phosphate and can be inhibited by the mitochondrial inhibitor protein $\mathrm{IF}_{1}$ (Cabezon et al. 2003). It was recently shown that IF1 is present in the serum, and its concentration correlates negatively with HDL-C levels and the risk for coronary heart disease (Genoux et al. 2013). Binding of lipid-free apoA-I to the high affinity side of ecto- $\mathrm{F}_{1}$-ATPase enhances binding of HDL to the low-affinity binding sites. The apoA-I binding to the ecto- $\mathrm{F}_{1}$-ATPase also increases the production of ADP that associates with its receptor, purinergic P2 $\mathrm{Y}_{13}$ (Jacquet et al. 2005). The ecto$\mathrm{F}_{1}$-ATPase/P2Y 13 -mediated HDL uptake pathway is under careful control. Adenylate kinase and niacin are important factors that regulate HDL metabolism and plasma levels via ecto-F1-ATPase (Fabre et al. 2006; Zhang et al. 2008). Inhibitors of ecto-F1-ATPase or adenylate kinase activity that consume ADP generated by ecto-F1-ATPase downregulate holo-HDL particle uptake (Genoux et al. 2013). In vivo studies using a $\mathrm{P} 2 \mathrm{Y}_{13}$-deficient mouse model also indicated that the $\mathrm{P}_{2} \mathrm{Y}_{13}$ ADP receptor may have an important role in HDL-mediated reverse cholesterol transport (Fabre et al. 2010). It is possible that induction of hepatic ecto$\mathrm{F}_{1}$-ATPase/P2Y 13 pathway might enhance hepatic HDL endocytosis and turnover and accelerate cholesterol removal from cholesterol-laden macrophages and other tissues and cells of the body.

\subsection{Transcytosis of apoA-I and HDL by Endothelial Cells}

It has been shown that endothelial cells have the ability to bind and transcytose lipid-free apoA-I in a specific manner. This process depends on ABCA1 and leads to the generation of a lipidated apoA-I particle that is secreted (Cavelier et al. 2006; Rohrer et al. 2006). Endothelial cells can also transcytose HDL and this process required the functions of SR-BI and ABCG1 (Rohrer et al. 2009). ApoA-I mutants with defective C-terminal apoA-I[ $\Delta(185-243)]$ and apoA-I[L218A/L219A/V221A/ L222A] had $80 \%$ decreased specific binding and $90 \%$ decreased specific transport by aortic endothelial cells. Following lipidation of these mutants, the rHDL particles formed were transported through endothelial cells by an ABCG1- and SR-BI-dependent process. Amino and combined amino- and carboxy-terminal apoA-I deletion mutants displayed increased nonspecific binding, but the specific binding or transport remained absent (Ohnsorg et al. 2011). These data support the model in which apoA-I is initially lipidated by ABCA1 and subsequently processed 
by ABCA1-independent mechanisms. Transcytosis of apoA-I and HDL may provide a mechanism for transfer of HDL into the subendothelial space.

\subsection{The Role of Cubilin in apoA-I and HDL Catabolism by the Kidney}

It has been shown that in humans, impaired cubilin and amnionless function results in the Imerslunds-Gräsbeck syndrome, which is characterized by intestinal vitamin B12 malabsorption and proteinuria (Fyfe et al. 2004). Cubilin is a $460 \mathrm{kDa}$ endocytic receptor which is co-expressed with megalin, a $600 \mathrm{kDa}$ multi-ligand receptor belonging to the LDL receptor gene family. It is localized in the apical membranes of epithelial cells in the proximal tubules in the kidney cortex (Kozyraki 2001). In addition to co-localization of cubilin with megalin, the transmembrane protein amnionless is a renal protein that interacts with cubilin and forms a large cubilin/amnionless complex. In this complex, cubilin plays a role as a ligand-binding domain, whereas amnionless is essential for subcellular localization and endocytosis of cubilin bound to its ligand (Strope et al. 2004; Fyfe et al. 2004). An important function of cubilin is related to its ability to bind apoA-I or HDL (Kozyraki et al. 1999). In the kidney, however, HDL particles are too large to cross the glomerular filtration barrier, and therefore megalin and cubilin/amnionless protein receptor system is only exposed to filtered lipid-free or poorly lipidated apoA-I, thereby affecting the overall HDL metabolism (Kozyraki et al. 1999; Moestrup and Nielsen 2005). In physiological terms, it is considered that the kidney cortex is a major site of catabolism for lipid-free and poorly lipidated apoA-I and that this uptake is a concerted action of glomerular filtration, tubular reabsorption, and intracellular degradation of free apoA-I (Woollett and Spady 1997). Graversen et al. (2008) analyzed urine samples from patients with Fanconi syndrome. This is a rare renal proximal tubular reabsorption failure and also includes dysfunction of cubilin. A high urinary excretion of both apoA-I and apoA-IV but not apoA-II was evident. This study demonstrated that the human kidney is a major site for filtered apoA-I and A-IV but not for HDL particles since urinary excretion of all major lipid classes (phospholipids, triglycerides, cholesterol, and cholesterol esters) in Fanconi patients was as low as in control subjects (Graversen et al. 2008). Although the kidney is not considered a central organ in lipoprotein catabolism, it plays an important role in the degradation of lipid-poor apoA-I via the cubilin function. 


\section{HDL Subclasses}

\subsection{The Origin and Metabolism of Pre $\beta-H D L$ Subpopulations}

Several pre $\beta$ - and $\alpha$-HDL subpopulations exist in plasma and are generated as a consequence of the pathway of biogenesis and remodeling of HDL. These subpopulations can be separated based on different fractionation procedures (Fielding and Fielding 1996; Chung et al. 1986; Nichols et al. 1986; Davidson et al. 1994). The precursor-product relationship between pre $\beta$ - and $\alpha$-HDL particles as well as the precise origin and functions of the pre $\beta$-HDL particles is still a matter of investigation.

It has been reported earlier that pre $\beta$-HDL comprises approximately $5 \%$ of total plasma apoA-I level. It is heterogeneous in size and contains several species of 5$6 \mathrm{~nm}$ in diameter (Fielding and Fielding 1995; Nanjee et al. 2000). The best characterized species are pre $\beta 1$ and pre $\beta 2$ (Fielding and Fielding 1995). The concentration of pre $\beta 1-\mathrm{HDL}$ is increased in large lymph vessels (Asztalos et al. 1993) and in aortic intima (Heideman and Hoff 1982).

Pre $\beta$-HDL particles can be formed by two different routes. The first is de novo synthesis by the HDL biogenesis pathway (Fig. 8a). The second is generation of pre $\beta$-HDL particles from $\alpha$-HDL particles by reactions catalyzed by CETP, PLTP, HL, EL, and apoM discussed earlier (Barrans et al. 1994; Maugeais et al. 2003c; Arai et al. 2000; Huuskonen et al. 2001; Christoffersen et al. 2008b) (Fig. 8a-c).

Cell culture studies showed that lipid-free apoA-I added to a culture medium of CHO cells can recruit phospholipids and cholesterol, initially to form small $73 \AA$ particles, and subsequently larger apoA-I-containing particles by the action of LCAT that have a precursor-product relationship (Forte et al. 1993, 1995).

Subsequent studies showed that a large proportion of apoA-I is secreted from HepG-2, CaCo-2, or apoA-I expressing CHO cells in lipid-free monomeric form, with a Stokes radius of $2.6 \mathrm{~nm}$ and pre $\alpha$ electrophoretic mobility that is unable to promote efflux of phospholipids and cholesterol. It was suggested that in a reaction dependent on ABCA1, the $2.6 \mathrm{~nm}$ form was converted into a $3.6 \mathrm{~nm}$ monomeric apoA-I form with pre $\beta$ electrophoretic mobility that was able to promote efflux of phospholipids and cholesterol from cells and thus increase its size (Chau et al. 2006). Expression of apoM in cells transfected with ABCA1 can also increase the size of pre $\beta$-HDL (Mulya et al. 2010). Other studies have shown that some types of pre $\beta$-HDL particles can be formed independently of apoA-I/ABCA1 interactions in the plasma of humans with Tangier disease and the plasma of apoA-I-deficient mice expressing mutant apoA-I forms (Chroni et al. 2007; Fotakis et al. 2013a; Asztalos et al. 2001). Furthermore, inhibition of ABCA1 in HepG2 cells and macrophage cultures by glyburide inhibited the formation of $\alpha$-HDL particles but did not affect the formation of pre $\beta$-HDL particles (Krimbou et al. 2005).

The presence of increased concentrations of pre $\beta 1-\mathrm{HDL}$ in the vascular bed suggests that these particles may be generated locally by gradual lipidation of lipidpoor apoA-I (Heideman and Hoff 1982; Smith et al. 1984). Pre $\beta$-HDL particles are typically lipid-poor and therefore they are efficient in promoting ABCA1-mediated 
cholesterol efflux. The ABCA1/pre $\beta 1$-HDL interaction provides phospholipids and cholesterol and thereby converts the pre $\beta$-HDL to $\alpha$-HDL-migrating particles. These particles may be enlarged further by recruitment of phospholipids and cholesterol from cell membranes (Fielding and Fielding 2007). In addition, esterification of the cholesterol of pre $\beta 1$-HDL by LCAT contributes to their gradual conversion into spherical HDL without prior formation of discoidal HDL particles (Nakamura et al. 2004b; Fielding and Fielding 2007).

\subsection{Complexity of HDL}

Genome-wide association studies demonstrated that new genes and the corresponding proteins affect plasma HDL levels by unknown mechanisms (Holleboom et al. 2008; Kathiresan et al. 2008b, 2009; Sabatti et al. 2009; Aulchenko et al. 2009; Teslovich et al. 2010; Richards et al. 2009; Willer et al. 2008; Chasman et al. 2009; Waterworth et al. 2010; Laurila et al. 2013). In parallel, proteomic analysis showed that a large number of plasma proteins can associate with HDL and this may affect the HDL structure and functions (Fig. 9) (Gordon et al. 2010). The proteins associated with HDL can be classified in six major categories and include proteins involved in lipid, lipoprotein, and HDL biogenesis and metabolism, acute phase proteins, protease inhibitors, complement regulatory proteins, and a few others (albumin, fibrinogen a chain platelet basic protein) (Vaisar et al. 2007; Davidson et al. 2009b). Differences were observed in

Proteins associated with HDL based on proteomic analyses

-Proteins of lipid \& lipoprotein metabolism

-Proteins capable of forming distinct HDL particles -Complement regulatory proteins

-Proteinase inhibitors -Acute phase response proteins - Other proteins

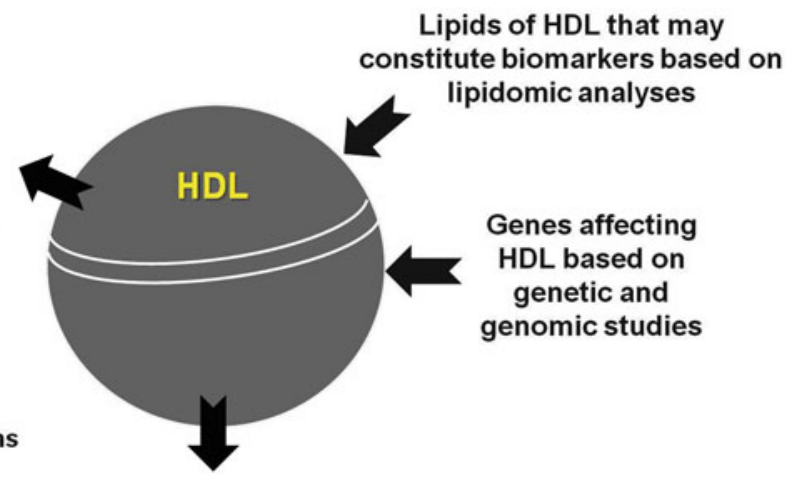

$$
\begin{aligned}
& \text { HDL functions: } \\
& \text {-Atheroprotective } \\
& \text {-SR-BI dependent release of NO } \\
& \text {-Anti-oxidant } \\
& \text {-Anti-inflammatory } \\
& \text {-Anti-thrombotic } \\
& \text {-SR-BI dependent protection of } \\
& \text { endothelial integrity }
\end{aligned}
$$

Fig. 9 Schematic representation of proteins associated with HDL and factors that may affect HDL levels and functions 
the proteomic composition of HDL subpopulations derived from HDL particles of different sizes (Davidson et al. 2009a). Furthermore the HDL proteome could be altered by pharmacological treatments (Green et al. 2008).

The modulation of the concentration of various proteins associated with HDL has been studied in more detail under conditions of infection, inflammation, or tissue injury. Under these conditions, acute phase response is triggered that causes huge alterations in hepatic protein synthesis in response to cytokines that alter HDL protein composition (Rohrer et al. 2004; Shah et al. 2013). These changes include the abrupt increase in serum amyloid A, apoJ, and secretory non-pancreatic phospholipase A2 and a decrease in apoA-I, paraoxonase-1, LCAT, and PLTP. These changes affect the capacity of HDL to promote cellular cholesterol efflux as well as other HDL functions (Rohrer et al. 2004; Shah et al. 2013).

In addition to the variety of proteins, a variety of lipids are also carried by HDL, and some of them are or can be transformed to potent bioactive molecules (Vickers and Remaley 2014). Furthermore, HDL carries and transports fat soluble vitamins, steroid hormones, carotenoids, as well as numerous more polar metabolites such as heneicosanoic acid, pentitol, and oxalic acid which were found to be significantly correlated with insulin resistance (Vickers and Remaley 2014). Finally, it has been reported that HDL also transports small RNAs, including microRNAs, tRNAderived RNA fragments, and RNase P-derived RNA fragments (Vickers et al. 2011). How all this protein decoration affects HDL metabolism and HDL particle function remain to be studied.

\section{$4 \quad$ Sources of Funding}

Collaboration among the groups of Drs Vassilis I. Zannis, Dimitris Kardassis, Matti Jauhiainen, and Angeliki Chroni is supported by COST Action BM0904. Dr Vassilis I. Zannis' research is supported by a grant from the National Institutes of Health HL48739. Drs Dimitris Kardassis and Angeliki Chroni's research is supported by grants of the General Secretariat of Research and Technology of Greece (Synergasia 09SYN-12-897) and by and the Ministry of Education of Greece (Thalis MIS 377286). P. Fotakis has been supported by pre-doctoral training Fellowship HERACLEITUS II by the European Union and Greek national funds through the Operational Program "Education and Lifelong Learning" of the National Strategic Reference Framework (NSRF). The work was also financially supported by the Academy of Finland (grant \# 257545 to MJ).

Open Access This chapter is distributed under the terms of the Creative Commons Attribution Noncommercial License, which permits any noncommercial use, distribution, and reproduction in any medium, provided the original author(s) and source are credited. 


\section{References}

Acton SL, Scherer PE, Lodish HF, Krieger M (1994) Expression cloning of SR-BI, a CD36-related class B scavenger receptor. J Biol Chem 269:21003-21009

Acton S, Rigotti A, Landschulz KT, Xu S, Hobbs HH, Krieger M (1996) Identification of scavenger receptor SR-BI as a high density lipoprotein receptor. Science 271:518-520

Ahras M, Naing T, McPherson R (2008) Scavenger receptor class B type I localizes to a late endosomal compartment. J Lipid Res 49:1569-1576

Aiello RJ, Brees D, Bourassa PA, Royer L, Lindsey S, Coskran T, Haghpassand M, Francone OL (2002) Increased atherosclerosis in hyperlipidemic mice with inactivation of ABCA1 in macrophages. Arterioscler Thromb Vasc Biol 22:630-637

Albers JJ, Cheung MC (2004) Emerging roles for phospholipid transfer protein in lipid and lipoprotein metabolism. Curr Opin Lipidol 15:255-260

Albers JJ, Vuletic S, Cheung MC (2012) Role of plasma phospholipid transfer protein in lipid and lipoprotein metabolism. Biochim Biophys Acta 1821:345-357

Amar MJ, Shamburek RD, Vaisman B, Knapper CL, Foger B, Hoyt RF Jr, Santamarina-Fojo S, Brewer HB Jr, Remaley AT (2009) Adenoviral expression of human lecithin-cholesterol acyltransferase in nonhuman primates leads to an antiatherogenic lipoprotein phenotype by increasing high-density lipoprotein and lowering low-density lipoprotein. Metabolism 58:568575

Arai T, Wang N, Bezouevski M, Welch C, Tall AR (1999) Decreased atherosclerosis in heterozygous low density lipoprotein receptor-deficient mice expressing the scavenger receptor BI transgene. J Biol Chem 274:2366-2371

Arai T, Tsukada T, Murase T, Matsumoto K (2000) Particle size analysis of high density lipoproteins in patients with genetic cholesteryl ester transfer protein deficiency. Clin Chim Acta 301:103-117

Assmann G, von Eckardstein A, Brewer HB (2001) Familial analphalipoproteinemia: Tangier disease. In: Scriver CR, Beaudet AL, Sly WS, Valle D (eds) The metabolic and molecular basis of inherited disease. McGraw-Hill, New York, pp 2937-2960

Asztalos BF (2004) High-density lipoprotein metabolism and progression of atherosclerosis: new insights from the HDL Atherosclerosis Treatment Study. Curr Opin Cardiol 19:385-391

Asztalos BF, Sloop CH, Wong L, Roheim PS (1993) Comparison of apo A-I-containing subpopulations of dog plasma and prenodal peripheral lymph: evidence for alteration in subpopulations in the interstitial space. Biochim Biophys Acta 1169:301-304

Asztalos BF, Brousseau ME, McNamara JR, Horvath KV, Roheim PS, Schaefer EJ (2001) Subpopulations of high density lipoproteins in homozygous and heterozygous Tangier disease. Atherosclerosis 156:217-225

Aulchenko YS, Ripatti S, Lindqvist I, Boomsma D, Heid IM, Pramstaller PP, Penninx BW, Janssens AC, Wilson JF, Spector T, Martin NG, Pedersen NL, Kyvik KO, Kaprio J, Hofman A, Freimer NB, Jarvelin MR, Gyllensten U, Campbell H, Rudan I, Johansson A, Marroni F, Hayward C, Vitart V, Jonasson I, Pattaro C, Wright A, Hastie N, Pichler I, Hicks AA, Falchi M, Willemsen G, Hottenga JJ, de Geus EJ, Montgomery GW, Whitfield J, Magnusson P, Saharinen J, Perola M, Silander K, Isaacs A, Sijbrands EJ, Uitterlinden AG, Witteman JC, Oostra BA, Elliott P, Ruokonen A, Sabatti C, Gieger C, Meitinger T, Kronenberg F, Doring A, Wichmann HE, Smit JH, McCarthy MI, van Duijn CM, Peltonen L (2009) Loci influencing lipid levels and coronary heart disease risk in 16 European population cohorts. Nat Genet 41:47-55

Axler O, Ahnstrom J, Dahlback B (2007) An ELISA for apolipoprotein M reveals a strong correlation to total cholesterol in human plasma. J Lipid Res 48:1772-1780

Axler O, Ahnstrom J, Dahlback B (2008) Apolipoprotein M associates to lipoproteins through its retained signal peptide. FEBS Lett 582:826-828

Baldan A, Pei L, Lee R, Tarr P, Tangirala RK, Weinstein MM, Frank J, Li AC, Tontonoz P, Edwards PA (2006) Impaired development of atherosclerosis in hyperlipidemic $\mathrm{Ldlr}^{-1-}$ and 
$\mathrm{ApoE}^{-/-}$mice transplanted with $\mathrm{Abcg} 1^{-/-}$bone marrow. Arterioscler Thromb Vasc Biol 26: 2301-2307

Barrans A, Collet X, Barbaras R, Jaspard B, Manent J, Vieu C, Chap H, Perret B (1994) Hepatic lipase induces the formation of pre-beta 1 high density lipoprotein (HDL) from triacylglycerolrich HDL2. A study comparing liver perfusion to in vitro incubation with lipases. J Biol Chem 269:11572-11577

Barter PJ, Brewer HB Jr, Chapman MJ, Hennekens CH, Rader DJ, Tall AR (2003) Cholesteryl ester transfer protein: a novel target for raising HDL and inhibiting atherosclerosis. Arterioscler Thromb Vasc Biol 23:160-167

Belalcazar LM, Merched A, Carr B, Oka K, Chen KH, Pastore L, Beaudet A, Chan L (2003) Longterm stable expression of human apolipoprotein A-I mediated by helper-dependent adenovirus gene transfer inhibits atherosclerosis progression and remodels atherosclerotic plaques in a mouse model of familial hypercholesterolemia. Circulation 107:2726-2732

Benoit P, Emmanuel F, Caillaud JM, Bassinet L, Castro G, Gallix P, Fruchart JC, Branellec D, Denefle P, Duverger N (1999) Somatic gene transfer of human ApoA-I inhibits atherosclerosis progression in mouse models. Circulation 99:105-110

Biedzka-Sarek M, Metso J, Kateifides A, Meri T, Jokiranta TS, Muszynski A, RadziejewskaLebrecht J, Zannis V, Skurnik M, Jauhiainen M (2011) Apolipoprotein A-I exerts bactericidal activity against Yersinia enterocolitica serotype O:3. J Biol Chem 286:38211-38219

Bodzioch M, Orso E, Klucken J, Langmann T, Bottcher A, Diederich W, Drobnik W, Barlage S, Buchler C, Porsch-Ozcurumez M, Kaminski WE, Hahmann HW, Oette K, Rothe G, Aslanidis C, Lackner KJ, Schmitz G (1999) The gene encoding ATP-binding cassette transporter 1 is mutated in Tangier disease. Nat Genet 22:347-351

Borhani DW, Rogers DP, Engler JA, Brouillette CG (1997) Crystal structure of truncated human apolipoprotein A-I suggests a lipid-bound conformation. Proc Natl Acad Sci USA 94: 12291-12296

Borhani DW, Engler JA, Brouillette CG (1999) Crystallization of truncated human apolipoprotein A-I in a novel conformation. Acta Crystallogr D Biol Crystallogr 55(Pt 9):1578-1583

Boyer PD (1997) The ATP synthase-a splendid molecular machine. Annu Rev Biochem 66: 717-749

Braschi S, Couture N, Gambarotta A, Gauthier BR, Coffill CR, Sparks DL, Maeda N, Schultz JR (1998) Hepatic lipase affects both HDL and ApoB-containing lipoprotein levels in the mouse. Biochim Biophys Acta 1392:276-290

Braun A, Trigatti BL, Post MJ, Sato K, Simons M, Edelberg JM, Rosenberg RD, Schrenzel M, Krieger M (2002) Loss of SR-BI expression leads to the early onset of occlusive atherosclerotic coronary artery disease, spontaneous myocardial infarctions, severe cardiac dysfunction, and premature death in apolipoprotein E-deficient mice. Circ Res 90:270-276

Braun A, Zhang S, Miettinen HE, Ebrahim S, Holm TM, Vasile E, Post MJ, Yoerger DM, Picard MH, Krieger JL, Andrews NC, Simons M, Krieger M (2003) Probucol prevents early coronary heart disease and death in the high-density lipoprotein receptor SR-BI/apolipoprotein E double knockout mouse. Proc Natl Acad Sci USA 100:7283-7288

Breckenridge WC, Little JA, Alaupovic P, Wang CS, Kuksis A, Kakis G, Lindgren F, Gardiner G (1982) Lipoprotein abnormalities associated with a familial deficiency of hepatic lipase. Atherosclerosis 45:161-179

Brousseau ME, Schaefer EJ, Wolfe ML, Bloedon LT, Digenio AG, Clark RW, Mancuso JP, Rader DJ (2004) Effects of an inhibitor of cholesteryl ester transfer protein on HDL cholesterol. N Engl J Med 350:1505-1515

Brown RJ, Lagor WR, Sankaranaravanan S, Yasuda T, Quertermous T, Rothblat GH, Rader DJ (2010) Impact of combined deficiency of hepatic lipase and endothelial lipase on the metabolism of both high-density lipoproteins and apolipoprotein B-containing lipoproteins. Circ Res 107:357-364 
Browne RW, Bloom MS, Shelly WB, Ocque AJ, Huddleston HG, Fujimoto VY (2009) Follicular fluid high density lipoprotein-associated micronutrient levels are associated with embryo fragmentation during IVF. J Assist Reprod Genet 26:557-560

Brundert M, Heeren J, Greten H, Rinninger F (2003) Hepatic lipase mediates an increase in selective uptake of HDL-associated cholesteryl esters by cells in culture independent from SR-BI. J Lipid Res 44:1020-1032

Brundert M, Heeren J, Merkel M, Carambia A, Herkel J, Groitl P, Dobner T, Ramakrishnan R, Moore KJ, Rinninger F (2011) Scavenger receptor CD36 mediates uptake of high density lipoproteins in mice and by cultured cells. J Lipid Res 52:745-758

Brunham LR, Kruit JK, Iqbal J, Fievet C, Timmins JM, Pape TD, Coburn BA, Bissada N, Staels B, Groen AK, Hussain MM, Parks JS, Kuipers F, Hayden MR (2006a) Intestinal ABCA1 directly contributes to HDL biogenesis in vivo. J Clin Invest 116:1052-1062

Brunham LR, Singaraja RR, Hayden MR (2006b) Variations on a gene: rare and common variants in ABCA1 and their impact on HDL cholesterol levels and atherosclerosis. Annu Rev Nutr 26: 105-129

Brunzell JD, Deeb SS (2001) Familial lipoprotein lipase deficiency, apoC-II deficiency, and hepatic lipase deficiency. In: Scriver CR, Beaudet AL, Valle D, Sly WS (eds) The metabolic and molecular bases of inherited disease. McGraw-Hill, New York, pp 2789-2816

Burgess B, Naus K, Chan J, Hirsch-Reinshagen V, Tansley G, Matzke L, Chan B, Wilkinson A, Fan J, Donkin J, Balik D, Tanaka T, Ou G, Dyer R, Innis S, McManus B, Lutjohann D, Wellington C (2008) Overexpression of human ABCG1 does not affect atherosclerosis in fat-fed ApoE-deficient mice. Arterioscler Thromb Vasc Biol 28:1731-1737

Cabezon E, Montgomery MG, Leslie AG, Walker JE (2003) The structure of bovine F1-ATPase in complex with its regulatory protein IF1. Nat Struct Biol 10:744-750

Calabresi L, Baldassarre D, Castelnuovo S, Conca P, Bocchi L, Candini C, Frigerio B, Amato M, Sirtori CR, Alessandrini P, Arca M, Boscutti G, Cattin L, Gesualdo L, Sampietro T, Vaudo G, Veglia F, Calandra S, Franceschini G (2009a) Functional lecithin: cholesterol acyltransferase is not required for efficient atheroprotection in humans. Circulation 120:628-635

Calabresi L, Favari E, Moleri E, Adorni MP, Pedrelli M, Costa S, Jessup W, Gelissen IC, Kovanen PT, Bernini F, Franceschini G (2009b) Functional LCAT is not required for macrophage cholesterol efflux to human serum. Atherosclerosis 204:141-146

Cavelier C, Rohrer L, von Eckardstein A (2006) ATP-binding cassette transporter al modulates apolipoprotein A1 transcytosis through aortic endothelial cells. Circ Res 99:1060-1066

Chasman DI, Pare G, Mora S, Hopewell JC, Peloso G, Clarke R, Cupples LA, Hamsten A, Kathiresan S, Malarstig A, Ordovas JM, Ripatti S, Parker AN, Miletich JP, Ridker PM (2009) Forty-three loci associated with plasma lipoprotein size, concentration, and cholesterol content in genome-wide analysis. PLoS Genet 5

Chau P, Nakamura Y, Fielding CJ, Fielding PE (2006) Mechanism of prebeta-HDL formation and activation. Biochemistry 45:3981-3987

Christoffersen C, Ahnstrom J, Axler O, Christensen EI, Dahlback B, Nielsen LB (2008a) The signal peptide anchors apolipoprotein $\mathrm{M}$ in plasma lipoproteins and prevents rapid clearance of apolipoprotein M from plasma. J Biol Chem 283:18765-18772

Christoffersen C, Jauhiainen M, Moser M, Porse B, Ehnholm C, Boesl M, Dahlback B, Nielsen LB (2008b) Effect of apolipoprotein M on high density lipoprotein metabolism and atherosclerosis in low density lipoprotein receptor knock-out mice. J Biol Chem 283:1839-1847

Chroni A, Liu T, Gorshkova I, Kan HY, Uehara Y, von Eckardstein A, Zannis VI (2003) The central helices of apoA-I can promote ATP-binding cassette transporter A1 (ABCA1)mediated lipid efflux. Amino acid residues 220-231 of the wild-type apoA-I are required for lipid efflux in vitro and high density lipoprotein formation in vivo. J Biol Chem 278: 6719-6730

Chroni A, Kan HY, Kypreos KE, Gorshkova IN, Shkodrani A, Zannis VI (2004a) Substitutions of glutamate 110 and 111 in the middle helix 4 of human apolipoprotein A-I (apoA-I) by alanine 
affect the structure and in vitro functions of apoA-I and induce severe hypertriglyceridemia in apoA-I-deficient mice. Biochemistry 43:10442-10457

Chroni A, Liu T, Fitzgerald ML, Freeman MW, Zannis VI (2004b) Cross-linking and lipid efflux properties of apoA-I mutants suggest direct association between apoA-I helices and ABCA1. Biochemistry 43:2126-2139

Chroni A, Duka A, Kan HY, Liu T, Zannis VI (2005a) Point mutations in apolipoprotein a-I mimic the phenotype observed in patients with classical lecithin:cholesterol acyltransferase deficiency. Biochemistry 44:14353-14366

Chroni A, Kan HY, Shkodrani A, Liu T, Zannis VI (2005b) Deletions of helices 2 and 3 of human apoA-I are associated with severe dyslipidemia following adenovirus-mediated gene transfer in apoA-I-deficient mice. Biochemistry 44:4108-4117

Chroni A, Nieland TJ, Kypreos KE, Krieger M, Zannis VI (2005c) SR-BI mediates cholesterol efflux via its interactions with lipid-bound ApoE. Structural mutations in SR-BI diminish cholesterol efflux. Biochemistry 44:13132-13143

Chroni A, Koukos G, Duka A, Zannis VI (2007) The carboxy-terminal region of apoA-I is required for the ABCA1-dependent formation of alpha-HDL but not prebeta-HDL particles in vivo. Biochemistry 46:5697-5708

Chung BH, Segrest JP, Ray MJ, Brunzell JD, Hokanson JE, Krauss RM, Beaudrie K, Cone JT (1986) Single vertical spin density gradient ultracentrifugation. Methods Enzymol 128: 181-209

Croop JM, Tiller GE, Fletcher JA, Lux ML, Raab E, Goldenson D, Son D, Arciniegas S, Wu RL (1997) Isolation and characterization of a mammalian homolog of the Drosophila white gene. Gene 185:77-85

Cuchel M, Lund-Katz S, Llera-Moya M, Millar JS, Chang D, Fuki I, Rothblat GH, Phillips MC, Rader DJ (2010) Pathways by which reconstituted high-density lipoprotein mobilizes free cholesterol from whole body and from macrophages. Arterioscler Thromb Vasc Biol 30: 526-532

Dahlback B, Nielsen LB (2009) Apolipoprotein M affecting lipid metabolism or just catching a ride with lipoproteins in the circulation? Cell Mol Life Sci 66:559-564

Daniil G, Phedonos AA, Holleboom AG, Motazacker MM, Argyri L, Kuivenhoven JA, Chroni A (2011) Characterization of antioxidant/anti-inflammatory properties and apoA-I-containing subpopulations of HDL from family subjects with monogenic low HDL disorders. Clin Chim Acta 412:1213-1220

Daniil G, Zannis VI, Chroni A (2013) Effect of apoA-I mutations in the capacity of reconstituted HDL to promote ABCG1-mediated cholesterol efflux. PLoS ONE 8:e67993

Davidson WS, Sparks DL, Lund-Katz S, Phillips MC (1994) The molecular basis for the difference in charge between pre-beta- and alpha-migrating high density lipoproteins. J Biol Chem 269:8959-8965

Davidson WS, Silva RA, Chantepie S, Lagor WR, Chapman MJ, Kontush A (2009) Proteomic analysis of defined HDL subpopulations reveals particle-specific protein clusters: relevance to antioxidative function. Arterioscler Thromb Vasc Biol 29:870-876

de Grooth GJ, Kuivenhoven JA, Stalenhoef AF, de Graaf J, Zwinderman AH, Posma JL, van Tol A, Kastelein JJ (2002) Efficacy and safety of a novel cholesteryl ester transfer protein inhibitor, JTT-705, in humans: a randomized phase II dose-response study. Circulation 105: 2159-2165

deLemos AS, Wolfe ML, Long CJ, Sivapackianathan R, Rader DJ (2002) Identification of genetic variants in endothelial lipase in persons with elevated high-density lipoprotein cholesterol. Circulation 106:1321-1326

Duka A, Fotakis P, Georgiadou D, Kateifides A, Tzavlaki K, von Eckardstein L, Stratikos E, Kardassis D, Zannis VI (2013) ApoA-IV promotes the biogenesis of apoA-IV-containing HDL particles with the participation of ABCA1 and LCAT. J Lipid Res 54:107-115 
Dullaart RP, Plomgaard P, de Vries R, Dahlback B, Nielsen LB (2009) Plasma apolipoprotein M is reduced in metabolic syndrome but does not predict intima media thickness. Clin Chim Acta 406:129-133

Eberini I, Calabresi L, Wait R, Tedeschi G, Pirillo A, Puglisi L, Sirtori CR, Gianazza E (2002) Macrophage metalloproteinases degrade high-density-lipoprotein-associated apolipoprotein A-I at both the N- and C-termini. Biochem J 362:627-634

Edmondson AC, Brown RJ, Kathiresan S, Cupples LA, Demissie S, Manning AK, Jensen MK, Rimm EB, Wang J, Rodrigues A, Bamba V, Khetarpal SA, Wolfe ML, Derohannessian S, Li M, Reilly MP, Aberle J, Evans D, Hegele RA, Rader DJ (2009) Loss-of-function variants in endothelial lipase are a cause of elevated HDL cholesterol in humans. J Clin Invest 119: $1042-1050$

Edmondson AC, Braund PS, Stylianou IM, Khera AV, Nelson CP, Wolfe ML, Derohannessian SL, Keating BJ, Qu L, He J, Tobin MD, Tomaszewski M, Baumert J, Klopp N, Doring A, Thorand B, Li M, Reilly MP, Koenig W, Samani NJ, Rader DJ (2011) Dense genotyping of candidate gene loci identifies variants associated with high-density lipoprotein cholesterol. Circ Cardiovasc Genet 4:145-155

Emmanuel F, Caillaud JM, Hennuyer N, Fievet C, Viry I, Houdebine JC, Fruchart JC, Denefle P, Duverger N (1996) Overexpression of human apolipoprotein A-I inhibits atherosclerosis development in Watanabe rabbits. Circulation 94:632

Escola-Gil JC, Chen X, Julve J, Quesada H, Santos D, Metso J, Tous M, Jauhiainen M, BlancoVaca F (2013) Hepatic lipase- and endothelial lipase-deficiency in mice promotes macrophageto-feces RCT and HDL antioxidant properties. Biochim Biophys Acta 1831:691-697

Fabre AC, Vantourout P, Champagne E, Terce F, Rolland C, Perret B, Collet X, Barbaras R, Martinez LO (2006) Cell surface adenylate kinase activity regulates the F(1)-ATPase/P2Y (13)-mediated HDL endocytosis pathway on human hepatocytes. Cell Mol Life Sci 63: 2829-2837

Fabre AC, Malaval C, Ben AA, Verdier C, Pons V, Serhan N, Lichtenstein L, Combes G, Huby T, Briand F, Collet X, Nijstad N, Tietge UJ, Robaye B, Perret B, Boeynaems JM, Martinez LO (2010) P2Y13 receptor is critical for reverse cholesterol transport. Hepatology 52:1477-1483

Favari E, Calabresi L, Adorni MP, Jessup W, Simonelli S, Franceschini G, Bernini F (2009) Small discoidal pre-beta1 HDL particles are efficient acceptors of cell cholesterol via ABCA1 and ABCG1. Biochemistry 48:11067-11074

Fenske SA, Yesilaltay A, Pal R, Daniels K, Barker C, Quinones V, Rigotti A, Krieger M, Kocher O (2009) Normal hepatic cell surface localization of the high density lipoprotein receptor, scavenger receptor class $\mathrm{B}$, type I, depends on all four PDZ domains of PDZK1. J Biol Chem 284:5797-5806

Fielding CJ, Fielding PE (1995) Molecular physiology of reverse cholesterol transport. J Lipid Res 36:211-228

Fielding CJ, Fielding PE (1996) Two-dimensional nondenaturing electrophoresis of lipoproteins: applications to high-density lipoprotein speciation. Methods Enzymol 263:251-259

Fielding CJ, Fielding PE (2007) Reverse cholesterol transport - new roles for preb1-HDL and lecithin: cholesterol acyltransferase. In: Fielding CJ (ed) High-density lipoproteins: from basic biology to clinical aspects. Wiley, Weinheim, pp 143-162

Fielding CJ, Shore VG, Fielding PE (1972) A protein cofactor of lecithin:cholesterol acyltransferase. Biochem Biophys Res Commun 46:1493-1498

Fitzgerald ML, Mendez AJ, Moore KJ, Andersson LP, Panjeton HA, Freeman MW (2001) ATP-binding cassette transporter A1 contains an NH2-terminal signal anchor sequence that translocates the protein's first hydrophilic domain to the exoplasmic space. J Biol Chem 276: $15137-15145$

Fitzgerald ML, Morris AL, Rhee JS, Andersson LP, Mendez AJ, Freeman MW (2002) Naturally occurring mutations in the largest extracellular loops of ABCA1 can disrupt its direct interaction with apolipoprotein A-I. J Biol Chem 277:33178-33187 
Forte TM, Goth-Goldstein R, Nordhausen RW, McCall MR (1993) Apolipoprotein A-I-cell membrane interaction: extracellular assembly of heterogeneous nascent HDL particles. J Lipid Res 34:317-324

Forte TM, Bielicki JK, Goth-Goldstein R, Selmek J, McCall MR (1995) Recruitment of cell phospholipids and cholesterol by apolipoproteins A-II and A-I: formation of nascent apolipoprotein-specific HDL that differ in size, phospholipid composition, and reactivity with LCAT. J Lipid Res 36:148-157

Fotakis P, Kateifides A, Gkolfinopoulou C, Georgiadou D, Beck M, Grundler K, Chroni A, Stratikos E, Kardassis D, Zannis VI (2013a) Role of the hydrophobic and charged residues in the 218 to 226 region of apoA-I in the biogenesis of HDL. J Lipid Res 54:3281-3292

Fotakis P, Tiniakou I, Kateifides AK, Gkolfinopoulou C, Chroni A, Stratikos E, Zannis VI, Kardassis D (2013b) Significance of the hydrophobic residues 225-230 of apoA-I for the biogenesis of HDL. J Lipid Res 54:3293-3302

Francone OL, Royer L, Haghpassand M (1996) Increased prebeta-HDL levels, cholesterol efflux, and LCAT-mediated esterification in mice expressing the human cholesteryl ester transfer protein (CETP) and human apolipoprotein A-I (apoA-I) transgenes. J Lipid Res 37:1268-1277

Frikke-Schmidt R, Nordestgaard BG, Jensen GB, Steffensen R, Tybjaerg-Hansen A (2008) Genetic variation in ABCA1 predicts ischemic heart disease in the general population. Arterioscler Thromb Vasc Biol 28:180-186

Fyfe JC, Madsen M, Hojrup P, Christensen EI, Tanner SM, de la Chapelle A, He Q, Moestrup SK (2004) The functional cobalamin (vitamin B12)-intrinsic factor receptor is a novel complex of cubilin and amnionless. Blood 103:1573-1579

Galis ZS, Muszynski M, Sukhova GK, Simon-Morrissey E, Libby P (1995) Enhanced expression of vascular matrix metalloproteinases induced in vitro by cytokines and in regions of human atherosclerotic lesions. Ann N Y Acad Sci 748:501-507

Genoux A, Ruidavets JB, Ferrieres J, Combes G, Lichtenstein L, Pons V, Laffargue M, Taraszkiewicz D, Carrie D, Elbaz M, Perret B, Martinez LO (2013) Serum IF1 concentration is independently associated to HDL levels and to coronary heart disease: the GENES study. J Lipid Res 54:2550-2558

Gong M, Wilson M, Kelly T, Su W, Dressman J, Kincer J, Matveev SV, Guo L, Guerin T, Li XA, Zhu W, Uittenbogaard A, Smart EJ (2003) HDL-associated estradiol stimulates endothelial NO synthase and vasodilation in an SR-BI-dependent manner. J Clin Invest 111:1579-1587

Gordon DJ, Probstfield JL, Garrison RJ, Neaton JD, Castelli WP, Knoke JD, Jacobs DR Jr, Bangdiwala S, Tyroler HA (1989) High-density lipoprotein cholesterol and cardiovascular disease. Four prospective American studies. Circulation 79:8-15

Gordon SM, Deng JY, Lu LJ, Davidson WS (2010) Proteomic characterization of human plasma high density lipoprotein fractionated by gel filtration chromatography. J Proteome Res 9: 5239-5249

Gorshkova IN, Atkinson D (2011) Enhanced binding of apolipoprotein A-I variants associated with hypertriglyceridemia to triglyceride-rich particles. Biochemistry 50:2040-2047

Graversen JH, Castro G, Kandoussi A, Nielsen H, Christensen EI, Norden A, Moestrup SK (2008) A pivotal role of the human kidney in catabolism of HDL protein components apolipoprotein A-I and A-IV but not of A-II. Lipids 43:467-470

Green PS, Vaisar T, Pennathur S, Kulstad JJ, Moore AB, Marcovina S, Brunzell J, Knopp RH, Zhao XQ, Heinecke JW (2008) Combined statin and niacin therapy remodels the high-density lipoprotein proteome. Circulation 118:1259-1267

Greene DJ, Skeggs JW, Morton RE (2001) Elevated triglyceride content diminishes the capacity of high density lipoprotein to deliver cholesteryl esters via the scavenger receptor class B type I (SR-BI). J Biol Chem 276:4804-4811

Groen AK, Bloks VW, Bandsma RH, Ottenhoff R, Chimini G, Kuipers F (2001) Hepatobiliary cholesterol transport is not impaired in Abca1-null mice lacking HDL. J Clin Invest 108: $843-850$ 
Gu X, Trigatti B, Xu S, Acton S, Babitt J, Krieger M (1998) The efficient cellular uptake of high density lipoprotein lipids via scavenger receptor class B type I requires not only receptormediated surface binding but also receptor-specific lipid transfer mediated by its extracellular domain. J Biol Chem 273:26338-26348

Gu X, Kozarsky K, Krieger M (2000a) Scavenger receptor class B, type I-mediated [3H]cholesterol efflux to high and low density lipoproteins is dependent on lipoprotein binding to the receptor. J Biol Chem 275:29993-30001

Gu X, Lawrence R, Krieger M (2000b) Dissociation of the high density lipoprotein and low density lipoprotein binding activities of murine scavenger receptor class B type I (mSR-BI) using retrovirus library-based activity dissection. J Biol Chem 275:9120-9130

Guendouzi K, Jaspard B, Barbaras R, Motta C, Vieu C, Marcel Y, Chap H, Perret B, Collet X (1999) Biochemical and physical properties of remnant-HDL2 and of pre beta 1-HDL produced by hepatic lipase. Biochemistry 38:2762-2768

Haase CL, Frikke-Schmidt R, Nordestgaard BG, Kateifides AK, Kardassis D, Nielsen LB, Andersen CB, Kober L, Johnsen AH, Grande P, Zannis VI, Tybjaerg-Hansen A (2011) Mutation in APOA1 predicts increased risk of ischaemic heart disease and total mortality without low HDL cholesterol levels. J Intern Med 270:136-146

Hailman E, Albers JJ, Wolfbauer G, Tu AY, Wright SD (1996) Neutralization and transfer of lipopolysaccharide by phospholipid transfer protein. J Biol Chem 271:12172-12178

Hammad SM, Stefansson S, Twal WO, Drake CJ, Fleming P, Remaley A, Brewer HB Jr, Argraves WS (1999) Cubilin, the endocytic receptor for intrinsic factor-vitamin B(12) complex, mediates high-density lipoprotein holoparticle endocytosis. Proc Natl Acad Sci USA 96: 10158-10163

Harder CJ, McPherson R (2007) HDL remodeling by CETP and SR-BI. In: Fielding CJ (ed) Highdensity lipoproteins. From basic biology to clinical aspects. Wiley, Weinheim, pp 163-182

Heideman CL, Hoff HF (1982) Lipoproteins containing apolipoprotein A-I extracted from human aortas. Biochim Biophys Acta 711:431-444

Hildebrand RB, Lammers B, Meurs I, Korporaal SJ, De Haan W, Zhao Y, Kruijt JK, Pratico D, Schimmel AW, Holleboom AG, Hoekstra M, Kuivenhoven JA, van Berkel TJ, Rensen PC, Van Eck M (2010) Restoration of high-density lipoprotein levels by cholesteryl ester transfer protein expression in scavenger receptor class B type I (SR-BI) knockout mice does not normalize pathologies associated with SR-BI deficiency. Arterioscler Thromb Vasc Biol 30: $1439-1445$

Hirano K, Yamashita S, Kuga Y, Sakai N, Nozaki S, Kihara S, Arai T, Yanagi K, Takami S, Menju M et al (1995) Atherosclerotic disease in marked hyperalphalipoproteinemia. Combined reduction of cholesteryl ester transfer protein and hepatic triglyceride lipase. Arterioscler Thromb Vasc Biol 15:1849-1856

Hirano K, Yamashita S, Nakajima N, Arai T, Maruyama T, Yoshida Y, Ishigami M, Sakai N, Kameda-Takemura K, Matsuzawa Y (1997) Genetic cholesteryl ester transfer protein deficiency is extremely frequent in the Omagari area of Japan. Marked hyperalphalipoproteinemia caused by CETP gene mutation is not associated with longevity. Arterioscler Thromb Vasc Biol 17:1053-1059

Holleboom AG, Vergeer M, Hovingh GK, Kastelein JJ, Kuivenhoven JA (2008) The value of HDL genetics. Curr Opin Lipidol 19:385-394

Holm TM, Braun A, Trigatti BL, Brugnara C, Sakamoto M, Krieger M, Andrews NC (2002) Failure of red blood cell maturation in mice with defects in the high-density lipoprotein receptor SR-BI. Blood 99:1817-1824

Homanics GE, de Silva HV, Osada J, Zhang SH, Wong H, Borensztajn J, Maeda N (1995) Mild dyslipidemia in mice following targeted inactivation of the hepatic lipase gene. J Biol Chem 270:2974-2980

Hopkins GJ, Barter PJ (1980) Transfers of esterified cholesterol and triglyceride between high density and very low density lipoproteins: in vitro studies of rabbits and humans. Metabolism 29:546-550 
Hu YW, Zheng L, Wang Q (2010) Characteristics of apolipoprotein M and its relation to atherosclerosis and diabetes. Biochim Biophys Acta 1801:100-105

Huang W, Sasaki J, Matsunaga A, Nanimatsu H, Moriyama K, Han H, Kugi M, Koga T, Yamaguchi K, Arakawa K (1998) A novel homozygous missense mutation in the apo A-I gene with apo A-I deficiency. Arterioscler Thromb Vasc Biol 18:389-396

Huang R, Silva RA, Jerome WG, Kontush A, Chapman MJ, Curtiss LK, Hodges TJ, Davidson WS (2011) Apolipoprotein A-I structural organization in high-density lipoproteins isolated from human plasma. Nat Struct Mol Biol 18:416-422

Huszar D, Varban ML, Rinninger F, Feeley R, Arai T, Fairchild-Huntress V, Donovan MJ, Tall AR (2000) Increased LDL cholesterol and atherosclerosis in LDL receptor-deficient mice with attenuated expression of scavenger receptor B1. Arterioscler Thromb Vasc Biol 20:1068-1073

Huuskonen J, Olkkonen VM, Ehnholm C, Metso J, Julkunen I, Jauhiainen M (2000) Phospholipid transfer is a prerequisite for PLTP-mediated HDL conversion. Biochemistry 39:16092-16098

Huuskonen J, Olkkonen VM, Jauhiainen M, Ehnholm C (2001) The impact of phospholipid transfer protein (PLTP) on HDL metabolism. Atherosclerosis 155:269-281

Inazu A, Brown ML, Hesler CB, Agellon LB, Koizumi J, Takata K, Maruhama Y, Mabuchi H, Tall AR (1990) Increased high-density lipoprotein levels caused by a common cholesterylester transfer protein gene mutation. N Engl J Med 323:1234-1238

Ishida T, Choi S, Kundu RK, Hirata K, Rubin EM, Cooper AD, Quertermous T (2003) Endothelial lipase is a major determinant of HDL level. J Clin Invest 111:347-355

Ishida T, Choi SY, Kundu RK, Spin J, Yamashita T, Hirata K, Kojima Y, Yokoyama M, Cooper AD, Quertermous T (2004) Endothelial lipase modulates susceptibility to atherosclerosis in apolipoprotein-E-deficient mice. J Biol Chem 279:45085-45092

Jacquet S, Malaval C, Martinez LO, Sak K, Rolland C, Perez C, Nauze M, Champagne E, Terce F, Gachet C, Perret B, Collet X, Boeynaems JM, Barbaras R (2005) The nucleotide receptor P2Y13 is a key regulator of hepatic high-density lipoprotein (HDL) endocytosis. Cell Mol Life Sci 62:2508-2515

Janis MT, Metso J, Lankinen H, Strandin T, Olkkonen VM, Rye KA, Jauhiainen M, Ehnholm C (2005) Apolipoprotein E activates the low-activity form of human phospholipid transfer protein. Biochem Biophys Res Commun 331:333-340

Jaye M, Lynch KJ, Krawiec J, Marchadier D, Maugeais C, Doan K, South V, Amin D, Perrone M, Rader DJ (1999) A novel endothelial-derived lipase that modulates HDL metabolism. Nat Genet 21:424-428

Ji Y, Jian B, Wang N, Sun Y, Moya ML, Phillips MC, Rothblat GH, Swaney JB, Tall AR (1997) Scavenger receptor BI promotes high density lipoprotein-mediated cellular cholesterol efflux. J Biol Chem 272:20982-20985

Ji Y, Wang N, Ramakrishnan R, Sehayek E, Huszar D, Breslow JL, Tall AR (1999) Hepatic scavenger receptor BI promotes rapid clearance of high density lipoprotein free cholesterol and its transport into bile. J Biol Chem 274:33398-33402

Jiang XC, Bruce C, Mar J, Lin M, Ji Y, Francone OL, Tall AR (1999) Targeted mutation of plasma phospholipid transfer protein gene markedly reduces high-density lipoprotein levels. J Clin Invest 103:907-914

Jiang XC, Qin S, Qiao C, Kawano K, Lin M, Skold A, Xiao X, Tall AR (2001) Apolipoprotein B secretion and atherosclerosis are decreased in mice with phospholipid-transfer protein deficiency. Nat Med 7:847-852

Jiao GQ, Yuan ZX, Xue YS, Yang CJ, Lu CB, Lu ZQ, Xiao MD (2007) A prospective evaluation of apolipoprotein $\mathrm{M}$ gene $\mathrm{T}-778 \mathrm{C}$ polymorphism in relation to coronary artery disease in Han Chinese. Clin Biochem 40:1108-1112

Johannsen TH, Kamstrup PR, Andersen RV, Jensen GB, Sillesen H, Tybjaerg-Hansen A, Nordestgaard BG (2009) Hepatic lipase, genetically elevated high-density lipoprotein, and risk of ischemic cardiovascular disease. J Clin Endocrinol Metab 94:1264-1273

Jonas A (2000) Lecithin cholesterol acyltransferase. Biochim Biophys Acta 1529:245-256 
Jones MK, Catte A, Li L, Segrest JP (2009) Dynamics of activation of lecithin:cholesterol acyltransferase by apolipoprotein A-I. Biochemistry 48:11196-11210

Kan CC, Yan J, Bittman R (1992) Rates of spontaneous exchange of synthetic radiolabeled sterols between lipid vesicles. Biochemistry 31:1866-1874

Karackattu SL, Picard MH, Krieger M (2005) Lymphocytes are not required for the rapid onset of coronary heart disease in scavenger receptor class B type I/apolipoprotein E double knockout mice. Arterioscler Thromb Vasc Biol 25:803-808

Karackattu SL, Trigatti B, Krieger M (2006) Hepatic lipase deficiency delays atherosclerosis, myocardial infarction, and cardiac dysfunction and extends lifespan in SR-BI/apolipoprotein E double knockout mice. Arterioscler Thromb Vasc Biol 26:548-554

Karkkainen M, Oka T, Olkkonen VM, Metso J, Hattori H, Jauhiainen M, Ehnholm C (2002) Isolation and partial characterization of the inactive and active forms of human plasma phospholipid transfer protein (PLTP). J Biol Chem 277:15413-15418

Kateifides AK, Gorshkova IN, Duka A, Chroni A, Kardassis D, Zannis VI (2011) Alteration of negatively charged residues in the 89 to 99 domain of apoA-I affects lipid homeostasis and maturation of HDL. J Lipid Res 52:1363-1372

Kathiresan S, Melander O, Guiducci C, Surti A, Burtt NP, Rieder MJ, Cooper GM, Roos C, Voight BF, Havulinna AS, Wahlstrand B, Hedner T, Corella D, Tai ES, Ordovas JM, Berglund G, Vartiainen E, Jousilahti P, Hedblad B, Taskinen MR, Newton-Cheh C, Salomaa V, Peltonen L, Groop L, Altshuler DM, Orho-Melander M (2008a) Six new loci associated with blood low-density lipoprotein cholesterol, high-density lipoprotein cholesterol or triglycerides in humans. Nat Genet 40:189-197

Kathiresan S, Musunuru K, Orho-Melander M (2008b) Defining the spectrum of alleles that contribute to blood lipid concentrations in humans. Curr Opin Lipidol 19:122-127

Kathiresan S, Willer CJ, Peloso GM, Demissie S, Musunuru K, Schadt EE, Kaplan L, Bennett D, Li Y, Tanaka T, Voight BF, Bonnycastle LL, Jackson AU, Crawford G, Surti A, Guiducci C, Burtt NP, Parish S, Clarke R, Zelenika D, Kubalanza KA, Morken MA, Scott LJ, Stringham HM, Galan P, Swift AJ, Kuusisto J, Bergman RN, Sundvall J, Laakso M, Ferrucci L, Scheet P, Sanna S, Uda M, Yang Q, Lunetta KL, Dupuis J, de Bakker PI, O’Donnell CJ, Chambers JC, Kooner JS, Hercberg S, Meneton P, Lakatta EG, Scuteri A, Schlessinger D, Tuomilehto J, Collins FS, Groop L, Altshuler D, Collins R, Lathrop GM, Melander O, Salomaa V, Peltonen L, Orho-Melander M, Ordovas JM, Boehnke M, Abecasis GR, Mohlke KL, Cupples LA (2009) Common variants at 30 loci contribute to polygenic dyslipidemia. Nat Genet 41:56-65

Kawano K, Qin SC, Lin M, Tall AR, Jiang XC (2000) Cholesteryl ester transfer protein and phospholipid transfer protein have nonoverlapping functions in vivo. J Biol Chem 275: 29477-29481

Kee P, Rye KA, Taylor JL, Barrett PH, Barter PJ (2002) Metabolism of apoA-I as lipid-free protein or as component of discoidal and spherical reconstituted HDLs: studies in wild-type and hepatic lipase transgenic rabbits. Arterioscler Thromb Vasc Biol 22:1912-1917

Kennedy MA, Barrera GC, Nakamura K, Baldan A, Tarr P, Fishbein MC, Frank J, Francone OL, Edwards PA (2005) ABCG1 has a critical role in mediating cholesterol efflux to HDL and preventing cellular lipid accumulation. Cell Metab 1:121-131

Kielar D, Dietmaier W, Langmann T, Aslanidis C, Probst M, Naruszewicz M, Schmitz G (2001) Rapid quantification of human ABCA1 mRNA in various cell types and tissues by real-time reverse transcription-PCR. Clin Chem 47:2089-2097

Kivela AM, Dijkstra MH, Heinonen SE, Gurzeler E, Jauhiainen S, Levonen AL, Yla-Herttuala S (2012) Regulation of endothelial lipase and systemic HDL cholesterol levels by SREBPs and VEGF-A. Atherosclerosis 225:335-340

Klucken J, Buchler C, Orso E, Kaminski WE, Porsch-Ozcurumez M, Liebisch G, Kapinsky M, Diederich W, Drobnik W, Dean M, Allikmets R, Schmitz G (2000) ABCG1 (ABC8), the human homolog of the Drosophila white gene, is a regulator of macrophage cholesterol and phospholipid transport. Proc Natl Acad Sci USA 97:817-822 
Kocher O, Yesilaltay A, Shen CH, Zhang S, Daniels K, Pal R, Chen J, Krieger M (2008) Influence of PDZK1 on lipoprotein metabolism and atherosclerosis. Biochim Biophys Acta 1782: 310-316

Koizumi J, Mabuchi H, Yoshimura A, Michishita I, Takeda M, Itoh H, Sakai Y, Sakai T, Ueda K, Takeda R (1985) Deficiency of serum cholesteryl-ester transfer activity in patients with familial hyperalphalipoproteinaemia. Atherosclerosis 58:175-186

Kostner GM, Oettl K, Jauhiainen M, Ehnholm C, Esterbauer H, Dieplinger H (1995) Human plasma phospholipid transfer protein accelerates exchange/transfer of alpha-tocopherol between lipoproteins and cells. Biochem J 305(Pt 2):659-667

Koukos G, Chroni A, Duka A, Kardassis D, Zannis VI (2007a) LCAT can rescue the abnormal phenotype produced by the natural ApoA-I mutations (Leu141Arg)Pisa and (Leu159Arg)FIN. Biochemistry 46:10713-10721

Koukos G, Chroni A, Duka A, Kardassis D, Zannis VI (2007b) Naturally occurring and bioengineered apoA-I mutations that inhibit the conversion of discoidal to spherical HDL: the abnormal HDL phenotypes can be corrected by treatment with LCAT. Biochem J 406: $167-174$

Kozarsky KF, Donahee MH, Glick JM, Krieger M, Rader DJ (2000) Gene transfer and hepatic overexpression of the HDL receptor SR-BI reduces atherosclerosis in the cholesterol-fed LDL receptor-deficient mouse. Arterioscler Thromb Vasc Biol 20:721-727

Kozyraki R (2001) Cubilin, a multifunctional epithelial receptor: an overview. J Mol Med (Berl) 79:161-167

Kozyraki R, Fyfe J, Kristiansen M, Gerdes C, Jacobsen C, Cui S, Christensen EI, Aminoff M, de la Chapelle A, Krahe R, Verroust PJ, Moestrup SK (1999) The intrinsic factor-vitamin B12 receptor, cubilin, is a high-affinity apolipoprotein A-I receptor facilitating endocytosis of highdensity lipoprotein. Nat Med 5:656-661

Krauss RM, Levy RI, Fredrickson DS (1974) Selective measurement of two lipase activities in postheparin plasma from normal subjects and patients with hyperlipoproteinemia. J Clin Invest 54:1107-1124

Krieger M (1999) Charting the fate of the "good cholesterol": identification and characterization of the high-density lipoprotein receptor SR-BI. Annu Rev Biochem 68:523-558

Krieger M (2001) Scavenger receptor class B type I is a multiligand HDL receptor that influences diverse physiologic systems. J Clin Invest 108:793-797

Krimbou L, Hajj HH, Blain S, Rashid S, Denis M, Marcil M, Genest J (2005) Biogenesis and speciation of nascent apoA-I-containing particles in various cell lines. J Lipid Res 46: $1668-1677$

Kypreos KE, Zannis VI (2007) Pathway of biogenesis of apolipoprotein E-containing HDL in vivo with the participation of ABCA1 and LCAT. Biochem J 403:359-367

Landmesser U, von Eckardstein A, Kastelein J, Deanfield J, Luscher TF (2012) Increasing highdensity lipoprotein cholesterol by cholesteryl ester transfer protein-inhibition: a rocky road and lessons learned? The early demise of the dal-HEART programme. Eur Heart J 33:1712-1715

Landschulz KT, Pathak RK, Rigotti A, Krieger M, Hobbs HH (1996) Regulation of scavenger receptor, class B, type I, a high density lipoprotein receptor, in liver and steroidogenic tissues of the rat. J Clin Invest 98:984-995

Langmann T, Klucken J, Reil M, Liebisch G, Luciani MF, Chimini G, Kaminski WE, Schmitz G (1999) Molecular cloning of the human ATP-binding cassette transporter 1 (hABC1): evidence for sterol-dependent regulation in macrophages. Biochem Biophys Res Commun 257:29-33

Laurila PP, Surakka I, Sarin AP, Yetukuri L, Hyotylainen T, Soderlund S, Naukkarinen J, Tang J, Kettunen J, Mirel DB, Soronen J, Lehtimaki T, Ruokonen A, Ehnholm C, Eriksson JG, Salomaa V, Jula A, Raitakari OT, Jarvelin MR, Palotie A, Peltonen L, Oresic M, Jauhiainen M, Taskinen MR, Ripatti S (2013) Genomic, transcriptomic, and lipidomic profiling highlights the role of inflammation in individuals with low high-density lipoprotein cholesterol. Arterioscler Thromb Vasc Biol 33:847-857 
Leiva A, Verdejo H, Benitez ML, Martinez A, Busso D, Rigotti A (2011) Mechanisms regulating hepatic SR-BI expression and their impact on HDL metabolism. Atherosclerosis 217:299-307

Leren TP, Bakken KS, Daum U, Ose L, Berg K, Assmann G, von Eckardstein A (1997) Heterozygosity for apolipoprotein A-I(R160L)Oslo is associated with low levels of high density lipoprotein cholesterol and HDL-subclass LpA-I/A- II but normal levels of HDL-subclass LpA-I. J Lipid Res 38:121-131

Levels JH, Marquart JA, Abraham PR, van den Ende AE, Molhuizen HO, van Deventer SJ, Meijers JC (2005) Lipopolysaccharide is transferred from high-density to low-density lipoproteins by lipopolysaccharide-binding protein and phospholipid transfer protein. Infect Immun 73:2321-2326

Li XA, Titlow WB, Jackson BA, Giltiay N, Nikolova-Karakashian M, Uittenbogaard A, Smart EJ (2002) High density lipoprotein binding to scavenger receptor, Class B, type I activates endothelial nitric-oxide synthase in a ceramide-dependent manner. J Biol Chem 277: $11058-11063$

Li X, Kypreos K, Zanni EE, Zannis V (2003) Domains of apoE required for binding to apoE receptor 2 and to phospholipids: implications for the functions of apoE in the brain. Biochemistry 42:10406-10417

Li D, Zhang Y, Ma J, Ling W, Xia M (2010) Adenosine monophosphate activated protein kinase regulates ABCG1-mediated oxysterol efflux from endothelial cells and protects against hypercholesterolemia-induced endothelial dysfunction. Arterioscler Thromb Vasc Biol 30: 1354-1362

Liadaki KN, Liu T, Xu S, Ishida BY, Duchateaux PN, Krieger JP, Kane J, Krieger M, Zannis VI (2000) Binding of high density lipoprotein (HDL) and discoidal reconstituted HDL to the HDL receptor scavenger receptor class B type I. Effect of lipid association and APOA-I mutations on receptor binding. J Biol Chem 275:21262-21271

Lindstedt L, Saarinen J, Kalkkinen N, Welgus H, Kovanen PT (1999) Matrix metalloproteinases$3,-7$, and -12 , but not -9 , reduce high density lipoprotein-induced cholesterol efflux from human macrophage foam cells by truncation of the carboxyl terminus of apolipoprotein A-I. Parallel losses of pre-beta particles and the high affinity component of efflux. J Biol Chem 274:22627-22634

Liu T, Krieger M, Kan HY, Zannis VI (2002) The effects of mutations in helices 4 and 6 of apoA-I on scavenger receptor class B type I (SR-BI)-mediated cholesterol efflux suggest that formation of a productive complex between reconstituted high density lipoprotein and SR-BI is required for efficient lipid transport. J Biol Chem 277:21576-21584

Lorenzi I, von Eckardstein A, Cavelier C, Radosavljevic S, Rohrer L (2008) Apolipoprotein A-I but not high-density lipoproteins are internalised by RAW macrophages: roles of ATP-binding cassette transporter A1 and scavenger receptor BI. J Mol Med 86:171-183

Love-Gregory L, Sherva R, Sun L, Wasson J, Schappe T, Doria A, Rao DC, Hunt SC, Klein S, Neuman RJ, Permutt MA, Abumrad NA (2008) Variants in the CD36 gene associate with the metabolic syndrome and high-density lipoprotein cholesterol. Hum Mol Genet 17:1695-1704

Lusa S, Jauhiainen M, Metso J, Somerharju P, Ehnholm C (1996) The mechanism of human plasma phospholipid transfer protein-induced enlargement of high-density lipoprotein particles: evidence for particle fusion. Biochem J 313(Pt 1):275-282

Ma K, Cilingiroglu M, Otvos JD, Ballantyne CM, Marian AJ, Chan L (2003) Endothelial lipase is a major genetic determinant for high-density lipoprotein concentration, structure, and metabolism. Proc Natl Acad Sci USA 100:2748-2753

Mardones P, Quinones V, Amigo L, Moreno M, Miquel JF, Schwarz M, Miettinen HE, Trigatti B, Krieger M, VanPatten S, Cohen DE, Rigotti A (2001) Hepatic cholesterol and bile acid metabolism and intestinal cholesterol absorption in scavenger receptor class B type I-deficient mice. J Lipid Res 42:170-180

Marsh JB, Welty FK, Schaefer EJ (2000) Stable isotope turnover of apolipoproteins of highdensity lipoproteins in humans. Curr Opin Lipidol 11:261-266 
Martinez LO, Jacquet S, Esteve JP, Rolland C, Cabezon E, Champagne E, Pineau T, Georgeaud V, Walker JE, Terce F, Collet X, Perret B, Barbaras R (2003) Ectopic beta-chain of ATP synthase is an apolipoprotein A-I receptor in hepatic HDL endocytosis. Nature 421:75-79

Martinez LO, Perretv B, Barbaras R, Terce F, Collet X (2007) Hepatic and renal HDL receptors. In: Fielding CJ (ed) High-density lipoproteins. From basic biology to clinical aspects. Wiley, Weinheim, pp 307-338

Maruyama T, Sakai N, Ishigami M, Hirano K, Arai T, Okada S, Okuda E, Ohya A, Nakajima N, Kadowaki K, Fushimi E, Yamashita S, Matsuzawa Y (2003) Prevalence and phenotypic spectrum of cholesteryl ester transfer protein gene mutations in Japanese hyperalphalipoproteinemia. Atherosclerosis 166:177-185

Matsuura F, Wang N, Chen W, Jiang XC, Tall AR (2006) HDL from CETP-deficient subjects shows enhanced ability to promote cholesterol efflux from macrophages in an apoE- and ABCG1-dependent pathway. J Clin Invest 116:1435-1442

Maugeais C, Tietge UJ, Broedl UC, Marchadier D, Cain W, McCoy MG, Lund-Katz S, Glick JM, Rader DJ (2003) Dose-dependent acceleration of high-density lipoprotein catabolism by endothelial lipase. Circulation 108:2121-2126

McManus DC, Scott BR, Franklin V, Sparks DL, Marcel YL (2001) Proteolytic degradation and impaired secretion of an apolipoprotein A-I mutant associated with dominantly inherited hypoalphalipoproteinemia. J Biol Chem 276:21292-21302

McNeish J, Aiello RJ, Guyot D, Turi T, Gabel C, Aldinger C, Hoppe KL, Roach ML, Royer LJ, de Wet J, Broccardo C, Chimini G, Francone OL (2000) High density lipoprotein deficiency and foam cell accumulation in mice with targeted disruption of ATP-binding cassette transporter-1. Proc Natl Acad Sci USA 97:4245-4250

Melchior GW, Castle CK, Murray RW, Blake WL, Dinh DM, Marotti KR (1994) Apolipoprotein A-I metabolism in cholesteryl ester transfer protein transgenic mice. Insights into the mechanisms responsible for low plasma high density lipoprotein levels. J Biol Chem 269: 8044-8051

Meyer JM, Graf GA, van der Westhuyzen DR (2013) New developments in selective cholesteryl ester uptake. Curr Opin Lipidol 24:386-392

Mezdour H, Jones R, Dengremont C, Castro G, Maeda N (1997) Hepatic lipase deficiency increases plasma cholesterol but reduces susceptibility to atherosclerosis in apolipoprotein E-deficient mice. J Biol Chem 272:13570-13575

Miccoli R, Bertolotto A, Navalesi R, Odoguardi L, Boni A, Wessling J, Funke H, Wiebusch H, Eckardstein A, Assmann G (1996) Compound heterozygosity for a structural apolipoprotein A-I variant, apo A-I(L141R)Pisa, and an apolipoprotein A-I null allele in patients with absence of HDL cholesterol, corneal opacifications, and coronary heart disease. Circulation 94: $1622-1628$

Miccoli R, Zhu Y, Daum U, Wessling J, Huang Y, Navalesi R, Assmann G, von Eckardstein A (1997) A natural apolipoprotein A-I variant, apoA-I (L141R)Pisa, interferes with the formation of alpha-high density lipoproteins (HDL) but not with the formation of pre beta 1-HDL and influences efflux of cholesterol into plasma. J Lipid Res 38:1242

Miettinen HE, Gylling H, Miettinen TA, Viikari J, Paulin L, Kontula K (1997a) Apolipoprotein A-IFin. Dominantly inherited hypoalphalipoproteinemia due to a single base substitution in the apolipoprotein A-I gene. Arterioscler Thromb Vasc Biol 17:83-90

Miettinen HE, Jauhiainen M, Gylling H, Ehnholm S, Palomaki A, Miettinen TA, Kontula K (1997b) Apolipoprotein A-IFIN (Leu159->Arg) mutation affects lecithin cholesterol acyltransferase activation and subclass distribution of HDL but not cholesterol efflux from fibroblasts. Arterioscler Thromb Vasc Biol 17:3021-3032

Miller M, Aiello D, Pritchard H, Friel G, Zeller K (1998) Apolipoprotein A-I(Zavalla) (Leu159$>$ Pro): HDL cholesterol deficiency in a kindred associated with premature coronary artery disease. Arterioscler Thromb Vasc Biol 18:1242-1247 
Mineo C, Yuhanna IS, Quon MJ, Shaul PW (2003) High density lipoprotein-induced endothelial nitric-oxide synthase activation is mediated by Akt and MAP kinases. J Biol Chem 278: 9142-9149

Moestrup SK, Nielsen LB (2005) The role of the kidney in lipid metabolism. Curr Opin Lipidol 16: 301-306

Mulya A, Seo J, Brown AL, Gebre AK, Boudyguina E, Shelness GS, Parks JS (2010) Apolipoprotein $\mathrm{M}$ expression increases the size of nascent pre beta HDL formed by ATP binding cassette transporter A1. J Lipid Res 51:514-524

Murao K, Terpstra V, Green SR, Kondratenko N, Steinberg D, Quehenberger O (1997) Characterization of CLA-1, a human homologue of rodent scavenger receptor BI, as a receptor for high density lipoprotein and apoptotic thymocytes. J Biol Chem 272:17551-17557

Nakamura K, Kennedy MA, Baldan A, Bojanic DD, Lyons K, Edwards PA (2004a) Expression and regulation of multiple murine ATP-binding cassette transporter G1 mRNAs/isoforms that stimulate cellular cholesterol efflux to high density lipoprotein. J Biol Chem 279:45980-45989

Nakamura Y, Kotite L, Gan Y, Spencer TA, Fielding CJ, Fielding PE (2004b) Molecular mechanism of reverse cholesterol transport: reaction of pre-beta-migrating high-density lipoprotein with plasma lecithin/cholesterol acyltransferase. Biochemistry 43:14811-14820

Nanjee MN, Cooke CJ, Olszewski WL, Miller NE (2000) Concentrations of electrophoretic and size subclasses of apolipoprotein A-I-containing particles in human peripheral lymph. Arterioscler Thromb Vasc Biol 20:2148-2155

Navab M, Hama SY, Anantharamaiah GM, Hassan K, Hough GP, Watson AD, Reddy ST, Sevanian A, Fonarow GC, Fogelman AM (2000) Normal high density lipoprotein inhibits three steps in the formation of mildly oxidized low density lipoprotein: steps 2 and 3. J Lipid Res 41:1495-1508

Neufeld EB, Remaley AT, Demosky SJ, Stonik JA, Cooney AM, Comly M, Dwyer NK, Zhang M, Blanchette-Mackie J, Santamarina-Fojo S, Brewer HB Jr (2001) Cellular localization and trafficking of the human ABCA1 transporter. J Biol Chem 276:27584-27590

Neufeld EB, Demosky SJ Jr, Stonik JA, Combs C, Remaley AT, Duverger N, Santamarina-Fojo S, Brewer HB Jr (2002) The ABCA1 transporter functions on the basolateral surface of hepatocytes. Biochem Biophys Res Commun 297:974-979

Nichols AV, Krauss RM, Musliner TA (1986) Nondenaturing polyacrylamide gradient gel electrophoresis. Methods Enzymol 128:417-431

Nielsen LB, Christoffersen C, Ahnstrom J, Dahlback B (2009) ApoM: gene regulation and effects on HDL metabolism. Trends Endocrinol Metab 20:66-71

Nijstad N, Wiersma H, Gautier T, van der Giet M, Maugeais C, Tietge UJ (2009) Scavenger receptor BI-mediated selective uptake is required for the remodeling of high density lipoprotein by endothelial lipase. J Biol Chem 284:6093-6100

Nishida HI, Nishida T (1997) Phospholipid transfer protein mediates transfer of not only phosphatidylcholine but also cholesterol from phosphatidylcholine-cholesterol vesicles to high density lipoproteins. J Biol Chem 272:6959-6964

Nolte RT, Atkinson D (1992) Conformational analysis of apolipoprotein A-I and E-3 based on primary sequence and circular dichroism. Biophys J 63:1221-1239

Ohnsorg PM, Rohrer L, Perisa D, Kateifides A, Chroni A, Kardassis D, Zannis VI, von Eckardstein A (2011) Carboxyl terminus of apolipoprotein A-I (ApoA-I) is necessary for the transport of lipid-free ApoA-I but not prelipidated ApoA-I particles through aortic endothelial cells. J Biol Chem 286:7744-7754

Oka T, Kujiraoka T, Ito M, Egashira T, Takahashi S, Nanjee MN, Miller NE, Metso J, Olkkonen VM, Ehnholm C, Jauhiainen M, Hattori H (2000) Distribution of phospholipid transfer protein in human plasma: presence of two forms of phospholipid transfer protein, one catalytically active and the other inactive. J Lipid Res 41:1651-1657

Orso E, Broccardo C, Kaminski WE, Bottcher A, Liebisch G, Drobnik W, Gotz A, Chambenoit O, Diederich W, Langmann T, Spruss T, Luciani MF, Rothe G, Lackner KJ, Chimini G, 
Schmitz G (2000) Transport of lipids from golgi to plasma membrane is defective in tangier disease patients and Abc1-deficient mice. Nat Genet 24:192-196

Out R, Hoekstra M, Spijkers JA, Kruijt JK, Van Eck M, Bos IS, Twisk J, van Berkel TJ (2004a) Scavenger receptor class B type I is solely responsible for the selective uptake of cholesteryl esters from HDL by the liver and the adrenals in mice. J Lipid Res 45:2088-2095

Out R, Kruijt JK, Rensen PC, Hildebrand RB, De Vos P, Van Eck M, van Berkel TJ (2004b) Scavenger receptor BI plays a role in facilitating chylomicron metabolism. J Biol Chem 279: 18401-18406

Out R, Hoekstra M, de Jager SC, Vos PD, van der Westhuyzen DR, Webb NR, Van Eck M, Biessen EA, van Berkel TJ (2005) Adenovirus-mediated hepatic overexpression of scavenger receptor BI accelerates chylomicron metabolism in C57BL/6J mice. J Lipid Res 46:1172-1181

Out R, Hoekstra M, Hildebrand RB, Kruit JK, Meurs I, Li Z, Kuipers F, van Berkel TJ, Van Eck M (2006) Macrophage ABCG1 deletion disrupts lipid homeostasis in alveolar macrophages and moderately influences atherosclerotic lesion development in LDL receptor-deficient mice. Arterioscler Thromb Vasc Biol 26:2295-2300

Out R, Hoekstra M, Meurs I, de Vos P, Kuiper J, Van Eck M, van Berkel TJ (2007) Total body ABCG1 expression protects against early atherosclerotic lesion development in mice. Arterioscler Thromb Vasc Biol 27:594-599

Pagler TA, Rhode S, Neuhofer A, Laggner H, Strobl W, Hinterndorfer C, Volf I, Pavelka M, Eckhardt ER, van der Westhuyzen DR, Schutz GJ, Stangl H (2006) SR-BI-mediated high density lipoprotein (HDL) endocytosis leads to HDL resecretion facilitating cholesterol efflux. J Biol Chem 281:11193-11204

Parathath S, Sahoo D, Darlington YF, Peng Y, Collins HL, Rothblat GH, Williams DL, Connelly MA (2004) Glycine 420 near the C-terminal transmembrane domain of SR-BI is critical for proper delivery and metabolism of high density lipoprotein cholesteryl ester. J Biol Chem 279:24976-24985

Paszty C, Maeda N, Verstuyft J, Rubin EM (1994) Apolipoprotein AI transgene corrects apolipoprotein E deficiency-induced atherosclerosis in mice. J Clin Invest 94:899-903

Pisciotta L, Miccoli R, Cantafora A, Calabresi L, Tarugi P, Alessandrini P, Bittolo BG, Franceschini G, Cortese C, Calandra S, Bertolini S (2003) Recurrent mutations of the apolipoprotein A-I gene in three kindreds with severe HDL deficiency. Atherosclerosis 167:335-345

Plomgaard P, Dullaart RP, de Vries R, Groen AK, Dahlback B, Nielsen LB (2009) Apolipoprotein $\mathrm{M}$ predicts pre-beta-HDL formation: studies in type 2 diabetic and nondiabetic subjects. $\mathrm{J}$ Intern Med 266:258-267

Plump AS, Smith JD, Hayek T, Aalto-Setala K, Walsh A, Verstuyft JG, Rubin EM, Breslow JL (1992) Severe hypercholesterolemia and atherosclerosis in apolipoprotein E-deficient mice created by homologous recombination in ES cells. Cell 71:343-353

Plump AS, Masucci-Magoulas L, Bruce C, Bisgaier CL, Breslow JL, Tall AR (1999) Increased atherosclerosis in ApoE and LDL receptor gene knock-out mice as a result of human cholesteryl ester transfer protein transgene expression. Arterioscler Thromb Vasc Biol 19: $1105-1110$

Ranalletta M, Wang N, Han S, Yvan-Charvet L, Welch C, Tall AR (2006) Decreased atherosclerosis in low-density lipoprotein receptor knockout mice transplanted with $\mathrm{Abcg} 1^{-/-}$bone marrow. Arterioscler Thromb Vasc Biol 26:2308-2315

Rao R, Albers JJ, Wolfbauer G, Pownall HJ (1997) Molecular and macromolecular specificity of human plasma phospholipid transfer protein. Biochemistry 36:3645-3653

Reardon CA, Kan HY, Cabana V, Blachowicz L, Lukens JR, Wu Q, Liadaki K, Getz GS, Zannis VI (2001) In vivo studies of HDL assembly and metabolism using adenovirus-mediated transfer of ApoA-I mutants in ApoA-I-deficient mice. Biochemistry 40:13670-13680

Remaley AT, Stonik JA, Demosky SJ, Neufeld EB, Bocharov AV, Vishnyakova TG, Eggerman TL, Patterson AP, Duverger NJ, Santamarina-Fojo S, Brewer HB Jr (2001) Apolipoprotein specificity for lipid efflux by the human ABCAI transporter. Biochem Biophys Res Commun 280:818-823 
Richards JB, Waterworth D, O'Rahilly S, Hivert MF, Loos RJ, Perry JR, Tanaka T, Timpson NJ, Semple RK, Soranzo N, Song K, Rocha N, Grundberg E, Dupuis J, Florez JC, Langenberg C, Prokopenko I, Saxena R, Sladek R, Aulchenko Y, Evans D, Waeber G, Erdmann J, Burnett MS, Sattar N, Devaney J, Willenborg C, Hingorani A, Witteman JC, Vollenweider P, Glaser B, Hengstenberg C, Ferrucci L, Melzer D, Stark K, Deanfield J, Winogradow J, Grassl M, Hall AS, Egan JM, Thompson JR, Ricketts SL, Konig IR, Reinhard W, Grundy S, Wichmann HE, Barter P, Mahley R, Kesaniemi YA, Rader DJ, Reilly MP, Epstein SE, Stewart AF, van Duijn CM, Schunkert H, Burling K, Deloukas P, Pastinen T, Samani NJ, McPherson R, Davey SG, Frayling TM, Wareham NJ, Meigs JB, Mooser V, Spector TD (2009) A genome-wide association study reveals variants in ARL15 that influence adiponectin levels. PLoS Genet 5:e1000768

Rigotti A, Trigatti BL, Penman M, Rayburn H, Herz J, Krieger M (1997) A targeted mutation in the murine gene encoding the high density lipoprotein (HDL) receptor scavenger receptor class B type I reveals its key role in HDL metabolism. Proc Natl Acad Sci USA 94:12610-12615

Rohrer L, Hersberger M, von Eckardstein A (2004) High density lipoproteins in the intersection of diabetes mellitus, inflammation and cardiovascular disease. Curr Opin Lipidol 15:269-278

Rohrer L, Cavelier C, Fuchs S, Schluter MA, Volker W, von Eckardstein A (2006) Binding, internalization and transport of apolipoprotein A-I by vascular endothelial cells. Biochim Biophys Acta 1761:186-194

Rohrer L, Ohnsorg PM, Lehner M, Landolt F, Rinninger F, von Eckardstein A (2009) High-density lipoprotein transport through aortic endothelial cells involves scavenger receptor BI and ATP-binding cassette transporter G1. Circ Res 104:1142-1150

Rohrl C, Stangl H (2013) HDL endocytosis and resecretion. Biochim Biophys Acta 1831: $1626-1633$

Roosbeek S, Vanloo B, Duverger N, Caster H, Breyne J, De Beun I, Patel H, Vandekerckhove J, Shoulders C, Rosseneu M, Peelman F (2001) Three arginine residues in apolipoprotein A-I are critical for activation of lecithin:cholesterol acyltransferase. J Lipid Res 42:31-40

Rubin EM, Krauss RM, Spangler EA, Verstuyft JG, Clift SM (1991) Inhibition of early atherogenesis in transgenic mice by human apolipoprotein AI. Nature 353:265-267

Ruel IL, Couture P, Cohn JS, Bensadoun A, Marcil M, Lamarche B (2004) Evidence that hepatic lipase deficiency in humans is not associated with proatherogenic changes in HDL composition and metabolism. J Lipid Res 45:1528-1537

Russell RE, Culpitt SV, DeMatos C, Donnelly L, Smith M, Wiggins J, Barnes PJ (2002) Release and activity of matrix metalloproteinase- 9 and tissue inhibitor of metalloproteinase-1 by alveolar macrophages from patients with chronic obstructive pulmonary disease. Am J Respir Cell Mol Biol 26:602-609

Rye KA, Jauhiainen M, Barter PJ, Ehnholm C (1998) Triglyceride-enrichment of high density lipoproteins enhances their remodelling by phospholipid transfer protein. J Lipid Res 39: $613-622$

Sabatti C, Service SK, Hartikainen AL, Pouta A, Ripatti S, Brodsky J, Jones CG, Zaitlen NA, Varilo T, Kaakinen M, Sovio U, Ruokonen A, Laitinen J, Jakkula E, Coin L, Hoggart C, Collins A, Turunen H, Gabriel S, Elliot P, McCarthy MI, Daly MJ, Jarvelin MR, Freimer NB, Peltonen L (2009) Genome-wide association analysis of metabolic traits in a birth cohort from a founder population. Nat Genet 41:35-46

Sankaranarayanan S, Oram JF, Asztalos BF, Vaughan AM, Lund-Katz S, Adorni MP, Phillips MC, Rothblat GH (2009) Effects of acceptor composition and mechanism of ABCG1-mediated cellular free cholesterol efflux. J Lipid Res 50:275-284

Santamarina-Fojo S, Hoeg JM, Assmann G, Brewer HB Jr (2001) Lecithin cholesterol acyltransferase deficiency and fish eye disease. In: Scriver CR, Beaudet AL, Sly WS, Valle D (eds) The metabolic and molecular bases of inherited disease. McGraw-Hill, New York, pp 2817-2834

Santamarina-Fojo S, Gonzalez-Navarro H, Freeman L, Wagner E, Nong Z (2004) Hepatic lipase, lipoprotein metabolism, and atherogenesis. Arterioscler Thromb Vasc Biol 24:1750-1754 
Savary S, Denizot F, Luciani M, Mattei M, Chimini G (1996) Molecular cloning of a mammalian ABC transporter homologous to Drosophila white gene. Mamm Genome 7:673-676

Schaefer EJ, Foster DM, Jenkins LL, Lindgren FT, Berman M, Levy RI, Brewer HB Jr (1979) The composition and metabolism of high density lipoprotein subfractions. Lipids 14:511-522

Schaefer EJ, Anderson DW, Zech LA, Lindgren FT, Bronzert TB, Rubalcaba EA, Brewer HB Jr (1981) Metabolism of high density lipoprotein subfractions and constituents in Tangier disease following the infusion of high density lipoproteins. J Lipid Res 22:217-228

Schaefer EJ, Gregg RE, Ghiselli G, Forte TM, Ordovas JM, Zech LA, Brewer HB Jr (1986) Familial apolipoprotein E deficiency. J Clin Invest 78:1206-1219

Schou J, Frikke-Schmidt R, Kardassis D, Thymiakou E, Nordestgaard BG, Jensen G, Grande P, Tybjaerg-Hansen A (2012) Genetic variation in ABCG1 and risk of myocardial infarction and ischemic heart disease. Arterioscler Thromb Vasc Biol 32:506-515

Segrest JP, Jackson RL, Morrisett JD, Gotto AM Jr (1974) A molecular theory of lipid-protein interactions in the plasma lipoproteins. FEBS Lett 38:247-258

Segrest JP, Jones MK, Klon AE, Sheldahl CJ, Hellinger M, De Loof H, Harvey SC (1999) A detailed molecular belt model for apolipoprotein A-I in discoidal high density lipoprotein. J Biol Chem 274:31755-31758

Setala NL, Holopainen JM, Metso J, Wiedmer SK, Yohannes G, Kinnunen PK, Ehnholm C, Jauhiainen M (2007) Interfacial and lipid transfer properties of human phospholipid transfer protein: implications for the transfer mechanism of phospholipids. Biochemistry 46: 1312-1319

Shah AS, Tan L, Long JL, Davidson WS (2013) Proteomic diversity of high density lipoproteins: our emerging understanding of its importance in lipid transport and beyond. J Lipid Res 54: $2575-2585$

Shao B, Cavigiolio G, Brot N, Oda MN, Heinecke JW (2008) Methionine oxidation impairs reverse cholesterol transport by apolipoprotein A-I. Proc Natl Acad Sci USA 105: 12224-12229

Shih DQ, Bussen M, Sehayek E, Ananthanarayanan M, Shneider BL, Suchy FJ, Shefer S, Bollileni JS, Gonzalez FJ, Breslow JL, Stoffel M (2001) Hepatocyte nuclear factor-1alpha is an essential regulator of bile acid and plasma cholesterol metabolism. Nat Genet 27:375-382

Siggins S, Rye K-A, Olkkonen VM, Jauhiainen M, Ehnholm C (2007) Human plasma phospholipid transfer protein (PLTP) - structural and functional features. In: Fielding CJ (ed) Highdensity lipoproteins. From basic biology to clinical aspects. Wiley, Weinheim, pp 183-206

Silva RA, Huang R, Morris J, Fang J, Gracheva EO, Ren G, Kontush A, Jerome WG, Rye KA, Davidson WS (2008) Structure of apolipoprotein A-I in spherical high density lipoproteins of different sizes. Proc Natl Acad Sci USA 105:12176-12181

Simon JB, Boyer JL (1970) Production of lecithin: cholesterol acyltransferase by the isolated perfused rat liver. Biochim Biophys Acta 218:549-551

Singaraja RR, Brunham LR, Visscher H, Kastelein JJ, Hayden MR (2003) Efflux and atherosclerosis: the clinical and biochemical impact of variations in the ABCA1 gene. Arterioscler Thromb Vasc Biol 23:1322-1332

Singaraja RR, Stahmer B, Brundert M, Merkel M, Heeren J, Bissada N, Kang M, Timmins JM, Ramakrishnan R, Parks JS, Hayden MR, Rinninger F (2006) Hepatic ATP-binding cassette transporter A1 is a key molecule in high-density lipoprotein cholesteryl ester metabolism in mice. Arterioscler Thromb Vasc Biol 26:1821-1827

Singaraja RR, Sivapalaratnam S, Hovingh K, Dube MP, Castro-Perez J, Collins HL, Adelman SJ, Riwanto M, Manz J, Hubbard B, Tietjen I, Wong K, Mitnaul LJ, van Heek M, Lin L, Roddy TA, McEwen J, Dallinge-Thie G, van Vark-van der Zee L, Verwoert G, Winther M, van Duijn C, Hofman A, Trip MD, Marais AD, Asztalos B, Landmesser U, Sijbrands E, Kastelein JJ, Hayden MR (2013) The impact of partial and complete loss-of-function mutations in endothelial lipase on high-density lipoprotein levels and functionality in humans. Circ Cardiovasc Genet 6:54-62 
Smith EB, Ashall C, Walker JE (1984) High density lipoprotein (HDL) subfractions in interstitial fluid from human aortic intima and atherosclerostic lesions. Biochem Soc Trans 12:843-844

Smith JD, Waelde C, Horwitz A, Zheng P (2002) Evaluation of the role of phosphatidylserine translocase activity in ABCA1-mediated lipid efflux. J Biol Chem 277:17797-17803

Sorci-Thomas MG, Thomas MJ (2002) The effects of altered apolipoprotein A-I structure on plasma HDL concentration. Trends Cardiovasc Med 12:121-128

Stangl H, Hyatt M, Hobbs HH (1999) Transport of lipids from high and low density lipoproteins via scavenger receptor-BI. J Biol Chem 274:32692-32698

Stefulj J, Panzenboeck U, Becker T, Hirschmugl B, Schweinzer C, Lang I, Marsche G, Sadjak A, Lang U, Desoye G, Wadsack C (2009) Human endothelial cells of the placental barrier efficiently deliver cholesterol to the fetal circulation via ABCA1 and ABCG1. Circ Res 104: 600-608

Strope S, Rivi R, Metzger T, Manova K, Lacy E (2004) Mouse amnionless, which is required for primitive streak assembly, mediates cell-surface localization and endocytic function of cubilin on visceral endoderm and kidney proximal tubules. Development 131:4787-4795

Sturek JM, Castle JD, Trace AP, Page LC, Castle AM, Evans-Molina C, Parks JS, Mirmira RG, Hedrick CC (2010) An intracellular role for ABCG1-mediated cholesterol transport in the regulated secretory pathway of mouse pancreatic beta cells. J Clin Invest 120:2575-2589

Subbaiah PV, Albers JJ, Chen CH, Bagdade JD (1980) Low density lipoprotein-activated lysolecithin acylation by human plasma lecithin-cholesterol acyltransferase. Identity of lysolecithin acyltransferase and lecithin-cholesterol acyltransferase. J Biol Chem 255:9275-9280

Takahashi Y, Smith JD (1999) Cholesterol efflux to apolipoprotein AI involves endocytosis and resecretion in a calcium-dependent pathway. Proc Natl Acad Sci USA 96:11358-11363

Tall AR, Forester LR, Bongiovanni GL (1983) Facilitation of phosphatidylcholine transfer into high density lipoproteins by an apolipoprotein in the density $1.20-1.26 \mathrm{~g} / \mathrm{ml}$ fraction of plasma. J Lipid Res 24:277-289

Tangirala RK, Tsukamoto K, Chun SH, Usher D, Pure E, Rader DJ (1999) Regression of atherosclerosis induced by liver-directed gene transfer of apolipoprotein A-I in mice. Circulation 100:1816-1822

Tarling EJ, Edwards PA (2011) ATP binding cassette transporter G1 (ABCG1) is an intracellular sterol transporter. Proc Natl Acad Sci USA 108:19719-19724

Terasaka N, Wang N, Yvan-Charvet L, Tall AR (2007) High-density lipoprotein protects macrophages from oxidized low-density lipoprotein-induced apoptosis by promoting efflux of 7-ketocholesterol via ABCG1. Proc Natl Acad Sci USA 104:15093-15098

Teslovich TM et al (2010) Biological, clinical and population relevance of 95 loci for blood lipids. Nature 466:707-713

Thuahnai ST, Lund-Katz S, Williams DL, Phillips MC (2001) Scavenger receptor class B, type I-mediated uptake of various lipids into cells. Influence of the nature of the donor particle interaction with the receptor. J Biol Chem 276:43801-43808

Timmins JM, Lee JY, Boudyguina E, Kluckman KD, Brunham LR, Mulya A, Gebre AK, Coutinho JM, Colvin PL, Smith TL, Hayden MR, Maeda N, Parks JS (2005) Targeted inactivation of hepatic Abcal causes profound hypoalphalipoproteinemia and kidney hypercatabolism of apoA-I. J Clin Invest 115:1333-1342

Tollefson JH, Ravnik S, Albers JJ (1988) Isolation and characterization of a phospholipid transfer protein (LTP-II) from human plasma. J Lipid Res 29:1593-1602

Trigatti B, Rayburn H, Vinals M, Braun A, Miettinen H, Penman M, Hertz M, Schrenzel M, Amigo L, Rigotti A, Krieger M (1999) Influence of the high density lipoprotein receptor SR-BI on reproductive and cardiovascular pathophysiology. Proc Natl Acad Sci USA 96:9322-9327

Ueda Y, Royer L, Gong E, Zhang J, Cooper PN, Francone O, Rubin EM (1999) Lower plasma levels and accelerated clearance of high density lipoprotein (HDL) and non-HDL cholesterol in scavenger receptor class B type I transgenic mice. J Biol Chem 274:7165-7171 
Ueda Y, Gong E, Royer L, Cooper PN, Francone OL, Rubin EM (2000) Relationship between expression levels and atherogenesis in scavenger receptor class B, type I transgenics. J Biol Chem 275:20368-20373

Undurti A, Huang Y, Lupica JA, Smith JD, Didonato JA, Hazen SL (2009) Modification of high density lipoprotein by myeloperoxidase generates a pro-inflammatory particle. J Biol Chem 284:30825-30835

Urban S, Zieseniss S, Werder M, Hauser H, Budzinski R, Engelmann B (2000) Scavenger receptor BI transfers major lipoprotein-associated phospholipids into the cells. J Biol Chem 275: 33409-33415

Vaisar T, Pennathur S, Green PS, Gharib SA, Hoofnagle AN, Cheung MC, Byun J, Vuletic S, Kassim S, Singh P, Chea H, Knopp RH, Brunzell J, Geary R, Chait A, Zhao XQ, Elkon K, Marcovina S, Ridker P, Oram JF, Heinecke JW (2007) Shotgun proteomics implicates protease inhibition and complement activation in the antiinflammatory properties of HDL. J Clin Invest 117:746-756

Vaisman BL, Lambert G, Amar M, Joyce C, Ito T, Shamburek RD, Cain WJ, Fruchart-Najib J, Neufeld ED, Remaley AT, Brewer HB Jr, Santamarina-Fojo S (2001) ABCA1 overexpression leads to hyperalphalipoproteinemia and increased biliary cholesterol excretion in transgenic mice. J Clin Invest 108:303-309

Van Eck M, Bos IS, Kaminski WE, Orso E, Rothe G, Twisk J, Bottcher A, Van Amersfoort ES, Christiansen-Weber TA, Fung-Leung WP, van Berkel TJ, Schmitz G (2002) Leukocyte ABCA1 controls susceptibility to atherosclerosis and macrophage recruitment into tissues. Proc Natl Acad Sci USA 99:6298-6303

Van Eck M, Singaraja RR, Ye D, Hildebrand RB, James ER, Hayden MR, van Berkel TJ (2006) Macrophage ATP-binding cassette transporter A1 overexpression inhibits atherosclerotic lesion progression in low-density lipoprotein receptor knockout mice. Arterioscler Thromb Vasc Biol 26:929-934

Vaughan AM, Oram JF (2005) ABCG1 redistributes cell cholesterol to domains removable by HDL but not by lipid-depleted apolipoproteins. J Biol Chem 280:30150-30157

Venkateswaran A, Repa JJ, Lobaccaro JM, Bronson A, Mangelsdorf DJ, Edwards PA (2000) Human white/murine ABC8 mRNA levels are highly induced in lipid-loaded macrophages. A transcriptional role for specific oxysterols. J Biol Chem 275:14700-14707

Vergeer M, Boekholdt SM, Sandhu MS, Ricketts SL, Wareham NJ, Brown MJ, de Faire U, Leander K, Gigante B, Kavousi M, Hofman A, Uitterlinden AG, van Duijn CM, Witteman JC, Jukema JW, Schadt EE, van der Schoot E, Kastelein JJ, Khaw KT, Dullaart RP, van Tol A, Trip MD, Dallinga-Thie GM (2010a) Genetic variation at the phospholipid transfer protein locus affects its activity and high-density lipoprotein size and is a novel marker of cardiovascular disease susceptibility. Circulation 122:470-477

Vergeer M, Cohn DM, Boekholdt SM, Sandhu MS, Prins HM, Ricketts SL, Wareham NJ, Kastelein JJ, Khaw KT, Kamphuisen PW, Dallinga-Thie GM (2010b) Lack of association between common genetic variation in endothelial lipase (LIPG) and the risk for CAD and DVT. Atherosclerosis 211:558-564

Vergeer M, Korporaal SJA, Franssen R, Meurs I, Out R, Hovingh GK, Hoekstra M, Sierts JA, Dallinga-Thie GM, Motazacker MM, Holleboom AG, Van Berkel TJC, Kastelein JJP, Van Eck M, Kuivenhoven JA (2011) Genetic variant of the scavenger receptor BI in humans. N Engl J Med 364:136-145

Vezeridis AM, Chroni A, Zannis VI (2011) Domains of apoE4 required for the biogenesis of apoEcontaining HDL. Ann Med 43:302-311

Vickers KC, Remaley AT (2014) HDL and cholesterol: life after the divorce? J Lipid Res 55:4-12

Vickers KC, Palmisano BT, Shoucri BM, Shamburek RD, Remaley AT (2011) MicroRNAs are transported in plasma and delivered to recipient cells by high-density lipoproteins. Nat Cell Biol 13:423-433 
Vikstedt R, Metso J, Hakala J, Olkkonen VM, Ehnholm C, Jauhiainen M (2007a) Cholesterol efflux from macrophage foam cells is enhanced by active phospholipid transfer protein through generation of two types of acceptor particles. Biochemistry 46:11979-11986

Vikstedt R, Ye D, Metso J, Hildebrand RB, van Berkel TJ, Ehnholm C, Jauhiainen M, Van EM (2007b) Macrophage phospholipid transfer protein contributes significantly to total plasma phospholipid transfer activity and its deficiency leads to diminished atherosclerotic lesion development. Arterioscler Thromb Vasc Biol 27:578-586

Wang N, Arai T, Ji Y, Rinninger F, Tall AR (1998) Liver-specific overexpression of scavenger receptor BI decreases levels of very low density lipoprotein ApoB, low density lipoprotein ApoB, and high density lipoprotein in transgenic mice. J Biol Chem 273:32920-32926

Wang N, Silver DL, Costet P, Tall AR (2000) Specific binding of ApoA-I, enhanced cholesterol efflux, and altered plasma membrane morphology in cells expressing ABC1. J Biol Chem 275: 33053-33058

Wang N, Lan D, Chen W, Matsuura F, Tall AR (2004) ATP-binding cassette transporters G1 and G4 mediate cellular cholesterol efflux to high-density lipoproteins. Proc Natl Acad Sci USA 101:9774-9779

Wang N, Ranalletta M, Matsuura F, Peng F, Tall AR (2006) LXR-induced redistribution of ABCG1 to plasma membrane in macrophages enhances cholesterol mass efflux to HDL. Arterioscler Thromb Vasc Biol 26:1310-1316

Wang X, Collins HL, Ranalletta M, Fuki IV, Billheimer JT, Rothblat GH, Tall AR, Rader DJ (2007) Macrophage ABCA1 and ABCG1, but not SR-BI, promote macrophage reverse cholesterol transport in vivo. J Clin Invest 117:2216-2224

Warden CH, Langner CA, Gordon JI, Taylor BA, McLean JW, Lusis AJ (1989) Tissue-specific expression, developmental regulation, and chromosomal mapping of the lecithin: cholesterol acyltransferase gene. Evidence for expression in brain and testes as well as liver. J Biol Chem 264:21573-21581

Waterworth DM, Ricketts SL, Song K, Chen L, Zhao JH, Ripatti S, Aulchenko YS, Zhang W, Yuan X, Lim N, Luan J, Ashford S, Wheeler E, Young EH, Hadley D, Thompson JR, Braund PS, Johnson T, Struchalin M, Surakka I, Luben R, Khaw KT, Rodwell SA, Loos RJ, Boekholdt SM, Inouye M, Deloukas P, Elliott P, Schlessinger D, Sanna S, Scuteri A, Jackson A, Mohlke KL, Tuomilehto J, Roberts R, Stewart A, Kesaniemi YA, Mahley RW, Grundy SM, McArdle W, Cardon L, Waeber G, Vollenweider P, Chambers JC, Boehnke M, Abecasis GR, Salomaa V, Jarvelin MR, Ruokonen A, Barroso I, Epstein SE, Hakonarson HH, Rader DJ, Reilly MP, Witteman JC, Hall AS, Samani NJ, Strachan DP, Barter P, van Duijn CM, Kooner JS, Peltonen L, Wareham NJ, McPherson R, Mooser V, Sandhu MS (2010) Genetic variants influencing circulating lipid levels and risk of coronary artery disease. Arterioscler Thromb Vasc Biol 30:2264-2276

Webb NR, de Beer MC, Yu J, Kindy MS, Daugherty A, van der Westhuyzen DR, de Beer FC (2002) Overexpression of SR-BI by adenoviral vector promotes clearance of apoA-I, but not apoB, in human apoB transgenic mice. J Lipid Res 43:1421-1428

Willer CJ, Sanna S, Jackson AU, Scuteri A, Bonnycastle LL, Clarke R, Heath SC, Timpson NJ, Najjar SS, Stringham HM, Strait J, Duren WL, Maschio A, Busonero F, Mulas A, Albai G, Swift AJ, Morken MA, Narisu N, Bennett D, Parish S, Shen H, Galan P, Meneton P, Hercberg S, Zelenika D, Chen WM, Li Y, Scott LJ, Scheet PA, Sundvall J, Watanabe RM, Nagaraja R, Ebrahim S, Lawlor DA, Ben Shlomo Y, Davey-Smith G, Shuldiner AR, Collins R, Bergman RN, Uda M, Tuomilehto J, Cao A, Collins FS, Lakatta E, Lathrop GM, Boehnke M, Schlessinger D, Mohlke KL, Abecasis GR (2008) Newly identified loci that influence lipid concentrations and risk of coronary artery disease. Nat Genet 40:161-169

Wojcik AJ, Skaflen MD, Srinivasan S, Hedrick CC (2008) A critical role for ABCG1 in macrophage inflammation and lung homeostasis. J Immunol 180:4273-4282

Wolfrum C, Poy MN, Stoffel M (2005) Apolipoprotein M is required for prebeta-HDL formation and cholesterol efflux to HDL and protects against atherosclerosis. Nat Med 11:418-422 
Woollett LA, Spady DK (1997) Kinetic parameters for high density lipoprotein apoprotein AI and cholesteryl ester transport in the hamster. J Clin Invest 99:1704-1713

Wu Z, Gogonea V, Lee X, May RP, Pipich V, Wagner MA, Undurti A, Tallant TC, BaleanuGogonea C, Charlton F, Ioffe A, Didonato JA, Rye KA, Hazen SL (2011) The low resolution structure of ApoA1 in spherical high density lipoprotein revealed by small angle neutron scattering. J Biol Chem 286:12495-12508

Xie Q, Engel T, Schnoor M, Niehaus J, Hofnagel O, Buers I, Cullen P, Seedorf U, Assmann G, Lorkowski S (2006) Cell surface localization of ABCG1 does not require LXR activation. Arterioscler Thromb Vasc Biol 26:e143-e144

Xu N, Dahlback B (1999) A novel human apolipoprotein (apoM). J Biol Chem 274:31286-31290

$\mathrm{Xu}$ N, Nilsson-Ehle P (2007) ApoM - a novel apolipoprotein with antiatherogenic properties. In: Fielding CJ (ed) High-density lipoproteins. From basic biology to clinical aspects. Wiley, Weinheim, pp 89-110

Xu S, Laccotripe M, Huang X, Rigotti A, Zannis VI, Krieger M (1997) Apolipoproteins of HDL can directly mediate binding to the scavenger receptor SR-BI, an HDL receptor that mediates selective lipid uptake. J Lipid Res 38:1289-1298

Xu N, Nilsson-Ehle P, Ahren B (2006) Suppression of apolipoprotein M expression and secretion in alloxan-diabetic mouse: partial reversal by insulin. Biochem Biophys Res Commun 342: $1174-1177$

Xu WW, Zhang Y, Tang YB, Xu YL, Zhu HZ, Ferro A, Ji Y, Chen Q, Fan LM (2008) A genetic variant of apolipoprotein $\mathrm{M}$ increases susceptibility to coronary artery disease in a Chinese population. Clin Exp Pharmacol Physiol 35:546-551

Xu Y, Wang W, Zhang L, Qi LP, Li LY, Chen LF, Fang Q, Dang AM, Yan XW (2011) A polymorphism in the ABCG1 promoter is functionally associated with coronary artery disease in a Chinese Han population. Atherosclerosis 219:648-654

Yamakawa-Kobayashi K, Yanagi H, Fukayama H, Hirano C, Shimakura Y, Yamamoto N, Arinami T, Tsuchiya S, Hamaguchi H (1999) Frequent occurrence of hypoalphalipoproteinemia due to mutant apolipoprotein A-I gene in the population: a population-based survey. Hum Mol Genet 8:331-336

Yates M, Kolmakova A, Zhao Y, Rodriguez A (2011) Clinical impact of scavenger receptor class B type I gene polymorphisms on human female fertility. Hum Reprod 26:1910-1916

Yesilaltay A, Morales MG, Amigo L, Zanlungo S, Rigotti A, Karackattu SL, Donahee MH, Kozarsky KF, Krieger M (2006) Effects of hepatic expression of the high-density lipoprotein receptor SR-BI on lipoprotein metabolism and female fertility. Endocrinology 147:1577-1588

Yesilaltay A, Daniels K, Pal R, Krieger M, Kocher O (2009) Loss of PDZK1 causes coronary artery occlusion and myocardial infarction in Paigen diet-fed apolipoprotein E deficient mice. PLoS ONE 4:e8103

Yuhanna IS, Zhu Y, Cox BE, Hahner LD, Osborne-Lawrence S, Lu P, Marcel YL, Anderson RG, Mendelsohn ME, Hobbs HH, Shaul PW (2001) High-density lipoprotein binding to scavenger receptor-BI activates endothelial nitric oxide synthase. Nat Med 7:853-857

Yvan-Charvet L, Matsuura F, Wang N, Bamberger MJ, Nguyen T, Rinninger F, Jiang XC, Shear CL, Tall AR (2007) Inhibition of cholesteryl ester transfer protein by torcetrapib modestly increases macrophage cholesterol efflux to HDL. Arterioscler Thromb Vasc Biol 27:1132-1138

Yvan-Charvet L, Kling J, Pagler T, Li H, Hubbard B, Fisher T, Sparrow CP, Taggart AK, Tall AR (2010) Cholesterol efflux potential and antiinflammatory properties of high-density lipoprotein after treatment with niacin or anacetrapib. Arterioscler Thromb Vasc Biol 30:1430-1438

Zannis VI, Lees AM, Lees RS, Breslow JL (1982) Abnormal apoprotein A-I isoprotein composition in patients with Tangier disease. J Biol Chem 257:4978-4986

Zannis VI, Cole FS, Jackson CL, Kurnit DM, Karathanasis SK (1985) Distribution of apolipoprotein A-I, C-II, C-III, and E mRNA in fetal human tissues. Time-dependent induction of apolipoprotein E mRNA by cultures of human monocyte-macrophages. Biochemistry 24: $4450-4455$ 
Zannis VI, Chroni A, Kypreos KE, Kan HY, Cesar TB, Zanni EE, Kardassis D (2004a) Probing the pathways of chylomicron and HDL metabolism using adenovirus-mediated gene transfer. Curr Opin Lipidol 15:151-166

Zannis VI, Chroni A, Liu T, Liadaki KN, Laccotripe M (2004) New insights on the roles of apolipoprotein A-I, the ABCA1 lipid transporter, and the HDL receptor SR-BI in the biogenesis and the functions of HDL. In: Simionescu M, Sima A, Popov D (eds) Cellular dysfunction in atherosclerosis and diabetes. Romanian Academy Publishing House, Bucharest, pp 33-72

Zannis VI, Chroni A, Krieger M (2006a) Role of apoA-I, ABCA1, LCAT, and SR-BI in the biogenesis of HDL. J Mol Med 84:276-294

Zannis VI, Zanni EE, Papapanagiotou A, Kardassis D, Chroni A (2006b) ApoA-I functions and synthesis of HDL: insights from mouse models of human HDL metabolism. In: Fielding CJ (ed) High-density lipoproteins. From basic biology to clinical aspects. Wiley, Weinheim, pp 237-265

Zhang S, Picard MH, Vasile E, Zhu Y, Raffai RL, Weisgraber KH, Krieger M (2005) Diet-induced occlusive coronary atherosclerosis, myocardial infarction, cardiac dysfunction and premature death in SR-BI-deficient, hypomorphic apolipoprotein ER61 mice. Circulation 111:3457-3464

Zhang Y, Ahmed AM, Tran TL, Lin J, McFarlane N, Boreham DR, Igdoura SA, Truant R, Trigatti BL (2007) The inhibition of endocytosis affects HDL-lipid uptake mediated by the human scavenger receptor class B type I. Mol Membr Biol 24:442-454

Zhang LH, Kamanna VS, Zhang MC, Kashyap ML (2008) Niacin inhibits surface expression of ATP synthase beta chain in HepG2 cells: implications for raising HDL. J Lipid Res 49: 1195-1201

Zhang Y, McGillicuddy FC, Hinkle CC, O’Neill S, Glick JM, Rothblat GH, Reilly MP (2010) Adipocyte modulation of high-density lipoprotein cholesterol. Circulation 121:1347-1355

Zhong S, Sharp DS, Grove JS, Bruce C, Yano K, Curb JD, Tall AR (1996) Increased coronary heart disease in Japanese-American men with mutation in the cholesteryl ester transfer protein gene despite increased HDL levels. J Clin Invest 97:2917-2923 